SF

453

TRG

1919 


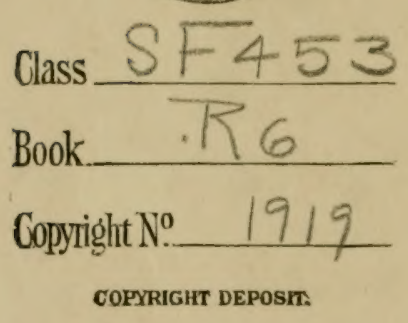








\section{Rabbit Culture}

\section{and Standard $\frac{995^{\circ}}{246}$}

BY

THE LATE W. F. ROTH, M. D.

AND

CHARLES T. CORNMAN

REVISED BY

C. R. DEARDORFF

The Standards contained herein have been revised to conform, in point valuations, to the latest official Standards, as adopted by the leading pet stock associations. The word descriptions used in the first edition of this work have been adopted by the net stock organizations with but slight changes in wording and arrangement, without altering the meaning or application, hence, no change in that respect necessary, except to add description of new varieties, thus bringing this edition down-to-date in every particular. 


\section{SF $\begin{array}{r}4^{53} \\ K 6 \\ 1919\end{array}$}

Copyright $1914-1916-1918$ By THE ITEM PUBLISHING CO. Sellersville, $\mathrm{Pa}$.

Fourth Edition-Revised and Up-To-Date Copyright 1919 By THE ITEM PUBLISHING CO. Sellersville, $\mathrm{Pa}$.

\section{DEC -31919}

Printed by the POULTRY ITEM PRESS

Sellersville, $\mathrm{Pa}$. 


\section{Index to Articles}

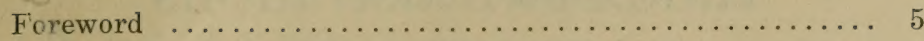

To our Friends and Readers, Old and New .......... 8

Rabbit Culture ........................ 9

Varieties of Domestic Rabbits .................. 14

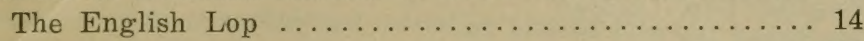

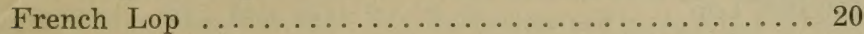

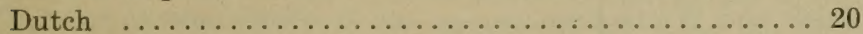

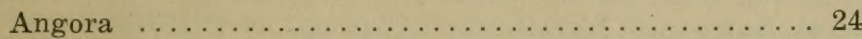

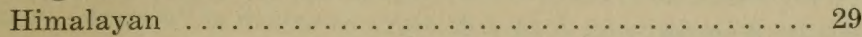

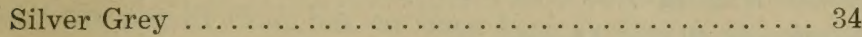

Silver Fawn, Silver Brown and Silver Blue ....... 37

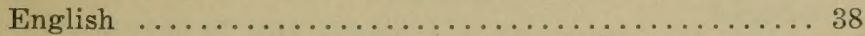

Polish . . . . . . . . . . . . . . . . . . . 39

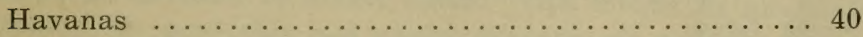

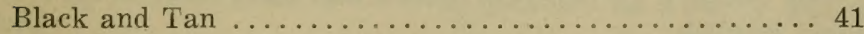

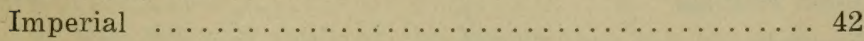

Selfs ............................. 42

American Blue ........................ 43

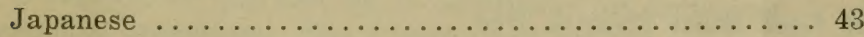

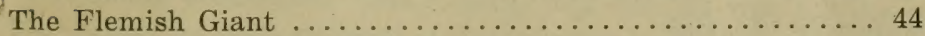

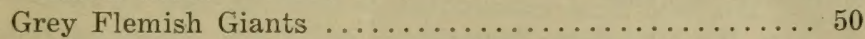

Solid Colored Giants .................... 51

American Spotted Giants .................. 51

Belgian Giants ......................... 53

The New Zealand Reds ................... 53

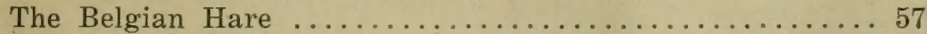

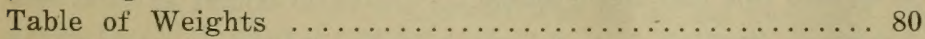

Breeding, Building Up a Strain and Inbreeding ........ 81

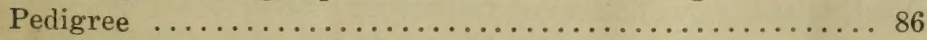

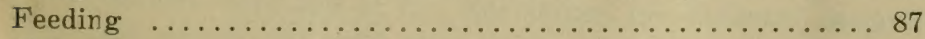

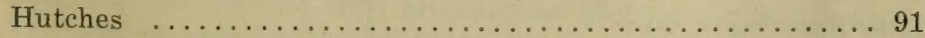

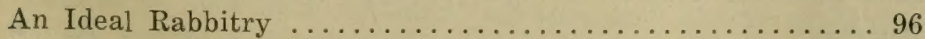

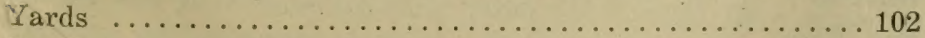

Preparation for Show Room ........................... 105

The Rabbit Hospital and Medicine Chest ............ 108

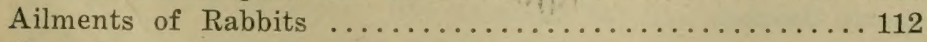

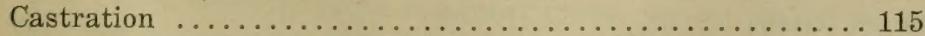

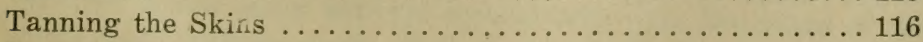

Nurse Does ............................ 119

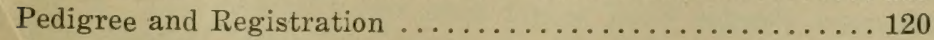

Condensed Information and Rules for the Rabbitry ...... 122

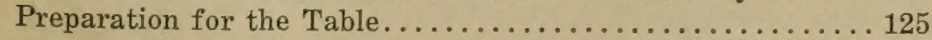




\section{Index to Illustrations}

Portrait of C. R. Deardorff ................. 8

English Lop, Colored ..................... 13

English Lop ............................ 15

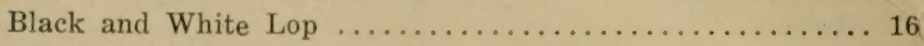

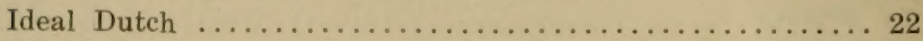

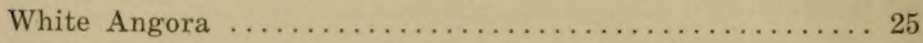

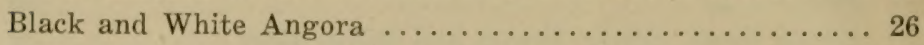

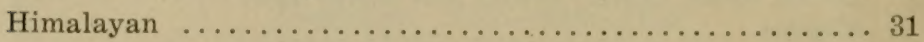

Trio of High Class Himalayans . . . . . . . . . . . . 32

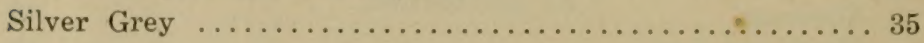

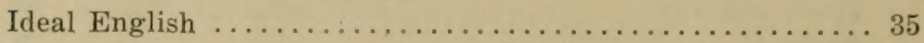

English . . . . . . . . . . . . . . . . . . . . 36

Steel Grey Flemish Giant . . . . . . . . . . . . . 45

A Good Steel Flemish Doe ................... 46

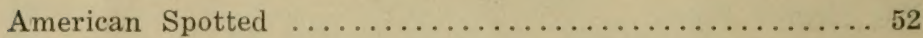

A Prize Winning New Zealand $. . \ldots \ldots \ldots \ldots \ldots \ldots \ldots . \ldots \ldots$

Another Prize Winning New Zealand ............. 56

Good Belgian Hare Doe .................... 56

Ideal Belgian Hare.$\ldots \ldots \ldots \ldots \ldots \ldots \ldots \ldots \ldots \ldots \ldots$

A Mother Doe and Her Family .................6. 66

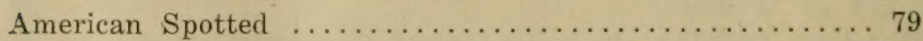

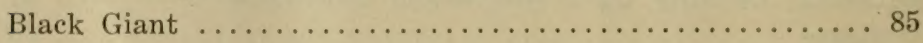

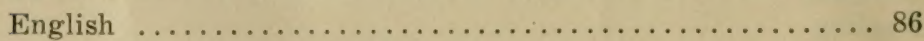

Line Breeding Chart $\ldots \ldots \ldots \ldots \ldots \ldots \ldots \ldots \ldots \ldots \ldots \ldots$

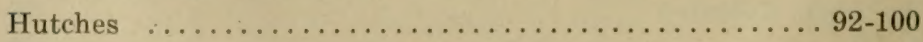

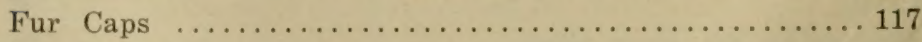

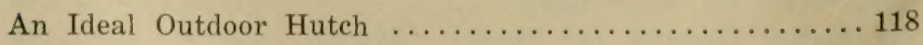

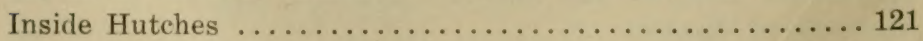

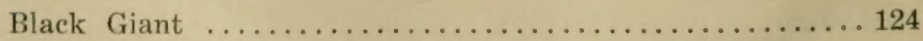




\section{Foreword}

D R. W. F. ROT'H died September 3, 1911. At the time of his death he was under contract with the Poultry Item, of Sellersville, Pa., to write a brochure on rabbits. The manuscript in an unfinished condition passed into our hands after his demise. The fact that Dr. Roth was not permitted to finish this work is one deeply to be regretted. He stood out as the greatest authority on this subject the United States has yet produced. It was his desire to erect this as a monument that would stand the test of time, but we have here another illustration of how man proposes and God disposes.

The intent of this brochure is to present the rabbit as a Fancy; an industry of utility value. This means its successful breeding for profitable and useful purposes as a fancy and for food.

It was not any fault of the rabbit that the "boom" some years back fell flat; but it was the fault of a false understanding of a venture of this sort by a "syndicate" of indiscreet, if not dishonest, promoters. The country was not yet ripe for the recognition by rush methods of an industry both new and foreign; and if anything, the hasty, vivid, and glaring claims were too palpably overwrought for intelligent absorption by a large and otherwise preoccupied community. America was too long and wide of expanse, with too well supplied a market of all foods which were then yet too honestly placed on the consumer's table, for him to realize that the rabbit was an actual necessity. "n fact, he didn't need it. If he desired "rabbit," which was hereıofore considered more a game than domestic food, the woods, fields and prairies were full of it. But things are different now. In the last decade the wild animal has become decidedly scarce; poultry is kept at a continual advance and almost prohibitive price, and those manipulating other food stuffs have made numerous products very close to a luxury, notably the meats. Nor is our population decreasing among any class except the " 400 " and food we must have. The necessity for food at more reasonable prices becomes more apparent every day by reason of the present prices being entirely inconsistent with the wage of the moderate working class-that class which needs most at alf times. This necessity has even forced itself vaguely upon the dim vision of "statesmen" occupying the State Legislative chairs to the extent that the 1907 Legislature of Pennsylvania enacted a law permitting the trading in slaughtered Belgians on the same 
footing as fowls in the open market the year round. We should all be grateful for this act, for it is largely a recognition of a meat for public consumption that has hitherto been considered more game than domestic. It places the rearing of the domestic rabbit as an industry and fancy on the same footing as that of fowls. What is now before the breeler is the exercise of wistom, prudence and judicious methods essential to the education of a consuming public to the value of this new meat as a reasonably priced food. Nor should this be especially difficult, since the meat of the rabbit is unquestionably the most dainty and most, nutritious of all meats. As an animal, the domestic rabbit is the cleanest and most prolific of all animals used for food, and weight for weight, it costs less to produce five pounds of meat than any other.

In France, Belgium, and to a great extent in England and Germany, the rabbit is largely the meat fool of the peasant population, owing not only to the delicacy and nutritious value of the flesh, but for its economic production.

The people of some foreign countries have passed through sad experiences relative to their meat supply, and while we in big America do not anticipate grave seriousness that our supply will run out, it is withal a serious issue with the dependent classes in our large cities to an extent involving millions. The daily papers publish thrilling stories in almost every issue of instances where suffering for lack of food, and meat in particular, are causes of suicide, sickness and even riots. Frequently uprisings by the poor were held from grave results by the Government making itself indirectly responsible for bringing about a reduction in the rate, so inordinately placed by the beef trust, which controlled almost every pound of beef and pork handled in city trade.

I cannot say how the essentials for living are manipulated in foreign countries-whether trusts or syndicates exist to make prices as they please-but if things do not change here by some authority more powerful than the moneyed monopolizers of the commodities of life, we need not go among the poor of foreign nations to find scarcity of food. As a people we are no better than our foreign brethren. We may be richer-at the present time- put if we keep on wasting things by inordinate living, misguided economy and without thought for next week or next month we are very liable one morning to wake up hungry.

Furthermore, statistics inform us that millions of poor people throughout all civilized countries can afford to eat meat no oftener than once a week, and many none the year round. Why this should be so I cannot understand. I do know, though, 
that the environments of the working classes in the cities are daily becoming more impossible in the way of securing food, and our country of large, free and abundant America is not by any means so secure within itself as to be immune from possible visitations of disaster in many forms affecting the food supply. Once a nation tolerates its business integrity to become so corrupt that business men obstruct food from reaching a distributing market in order to sustain an inordinate high price over the pretext of scarcity, and allow that food (meat and vegetables) to rot, while people are in want and starving, it is not without the bounds of reason to suppose that such flagrant injustice will go unpunished by the God of Nations. It is a question whether the densest heathen in any section of the world would pursue such tactics to punish an enemy.

These remarks are not inapropos to my subject under consideration, from the fact that the opportunities at hand in the rearing of rabbits makes it possible to offset much of the injustice endured by those who need meat and can't afford to secure it; for these little useful and delicate morsels of flesh can be reared in most any vacant space from a corner on the farm to a four by eight back yard or cellar of a town house. The rabbit is thus utilized by the peasant and poorer classes in foreign countries, and there is no reason why it should not be so utilized in this country, and made a staple food on the same basis as beef, fowl and fish.

Why all these arguments should be necessary in behalf of an industry that merits the closest recognition without them, is indeed strange when considered from any point of view-for instance: during the open season for "cotton tails" thousands upon thousands are killed by all manner of disagreeable and unsanitary means; placed on market, and sold at prices twice the actual value of meat per pound, considered even as a delicacy. Why not a far more desirable, cleanly, more readily obtainable at all times, more nutritious, and cheaper meat produced by the domestic rabbit? Observe the menu cards of hotels, restaurants and other resorts of the epicure and note lobsters, crab, turtle, and a dozen other disgusting and indigestible things prepared a la mode at fancy prices-none better, so clean, so digestible, more dainty, or so cheap as the unapproachable loin of a seasonably prepared rabbit. Why is this superb meat overlooked, or shall I say, neglected, for no reason whatever. I am sure once an intelligent acquaintance is had with it through the medium of judicious culinary experiment, it will become as staple as all the other meats, and the rearing of the domestic rabbit will be an industry of necessity.

CHAS. T. CORNMAN. 


\section{To Our Friends and Readers, Old and New:}

D HE RAPII) SALE of the third edition of labbit Culture and Standard, and the many kind words of commendation we have received have been very gratifying to both the publishers and myself. Some few have offered 'riticisms and suggestions in a kindly way, and these we have given consideration in preparing the fourth edition-chiefly among which are the abbreviation and omission of obsolete mat-

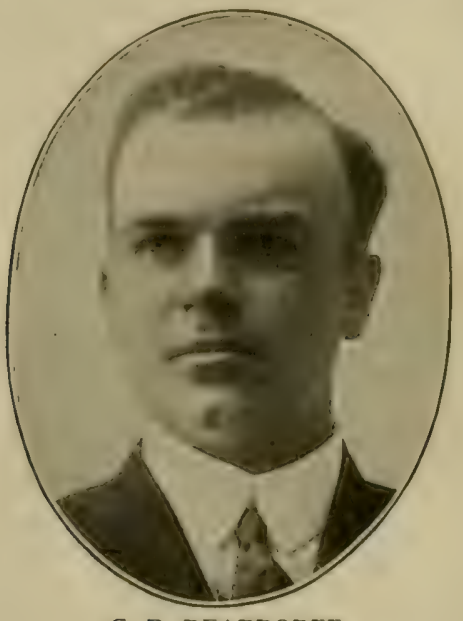

C. r. DEARDORFF

tor pertaining to the Belgian Hare, and the addition of new chapters on practical phases of the rabbit business. The standards have also been brought down to date.

Sincerely believing we are offering the rabbit industry a work of superior merit, better and more practical even than former editions of this work, we submit cur efforts for your kind consideration and approval.

Sincercly yours,

C. R. DEARDORFF

North Judson, Ind., Sept. 30, 1919. 


\title{
Rabbit Culture
}

\author{
By W. F. Roth \\ THE FANCY
}

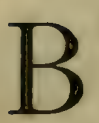

REEDING domestic rabbits is accomplished for two purposes-that of Fancy and Utility. For Fancy, implies breeding to requirements that have been formulated in accord with certain ideals, termed Standard; for Utility, means rearing them for market meat, and whatever commercial use can be made out of the fur and skin. I will refer to each separately.

Careful search has failed to identify the term fancy with that of rearing animals, nor that of fancier, unless a "cant name for sporting characters" can be so construed. The definition of the word Fancy is "to imagine"; to "form in one's mind an ideal" of a thing "which appeals to one's liking." Another definition is "the faculty by which the mind forms images or representations of things at pleasure;" and still another "taste, conception." Last and perhaps as near correct as any, makes it imply to like, to be pleased with, particularly on account of external appearances.

These definitions, it seems to me, are singularly applicable to the pact of folk who make it their object to rear animate creatures so they conform with certain pre-conceived ideals whose chief points are beauty, grace, usefulness, and harmonious blending of physical characteristics into a being as near perfect as the imagination can conceive. This, to my mind, is a technical Fancy, and it is not difficult to appreciate how interesting, attractive and profitable it can be made.

A Fancy, too, does not stop at mere admiration, or liking, as I fear many follow it. One can own and admire a creature, and yet not be a fancier; for a Fancy, as the above definition embodies, means development, advancement, and persistent effort toward an objective point along definite lines. A life-time of useful application can be vouchsafed in it as reflected by the beneficial results to mankind from the efforts of pioneers in its various branches-the horse, dairy cattle, sheep, swine, the dog and cat, many handsome breeds of fowls, and just as beautiful and useful for Fancy and food, the Belgian Hare, the Flemish 
(iiant, the New Zealand Red, and other valuable but perhaps less well known varieties of the commercial rabbit, as well as the smaller and more strictly "fancy" varieties. In all these departments the Fancy has assumed such merit that the Department of Agriculture recognized the necessity for assisting by the organization of experiment stations for advanced study of the different features embodied in it.

The commercial rabbit and fancy rabbit has lately received recognition from a Government departmental source, and several bulletins prepared relating to the rabbit industry. Once the commercial value of the rabbit is intelligently appreciated, recognition as a national industry must follow. Progress in this direction lies with the Fancy, and it is this body that must make the Utility subservient to it, with the fact before mind that no creature can be too beautiful and physically perfect for food purposes.

\section{A Fancier}

To be a fancier, is to interest one's self in the principles embodied under the term Fancy and as a breeder, aim at their consummation so far as possible. A fancier must needs be a breeder, but a breeder is not always a fancier. To be a true fancier does not merely imply the liking of a certain classified animate being known as breed, strain, or type of animal or fowl, but as already intimated, the knowledge of an ideal toward which the liking inclines to an extent that scientific effort is exercised in its growth for perfect attainment. This implies, too, a reasonable information on structural tissue; of the laws of pro-generation with regard to merits and defects that are influenced by heredity; and of physical characteristics that classify the variety in question.

To apply one's self as a fancier can be made an object of the highest merit in that the exercise of personal qualifications which stand for honor, honesty and business integrity can be placed on a par with all other occupations that call for man's noblest principles.

\section{The Need for a Fancy}

With regard to rearing rabbits as a matter of Fancy, its beauty and wislom as a chosen hobby, cannot be questioned. In several foreign countries, notably England, the breeding of pet stock has become as much an industry of importance as that of breeding thoroughbred stock of larger animals for domestic use. For its production they enter into it with as much care as that required for a first class specimen race horse, dairy cow, canine or fowl. The science to successfully produce any one of the 
many varieties of commercial or fancy rabbits to their present perfection is as intricate and interesting in detail as for the above and has advocates by way of membership of men and women who stand in the forefront of educational, social and professional station.

Fancy rabbits are particularly attractive in many ways. They are docile, useful, and exceptionally beautiful; while as a feature for relaxation from more weighty responsibilities no finer field is open for genuine pleasure.

They are singularly appreciative of intelligent attention, and since their growth is rather quick, one's pleasure in seeing the fruits of one's efforts is sooner realized than in many creatures of other fancies.

By way of unalloyed sportsmanship no Fancy brings more real satisfaction than that derived from the numerous shows for friendly competition, where often the specimens are bred so keenly to the edge of uniform quality as to almost make a judge look three ways at once. And it pays for when choice winners of any of the varieties, fetch as high as anywhere from $\$ 25$ to $\$ 125$, and win a trophy worth $\$ 50$ besides, one need not wonder why such a Fancy attracts good people to membership.

I know fanciers who annually have an income from $\$ 200$ to $\$ 1,000$ from the sale of specimens for breeding only; and in this country prices are not one-half that secured for winning specimens in England. That this is so, is entirely the fault of the Fancy here, and on the whole our stock is just as good as theirs -in many respects better in the matter of health and stamina.

The reader will pardon this personal introduction, but I have often been asked by frequent visitors to my rabbitry "What prices do you obtain for the general run of breeding specimens?" "From $\$ 5$ to $\$ 25$ per specimen I have heretofore considered reasonable" is my reply. To show an approximate average, I will state that for 27 there was remitted $\$ 222$.

That a Fancy can be made a nicely profitable feature is further qualified when I say, that the actual cost to rear a Belgian Hare or any variety of similar size and habits to maturity need not exceed 80 cents for a year's feeding when all foodstuffs have to be bought. Under many conditions the expense can be reduced to half this, so when one can secure stock of superior merit for such a limited outlay, and realize from $\$ 5$ to $\$ 50$ per specimen, such a Fancy commands more than passing notice.

A well informed fancier and author has this to say: "As a Fancy the Belgian Hare and fancy rabbit has few rivals which can claim such concentrated advantages, for, apart from the fact 
that each section of society is represcnted in its rank as exhibitors, the world-widle popularity of rabbits as an article of food and commerce grows by leaps and bounds annually." I look forward with the consciousness, that what has become in a number of densely populated foreign countries a Fancy and Industry of inestimable value to them in various ways, will not be long distant here.

\section{The Rabbit as a Species}

The rabbit is indigenous to virtually every part of Europe and America. Australia has also a species of rabbit somewhat akin in type and habits to the American "Jack."

The rabbit is a species of quadruped separate from that of the hare, nor will the two species "mix," as many suprose, unless in very exceptional instances. It appears, also that to whatever country the rabbit is indigenous, it has characteristics that differentiate from its brother of the same species in another; either larger or smaller, or of varied color markings. The same holds true of the hare in its native heath.

The rabbit is of the species lepus cuniculus, and the hare lepus timidus, though both belong to the family rolintiae-a creature with long, rat-like front gnawing teeth. Originally the rabbit was introduced into Europe from Africa, is the prevailing opinion among zoologists, and most likely what is now Spain; from thence into Brittany, and eventually over all Europe. How long since, or rather, in which of the earlier centuries this transpired is not definitely known.

In its gregarius habits the rabbit also differs widely from those of the hare, and in the wild state is said to be monogamous. This latter trait, however, ceases with domestication, and either sex becomes altogether polygamous. It also differs from the hare in that its young are born immature, with eyes closed and the body nude of hair, in a nest lined with fur pulled from thie mother, burrowed in the ground whenever possible; while those of the former (hare) are born with eyes open, and body nicely covered, in a "form" on top of the ground.

The fertility of the rabbit is also proverbial, a litter containing anywhere from 4 to 12 , while the female hare rarely brings forth more than 2 and seldom as many as 4 .

An old English name for the rabbit is cony, and its cognomen in many others is similar to this, as Latin cuniculus, Italian coniglio, German kaninchen, and Welsh owningen; but the rabbit is not the cony of Scripture.

Fach country, and in America, each state has laws which at this time regulate the destruction to which it may be subjected as game; but this point is not essential here. 
For domestic purposes the rabbit has been bred to many varieties, and virtually so from early times. As a dainty morsel it has graced the table of ancient monarch and his humblest peasant down the ages until now, so that as an article of food and commerce it is recognized the world over.

The actual consumption of rabbit as a food is not totally known from available statisties right now, but England alone uses upwards of $25,000,000$ pounds annually and in France, Germany, and Austria, as well as Belgium and Holland, it is, as already remarked, largely the food of their peasant class. What is known as the "Famous Ostend Rabbit" is merely a specially reared Belgian for culinary purposes, and occupies much the same position with epicures that the Canvass Back duck does in this country.

England has received her supply hitherto almost entirely from the colonies, notably Australia, where it was so abundant as to make wholesale destruction an absolute necessity because of menace to crops and fruit trees. I am informed quite recently however, that the Australian species is in some danger of extermination, for it is not alone for food that its use extended; in fact, at first it was not used for this purpose at all, but for fur ivery extensively utilized by hat manufacturers. Because of this, indiscriminate slaughter was executed so that now I am told by one of the largest hat makers in the world that fur from this source has fallen off in supply nearly 40 per cent. and price consequently advanced in the same ratio. This same hat maker was greatly concerned, and advanced the suggestion that it would become an absolute necessity to rear fur rabbits in large numbers for both hat and leather uses, as well as the more inexpensive furs for wear. In fact, large quantities of skins are already utilized for the latter purpose, which would seem to suggest a field for unusual profit when managed with a view to producing a specially grown article of superior "wool" merit and wearing qualities. I am convinced that this can be done.

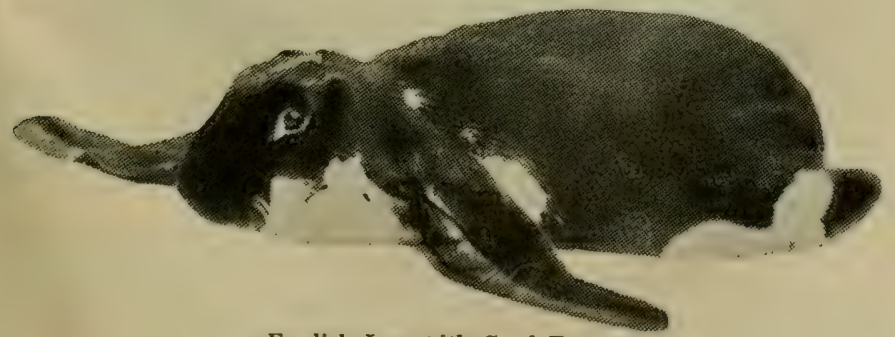

English Lop with Good Earage 


\section{Varities of Domestic Rabbits}

Descriptions and Standards by Roth, Cornman and Deardorff

Many varieties of rabbits have been "made" by domestir breeding, and here follow the more prominently recognized by fanciers: Flemish Giant, Belgian Hare, New Zealand, American Spotted, Lop, Dutch, Angora, Himalayan, Polish, English, the Silver in Grey, Fawn, Blue and Brown; the Tan in Black, and Blue; the Havana, Imperial, and Selfs.

\section{The English Lop Ear}

\section{The Lop}

As a fancy variety, the Lop has made itself decidedly popular, and while perhaps not so much so in this country as if England and Germany, it has, withal, many admirers. Its piricipal characteristics is the large ears for which it is noted and specimens of enormous proportions have been produced in recent years. Instances are recorderl with an earage of $271+$ by $71 / 4$ and a weight of 12 pounds. Because of this immense earage, however, its breeding for purposes other than Fancy is not so desirable as that of less bothersome varieties.

\section{Ears}

For show purposes the Lop has two classifications-one for entries of classified length, and the other for any length. For the former, classification usually exceds 24 inches, to any possible limit beyond this; while in the latter no specification if made, and these specimens are judged perhaps more for universal quality than earage alone.

Measurement of the ears is taken from one extremity across the hearl to the other, and the width of one ear must be at least one-quarter of the total; that is, if the earage is 24 inches, the wilth of one ear must be six inches.

There is also a characteristic pendancy to the ears when in natural sitting pose that must be looked for in well bred lops, which is due to a correct juncture of their roots with the cranjum. This is an important point, and means that an ideal speci- 


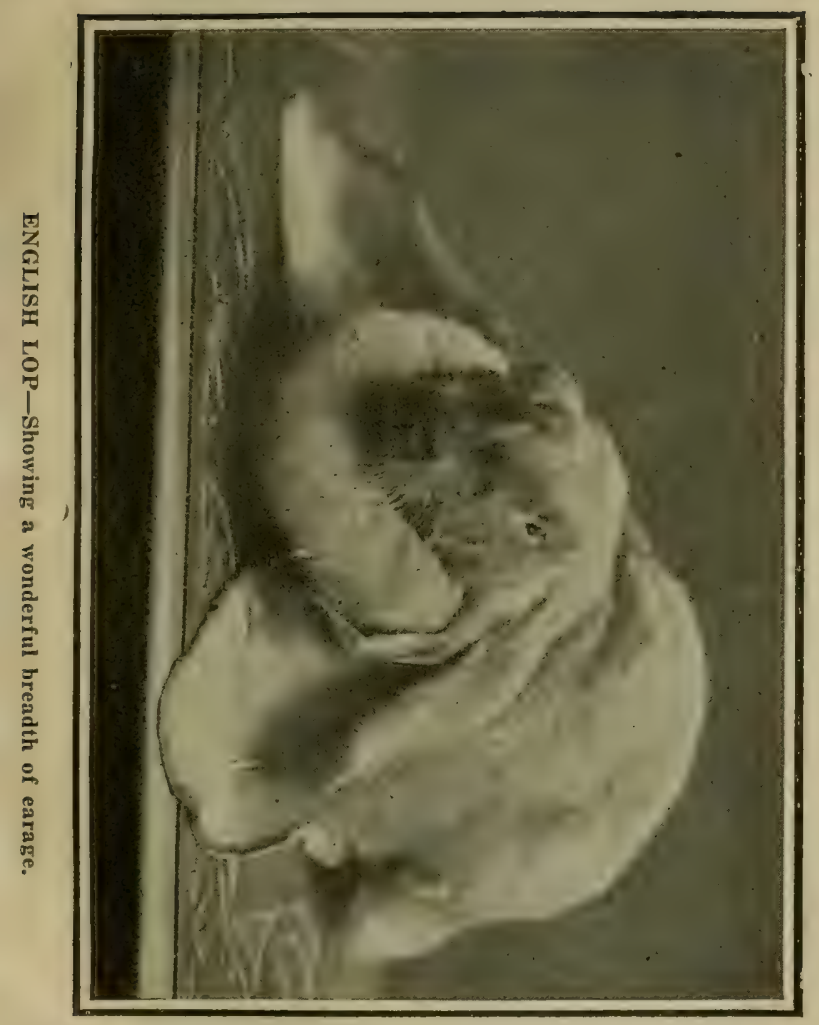




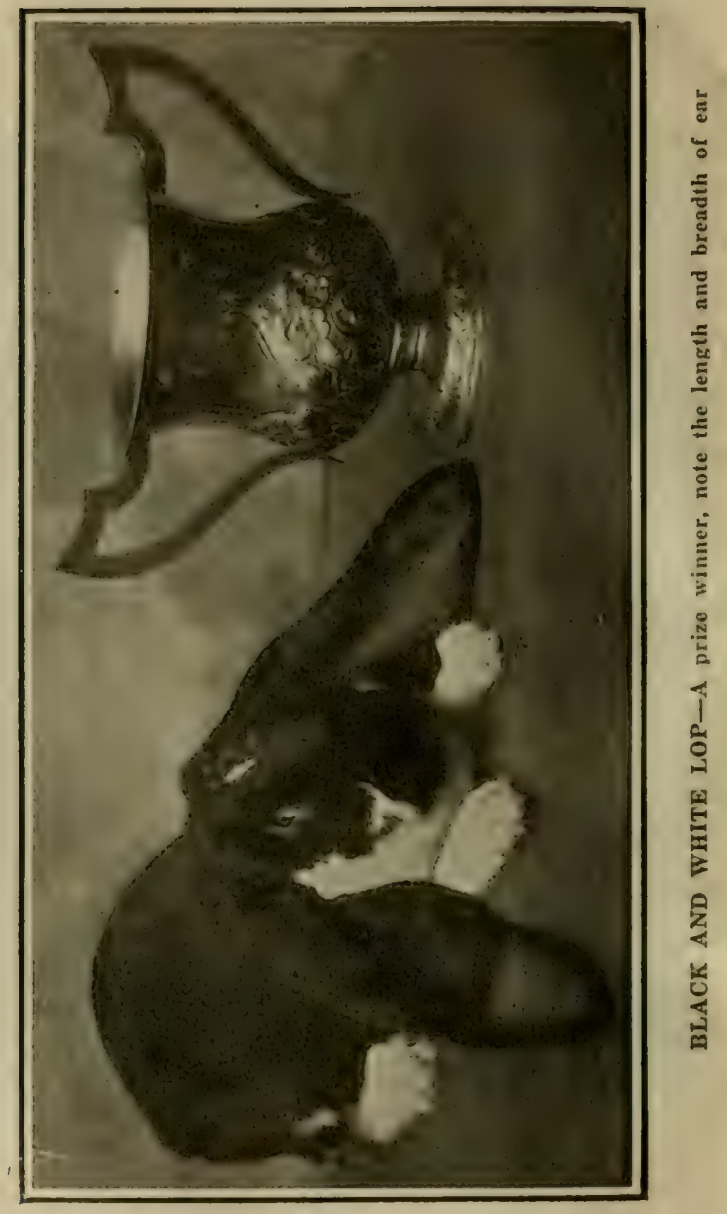


men has the contour of head over its highest portion where it joins the first (cervical) bone of the neck so adjusted as to compel the ears to suspend uniform, and gracefully curved around their convex distension, without collapsing appreciably in any place except where touching the floor.

\section{Pose and Shape}

When the hear is posed as just described, it gives position to the animal throughout, a point that qualifies for Standard merit. This will naturally approximate the fore legs beside each other from elbow to toes, so they are evenly paired under the rounded breast, and not much more than foot-length visible; neck rather sharply curved so as to start the back-curve from shoulder junction in a uniform, almost half circle, free from projections, to the root of the tail-_"in the buck rather straighter in saddle outline."

The hind legs are uniformly straight by the side of the body toes not pointing away nor toward it, and flat on the floor from knee-joint forward, altogether "humping" the body between two strongly outlined shanks so as to make it appear almost balanced in the middle of them.

\section{Color}

Unlike the Belgian and several other varieties, Lops are bred to no specific color, unless solid blacks can be so identified. They are represented in sooty, fawn, white, grey, yellow, or. modified buff, blue and self; or in broken colors of yellow-andwhite, grey-and-white, blue-and-white, or black-and-white.

In the distribution of these colors, there should be some appreciable regularity in that they are not to smear into ore another, while "the saddle should be entirely self, the markings breaking at the shoulders."

\section{Butterfly}

The head "has a star or blaze on the forehead; but its chiefly marked feature is the butterfly, a marking which, while it leaves the nose with no trace of white, is broken on the outline, resembling this beautiful insect."

This singular resemblance is physically due to the characteristic anatomy of a Lop head-the rounded, lateral-and-forward convex nose; conspicuous eye brows, and rather broad appearing forehead formed by the root of the ears.

All these points enter into classic breeding of this variety.

\section{Eyes}

There is nothing special about the eye of a Lop other than it should be sound and attentive. But I will add, there belongs 
yet something that makes it decidedly characteristic of this variety of fancy rabbit. The inordinate size of those pendant ears demand an anatomical adjustment of muscle and cartilage about the cranium that creates more or less corrugation around the eyes, which causes a singular droll expression quite typical of the Lop. It is an appearance of earnest effort to keep the eyes open in spite of those large ears.

\section{Tail}

Must be perfectly straight and "carried well up the body, without any suspicion of a twist." To carry the tail side-wise does not imply a twist in it, nor is it necessarily a disqualification when the specimen is otherwise meritorious.

\section{Breeding}

As remarked, the object of breeding Lops is virtually alone for their earage, and there has been considerable contention among fanciers just where success comes from-correct strain, or correct attention. Arguments of intense warmth with no small acrimony have been freely exchanged on this point, but I am reasonably certain that if the strain is not endowed with inherent propensity to procreate well developed ears, there is small chance for meritorious success.

The matter of artificial heat will, without doubt, also accentuate growth of ear; and when natural weather temperature is below 70 degrees within the quarters, becomes a necessity, notwithstanding all arguments to the contrary.

One prominent English authority insists that it is impossible to produce earage beyond 24 inches without artificial heat, but we must bear in mind that there is a marked difference in climate between our country and that of England, and that warm days are not so many there as with us. That artificial heat is extensively used by European fanciers is a fact, but whether it is a judicious procedure for the welfare of the breed is a question.

For the mere purpose of Fancy and general admiration, one can derive virtually as much pleasure from the "anylength" class-say, 20 to 25 inch earage-as for extra length. The latter is largely a fad.

With regard to mating, care, feed and general attention, the breeding of Lops does not differ essentially from that of other varieties, other than added care for the ears, which persistently hang on the floor. For this particular it is necessary that the guarters be kept clean continually, and the floor well covered with clean bedding of sawdust and chaff, straw, or hay. A dirty 
noor will soon bring on disease of the ears, and once this takes hold in a flock there is no end of trouble.

\section{Littering:}

For obvious reasons, it is not desirable that nest boxes are given the expectant mother doe. If the general habits of a Lop are considered, along with the preponderant ears, it will be plain that the more room a doe has, the better able will she be to care for the young. All she requires, therefore, is sufficient material with which to build a comfortable nest in one corner of her coop, along with the wool she will take from her body to line it.

After kindling, see that no dead ones are among the litter and for reasons of success, reduce the latter to no more than four. I would suggest a foster mother rather than destroying them, particularly so when one has a reliable strain for earage; for it often happens that those from which the least is expected turn out best in the end.

It is simply astonishing with what rapidity the ears of a young Lop will push for length. An old fancier who has bred this interesting variety for many years informed me that if the quality of a specimen is not apparent by length of ear in 10 weeks from birth, there is small purpose in bothering further with it. He tells me that he has often measured the ears of a youngster on an evening, and by the following morning there was an additional two inches in length. One would scarcely believe this possible but I have not the least reason for doubting this fancier's word. This qualification implies, that an earage upwards of 20 and 22 inches must show at the end of 10 weeks, and that further length is very limited.

I have often seen it in print that many practice "pulling the ears" to accentuate length, and on the other hand the accusation was also denied. Whether true or not, this practice should be condemned-with punishment, if necessary.

\section{Standard for Lops}

There are now two standards by which this variety is judged - for the Limit Classes, and Any Length Classes. The former has special significance for earage while the latter considers the specimens as a whole. 
Limit Classes:- $\quad$ Points

War length ....................

bar width ..................

Substance and shape of ears ...... 5

Shape and carriage ..............

Color and markings .............15

Condition .................... 10

Straight feet and tail ...........10

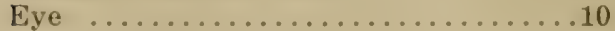

Size .................... 10

100

Any Length:-

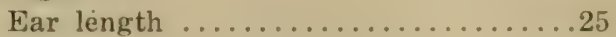

Ear width ................... 19

Substance and shape of cars .......9 9

Straight feet and tail ............10

Color and Condition .............21

Shape and size ................

Eyes ......................

100

Bucks to weigh 10 pounds and does 11 pounds or over.

\section{French Lop}

The French Lop is similar to the English, as described above, but is smaller in body and with smaller ears. They are judged 3y the same Standard as the "Any Length" class in the English Lariety.

Disqualifications-Permanent wry tail or feet.

\section{Dutch}

By many this is claimed as the handcomest variety of al: domestic rabbits, and with considerable justification.

The Dutch is not as popular in this country as in England and Germany, though it is making friends fast.

There is about this variety a certain fascination that ought appeal in particular to fanciers with a critical eye, for its color markings are such as to make a scientific breeding an absolute necessity. 
It has been said that Dutch are "hard to raise," but why more so than other varieties has not been marle clear, to my satisfaction at least. Were such the case, it is likely the trouble lies with the breeder rather than in the breed.

The Dutch is not a large rabbit compared with domestic rabbits in general. Standard qualifications want it comparatively small; so if there is any lack of stamina in the breed, it is possibly owing to a persistent effort at keeping down weight, accentuated also, by close in-breeding.

\section{Color}

Color markings of this variety are characteristic and very pronounced, one color being always white, and the other either black, blue, tortoise-shell, or a type of steel grey. The solid colors must be typical of the parts they cover, and distinctly separated from the white. Neither shall smear into the other and both must be entirely free from foreign hairs. Fancy value of a specimen depends altogether on the perfect markings thus characterized.

White must be the markings of shoulders, fore leg's and feet, under jaw and nose upward to between the ears, forming a distinct blaze. About $1 \frac{1}{2}$ inches of the hind leg's from toes upward is also white. Solid color covers the saddle from short ribs back all but the hind feet, and its junction with the white must be as clean cut a line of demarkation "like a string about the waist." Both sides of the face, jowls and ears, are of the same solid color, just as evenly separated from the white.

\section{Breeding}

The biggest contention associated with breeding this variety lies in persistently keeping down size, and maintaining solidity for the two color markings.

To breed high quality Dutch there is but one road to real success-that of establishing a reliable strain.

Start right, and the battle is near half won in the knowledge of personal results that relate to points of merit or demerit.

The greatest contention is to overcome a propensity for foreign hairs and splotches in solid markings, notably on the sides and flanks; specks in the eyes, or distinct discoloration; and white inside the ears.

When mating it is advisable to use breeding stock that has maintained solid markings after its second molt. Intelligent attention to this factor has been a leading guide to the establishment of permanency in markings; and largely, also, for physical characteristics in general. 


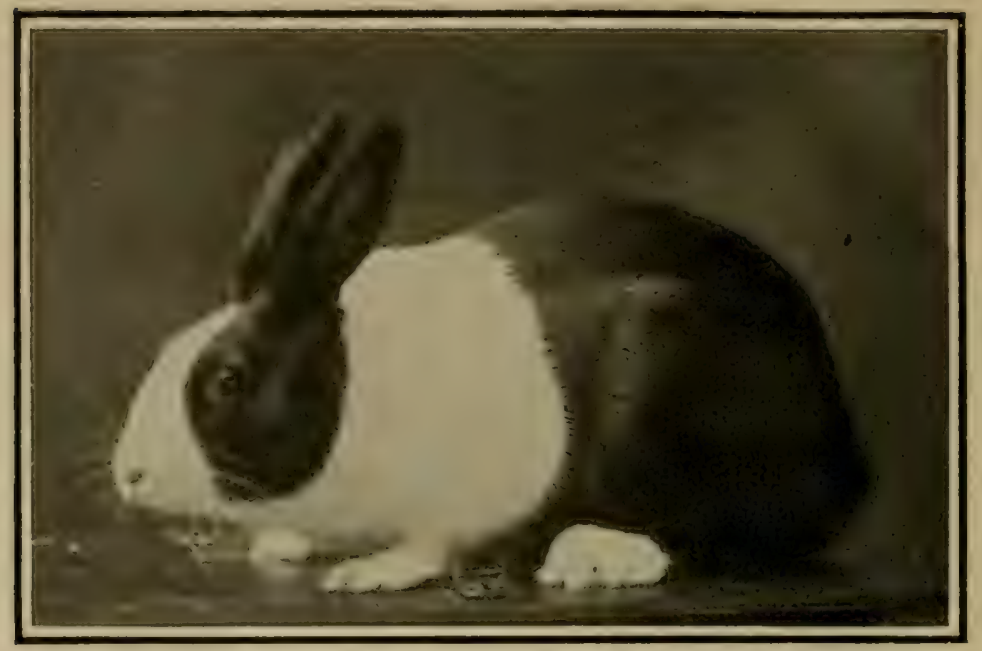

AN IDEAL DUTCH-Very nearly perfectly marked. Compare this fellow with the ideal cut helow Lines up in good shape, doesn't he?

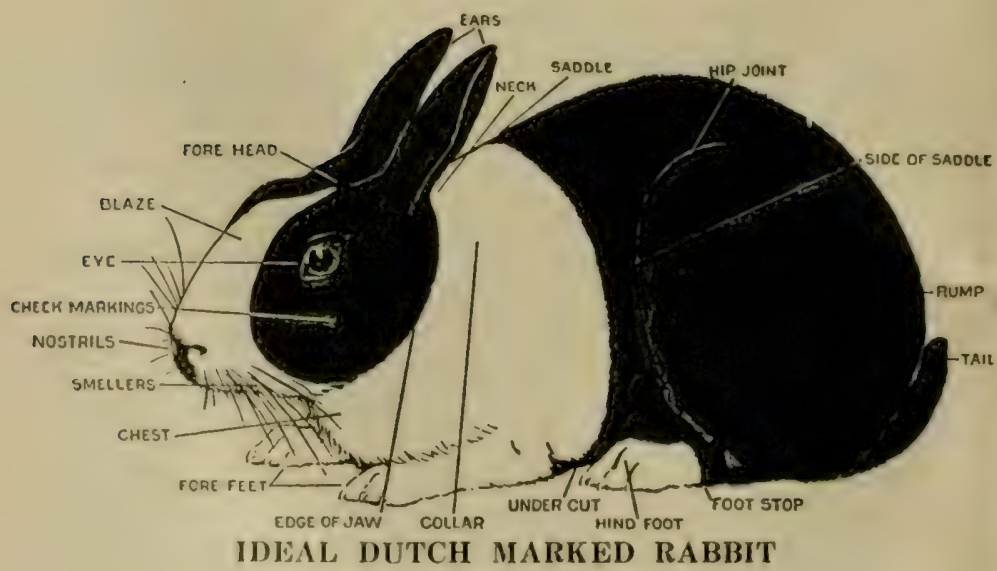


The breeders whose success I have noticed as most pronounced, mated either a second molt buck to younger does, or a two-year old to yearling females. Greatest stress was laid on color characteristics in the male, while the females were selected more for inferior size; thus, as near as possible, equalizing points for both color and weight.

Physically, the Dutch of whatever markings, is a beautiful rabbit when rightly bred. It should be neither racy nor cobby, but a graceful medium to which there is sufficient length that does away with pudginess. Never to grow above $5 \frac{1 / 2}{2}$ pounds, size and grace should be harmoniously proportioned to make an ideal. The ears are perhaps a trifle on the small size comparative to specimen.

As to markings, these are so well outlined in the young when born, that one need not waste effort in bringing up what will likely turn out worthless ones. I am alluding to the line of demarkation separating the colors. If this line is ragged or irregular, colors will show the same when fur is grown out.

\section{Feeding}

Standard weight for show purposes is five pounds, and not over five and one-half, hence one must keep in mind continually that overfeeding conduces to overweight. In fact, they do not seem to require as much as a few other varieties of the same size to keep in good condition; and so far as the nature of food required, there is no essential difference with that of other breeds-with the exception, perhaps, that not quite as free a supply of greens be allowed. This latter conduces to a disease known as scours.

\section{Quarters}

Every one will readily understand, that a small variety of rabbit does not require so much room as a large variety. The quarters should be comfortable, clean for the sake of color as well as health, and sufficiently high to allow free jumping exercise.

To keep down weight by exercise is far more desirous than doing so by stinting food. Exercise and air make for vigor and "blooming" fur. 


\section{Standard of Points}

Blaqe and Cheeks ................15

Clean neck ...................10

Saddle .......................... 10

Undercut $\ldots \ldots \ldots \ldots \ldots \ldots \ldots \ldots \ldots$

Feet-stops ....................

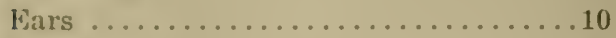

Eyes ................... 5

Color ..........................10

Size, Shape and Condition .........15

\section{Negative Points}

Small specks on eyes ......... to lose 10

Discolored, or wall eyes ......to lose 20

Distinct spots, or flesh marks ......20

Over $5 \frac{1 / 2}{2}$ pounds in weight ........20

\section{Angora}

In this country, the Angora has been heretofore an exclusively ornamental variety. It makes one of the most attractive pets one may wish, and in the show pen one of the finest exhibits.

In several European countries, notably France, this variety is reared quite extensively for its fur as a source of income by the peasant folk-furriers buying all that is rendered.

As a matter of information I will mention here, that one rabbit is estimated to furnish "wool" at a value of 5 to 7 francs per year, or approximately 20 francs for three years, after which it is considered worthless by reason of the "wool" becoming too coarse, and is then consigned to the peasant's food supply. One specimen is "pulled" twice each season, much after the methorl our forefathers employed to secure lown from greese.

To us hurrying and much-wanting Americans this source of income would scarcely appeal right now; but permit me to prognosticate, that time is not far distant when breeding rabbits for fur purposes will become an actual necessity-unless the wearer of fur and felt hats gradually affiliates himself with some sort of inferior substitute. Of this I have been assured by one of the largest mamufacturers of felt hats in this country, and he qualifies his assumption by saying that "it will be but a few years from now for us to sec rabbit farms in every community." 


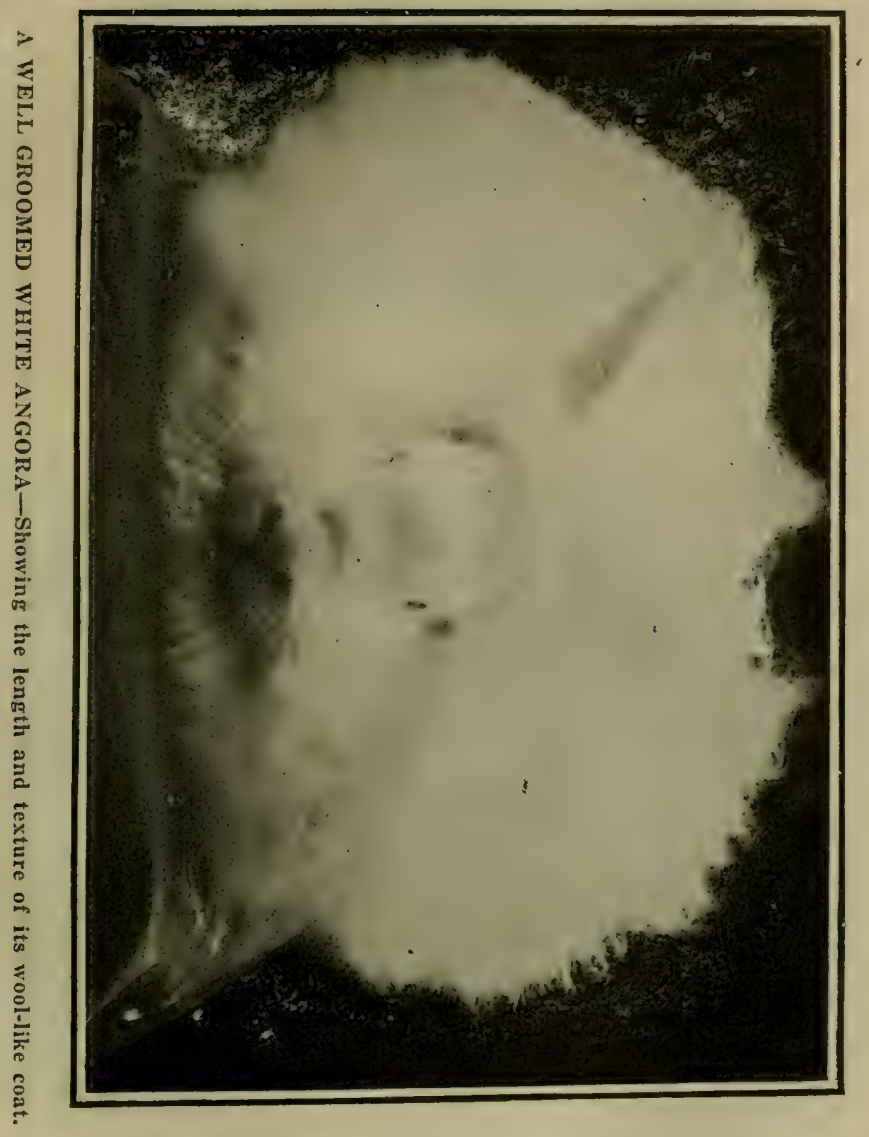




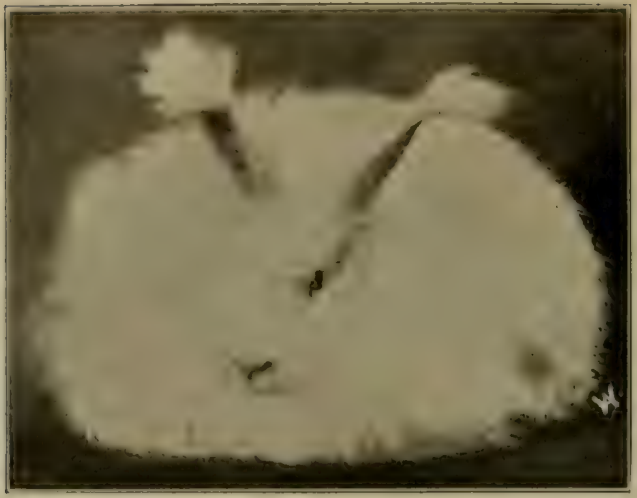

A Splendid Angora. Note the wonderful ear furnishings

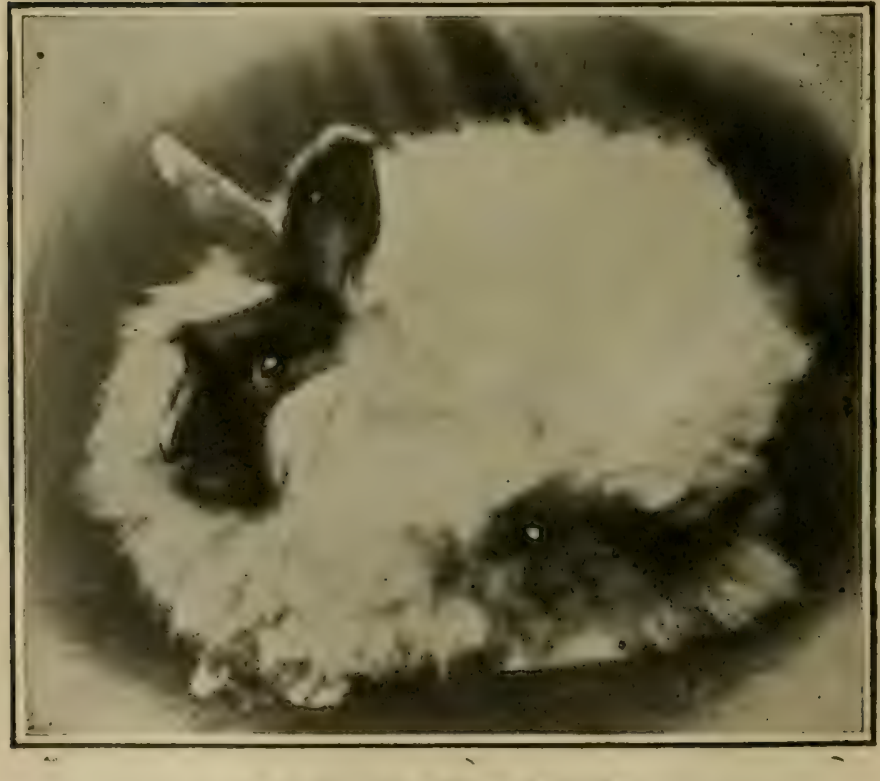

BLACK AND WHITE ANGORA

Colored Angoras come in Blues, Blacks, Grays and Fawns and combinations of these various colors with white. They are not so popular at present as the Whites. 
This would seem to bring the Angora forward as a clesirable rabbit along these lines-essentially so for cross purposes with other varieties to attain the most advantageous fur.

Among a batch of mongrel rabbits I shipped some time since to a New York commission house, was a specimen apparently the result of mating a near Angora with a part Belgian. The singularly beautiful fur attracted my attention and by looking it over carefully, was impressed with the possibility of what the hat industry opened to one who would give scientific attention toward the attainment of a species of fur rabit for this purpose -possibly from cross-mating thoroughbred Belgians, Angoras, and Silver Greys.

\section{For Fancy}

As remarked for purposes of Fancy the Angora is very attractive, and makes an ideal pet. It is perhaps the most docile of all varieties, tolerating whatever handling is required to keep it so with entire freedom.

Because of its long and delicate fur, it must of necessity be brought up in positively clean quarters. Constant disinfection must be applied to keep them so, and it must be remembered at the same time that all animals and creatures with long "wool" are ready carriers of disease germs.

In its most perfectly developed form the Angora resembles a puffy ball of snow, with the head almost hidden within its fleece. The longer and finer in texture its wool, the higher its value as a Fancy specimen. Wiry type of fur is not desired nor correct, while a tendency for it to mat appears an evidence of high quality.

It is bred, of course, mostly in white, though recently some effort is being made to bring out what are expected to be blacks and blues. These latter have created quite some controversy among their fanciers antagonistic to several judges who passed on them with considerable question-rather in the light of sports "in smoky color" than a bred up variety of true shade. The fur of blacks and blues has been found, also, to modify with each succcssive molt to an extent that one is scarcely distinguishable irom the other.

\section{Breeding}

Out of the 100 points called by Standard requirements, 55 are demanded for quantity, quality and length of wool. This should indicate to the intelligent fancier along what lines specimens ought to be selected to reproduce these qualities; and since the procreative functions are always more pronounced in the male, it becomes essential that this side of the line is well bal- 
ancel. In no instance of breeding live stock am I in favor of feminine characteristies to preponderate in the male, but when mating Angoras for the particular qualifications above mentioned I am positive that femininity on the fructifying side will produce best results. A coarse male rarely fails to reproduce coarse eflects in both boly and fur of his offspring. True, have the female as fine and pure of fur as available, but rather let size ard front furnishing be the preponderating characteristics.

Tufts on the cars are also an essential show quality, and should preponderate in the male.

\section{Grooming:}

Many an otherwise qualified specimen has failed to win, simply hecause it was carelessly groomed, or not at all; and to groom properly is a matter of no small attention.

The exceeding fineness in texture of fur indicates that the skin is compactly covered with almost microscopic hair follicles, and to be in any way rough to these with coarse brush, comb, or confections, possibly, mears a coat that will eventuate into coarseness. First essential, then, is to keep the skin clean and healthy from the day youngster's begin to show Angora wool type. For some months this is not a bothersome attention, providirg the quarters are kept clean and well bedded with shavings or fine hay. An abundance of the latter will do wonders by merely sifting through the fur, but to accustom the ball of wool to handling, and nurture the tender skin so its covering remains soft and fiufy, occasional brushing with a freely flexible wire brush, followed by a medium bristled hair brush, is desirable. At any rate, do not permit the coat to mat. But should this happen, and the specimen is desired for exhibition purposes, a genuine shampoo becomes necessary. Whatever one fails to do, under no circumstances fail in preventing vermin getting into the coat of an Angora; for here is trouble that becomes very real once it has a start.

To prepare a specimen for exhibition, one's object must be to have the skin and fur virgin white and clean, which is best accomplished by means of a shampoo and dry brush.

Select a warm place, say 75 to 80 degrees, and water of at least 98 to 104. Apply the shampoo with the wool scruffed "wrong way," use gentle rubbing, and then wash off with clean warm water, followed by a rub down from a soft Turkish towel. Before the fur is altogether dry, dash through it a bit of good Bay Rum, then linish. When brushed well, muss up the fluff and sprinkle through it borated talcum powder, which is in turn thorunghly gotten out by liberal brushing "in every direction" until 
the wool is woozly soft as the driven snow. There is no danger of the specimen taking cold if these directions are observed. Just be sure the fur and skin is entirely dry, and when Bay Rum and talcum is applied its pores are effectually protected.

I have often been asked what to do for the removal of brassiness and stains, and "what to apply to make a pelt pure white?" If brassiness is not inherent with the strain, and stains have not remained too long, a shampoo is usually sufficient. But remember, there is a vast difference in brassiness acquired from environment and that of heredity, and in a properly cared Angora ought not to show.

\section{Standard of Points}

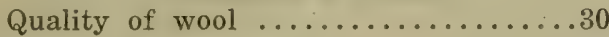

Length and quantity .............25

Front furnishing .................

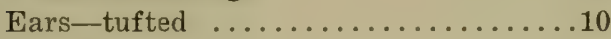

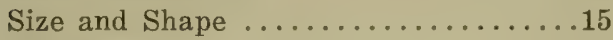

Condition ...................

100

\section{Himalayan}

In Europe this variety of rabbit is reared in considerable quantity for its fur, and many fashionable women carry pelts with the belief that they are wearing beautiful ermine.

The Himalayan is one of the handsomest species of domestic rabbit that can be desired, and beside being an ideal pet, brings real satisfaction to the critical fancier in the breeding of it for classic points. It is worthy of a stronger position in the Fancy than it now occupies.

By the way of description it has a beautiful white coat of short, fine, flossy fur, soft as down, and looks at one with droll, attentive pink eyes. The nose, ears, tail and four feet are deep chocolate black, a beautiful contrast to the white dress over all. If these back points are deep and dense, and nicely even separated from the white, a specimen becomes all the more enhanced in value. The young when born are white entirely, but about a month old the dark extremities begin to come out gradually, and at four months their development is complete.

A singular peculiarity about this varicty is the anomaly of their black points growing lighter on exposure in the sun, and for this reason their breeding should be conducted in hutches with subdued light. Indoor quarters would therefore appear best adapted for successful effect, and which, on account of the delicate fur, must be kept scrupulously clean. 
In size a speeimen should weigh about four pounds, and in general physical outlines conforms harmoniously with that of Dutch. Ears are neat, small comparatively, and black to the roots. No lewlap. White fur entirely free from blemishes of alien color.

To make all salient points clear with regard to rearing this variety successfully, I will quote verbatim how a reliable breeder says in "Fur and Feathers" he goes about it: "Allow the young to remain with the doe until they are 8 or 9 weeks old. If you take them away before, they will in all probability stop growing, and a young Himalayan must keep on growing until it has got all its points cleared.

"With regard to mating, the question of relationship does not concern me so much as fitness from the standpoint of increasing points of excellence, and correcting faults. I never trouble about how closely they are related, providing they are perfectly sound and robust. Never on any account inbreed from stock tainted with any kind of disease, or regret is sure to follow. For my part I like stock closely inbred, because it keeps your operations more closely confined. (Of this theory associated with breeding the English fancier is virtually obsessed. I will refer to it in the chapter on Belgians.-Author.) These are the lines I work on, and I feel sure a great many of the most successful breeders of live stock have done the same.

"As to feeding, I never found that Himalayans wanted treating any different to other kinds of exhibition rabbits, only perhaps, that you should not gire them quite as much green food, and not change it quite so often or so suddenly, as they are very subject to looseness. In very hot weather let them by all means have a drink of cooling water; but don't leave it in the hutches that they knock it over, for this soils them, and spoils the color of the feet.

"And now I must get to feeding. Some Himalayan fanciers swear by hard feed and some by soft, but I don't stick to either. $I$ just give them a nice change as often as I think good for them and if $I$ find a rabbit does not care for the food I am giving, I take it away and give something it does like. Oats and wheat are the staple food for breeding stock and growing youngsters, but when preparing them for exhibition I like soft food, because I can mix together various kinds of food of an oily nature, and this keeps them on the move, and the molt. As soon as I have got their points clean, however, I give them hard feed, and three times a week some bean and pea meal, just to tighten them up and get them in fine condition. 


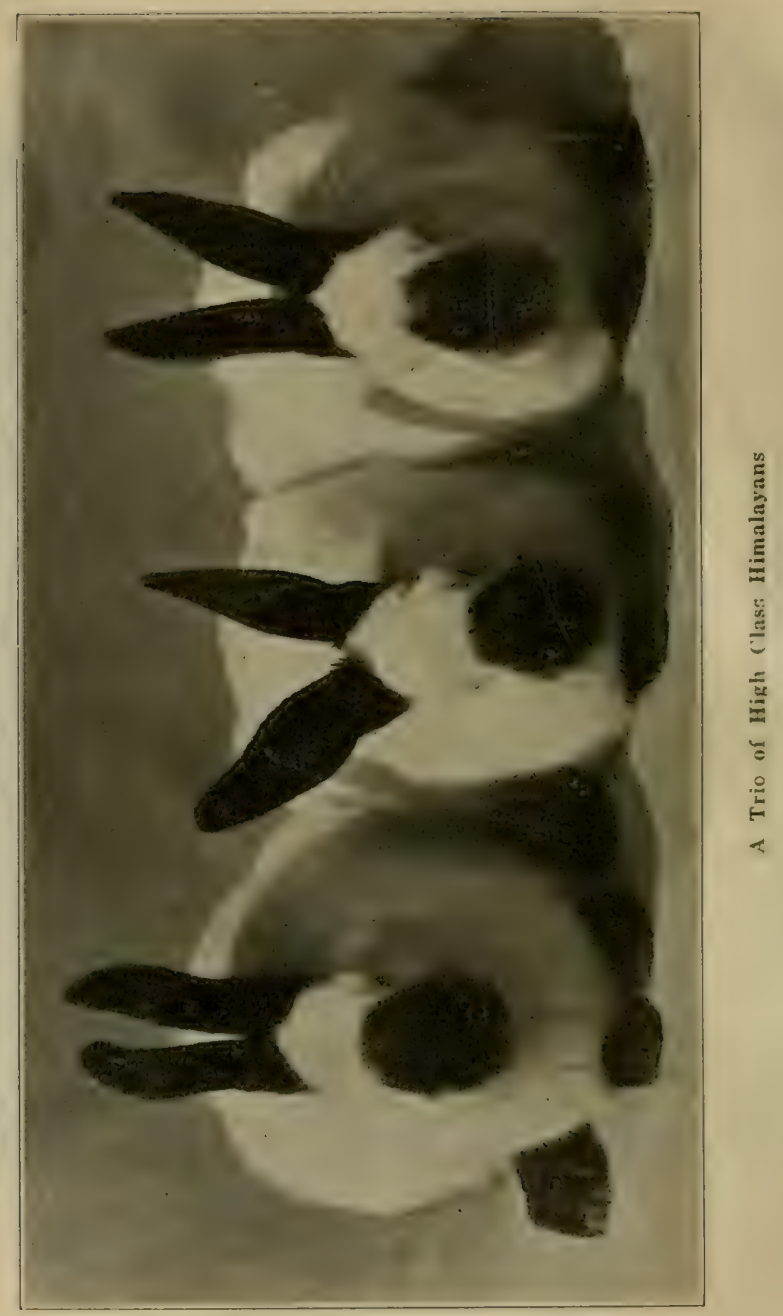


"I have referred to food of an oily nature, but this in no way gives them color, which must be bred for, though it gives their dense points a lustre which is so fascinating, and which a judge likes. Some of the oily foods I used were linseed and molassine meal, whilst I have also used with great success a mixture of cod-liver oil and lime water-the lime water taking away the fishy taste from the oil. This is a fine conditioner and flesh-forming food for any kind of rabbits that are inclined to be poor and in low condition.

"And just a few lines with reference to stained eye-lids. I am very much afraid we shall have this defect for a considerable number of years; in fact, I very much question if it will ever be gotten rid of, unless Himalayan fanciers import quite a fresh lot from their native land."

Regarding the above points on care and feeding for Himalayans I quote the writer entire, for the reason that he conveys with but slight modification the process pursued by virtually the whole English Fancy. It gives the reader a clear idea how fancy rabbits are reared over there, and to what fastidious lengths they will go to make a specimen showy. After results do not seem to be considered, and in the light of such effort, with its noncommittant environment as to climate and limited quarters, one need not wonder that stock coming from there is without stamina, and too frequently diseased. Once we are obliged to rear stock for show effect only, there will be small interest for the scientific breeder. I allude to the efforts of forcing Nature to yield beauty at the expense of inherent physical qualities.

It is a physiological fact, that rabbits with pink eyes are not so tolerant of light as those with dark. As an act of comfort therefore, if for no other reason, they should be kept in dim light quarters; and particularly should the young be protected until at least six weeks old.

\section{Standard for the Himalayans} Density, Shape and Size of Markings:-

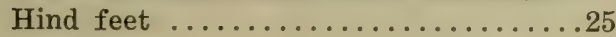

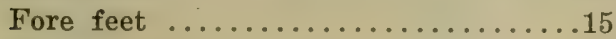

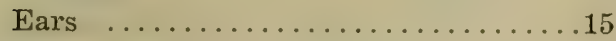

Tail $\ldots \ldots \ldots \ldots \ldots \ldots \ldots \ldots \ldots \ldots \ldots$

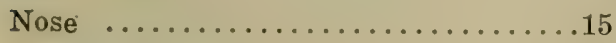

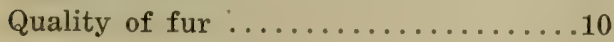

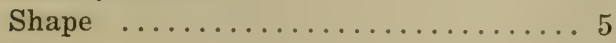

Size ..................... 5

Condition ................. 5 


\section{Silver Grey}

Here is a distinctly useful variety of comestic rabbit, and in referring to its physical characteristics, I wish at the same time to express a hope that shall actuate a better appreciation for the real merit to which it is entitled.

On superficial observation the Silver will scarcely be estimated as handsome, but on close examination of a correctly bred specimen there will be discovered a delicacy of fur that is more like silk than wool, and when that beautiful "pepper and salt" silvering is seen shimmering through it, there can not fail of real enthusiasm for the production of a good type animal.

The Silver is neither large nor small, ranging from five to seven pounds. It has not the racy, reachy style of the Belgian, nor the compactness, "get-together" appearance of the Flemish. Fine of bone, clean and dainty, delicately valuable fur, and as near an ideal meat as the most fastidious epicure can demand. Indeed, it is almost too fine a meat, so that cross-mating, say with the Belgian largely enhances its food value.

I have given considerable attention to finding the origin of this variety, and while it is essentially an English product, the several fanciers who have rendered an opinion were so diversified that I am loath to say anything authoritative.

One may inquire why this variety is named "silver Grey" rather than merely "Grey," as one is readily impressed on first seeing a correct specimen. There is a certain shimmer to the fur that clearly conveys the tinge of silver, due to a proportionate number of tipped hairs evenly distributed, known as ticking. The shade may vary from light to lark silvering according to the greater or lesser quantity of light hairs. In fact, from the standpoint of Fancy, the value of a Silver is estimated entirely by the evenness of its silvering, which ought to be as near alike over all the animal as possible-ears, nose, feet and tail should match body color.

Undercolor is by some termed slate blue, and by others blue black. This should extend distinct to the skin. What is often an otherwise good specimen Silver Crey is frequently made inferior by entire lack of undercolor on the chest-a point to be constantly kept in mind when one's matings are made up, or new stock purchased.

Likewise, specimens that are otherwise evenly silvered but have a "cloudy appearance" usually possess a strain from the Browns. 


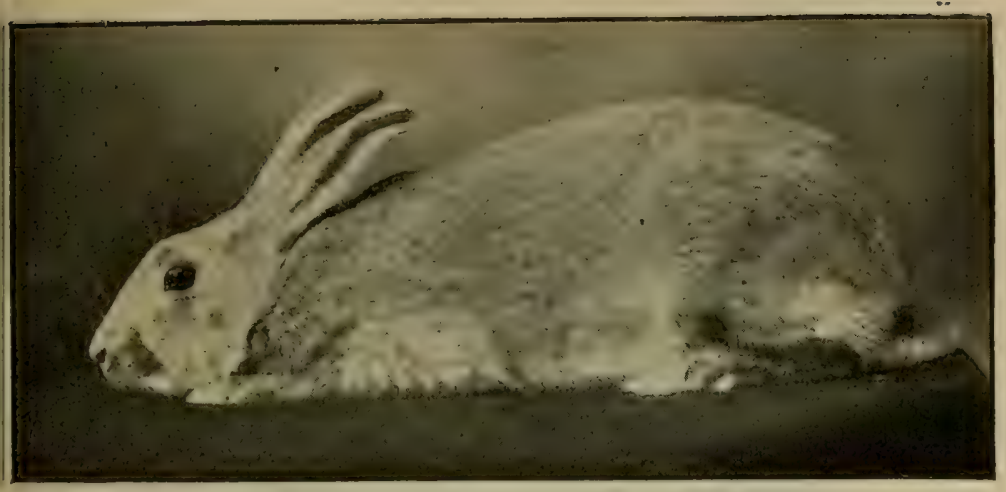

SIL:ER GREY

A beautiful variety, not given the attention in this country it deserves. Excepting the defect of slight kinks in the ears (caused hy hutch conditions) the above is a very good specimen.

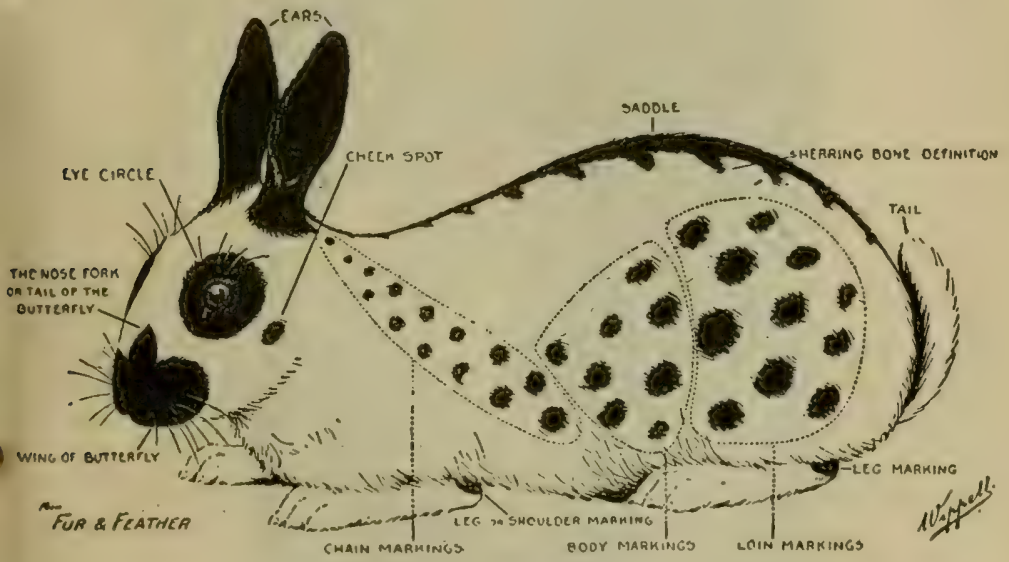

\section{IDEAL ENGLISH RABBIT}

(NOTE:-Eliminate the "chain markings" and substitute two or more large patches for the body and loin markings in the above, and you have the ideal markings for the American Spotted Giant, the shape and size of which, however, corresponds to the Flemish Giant-see page 53.) 


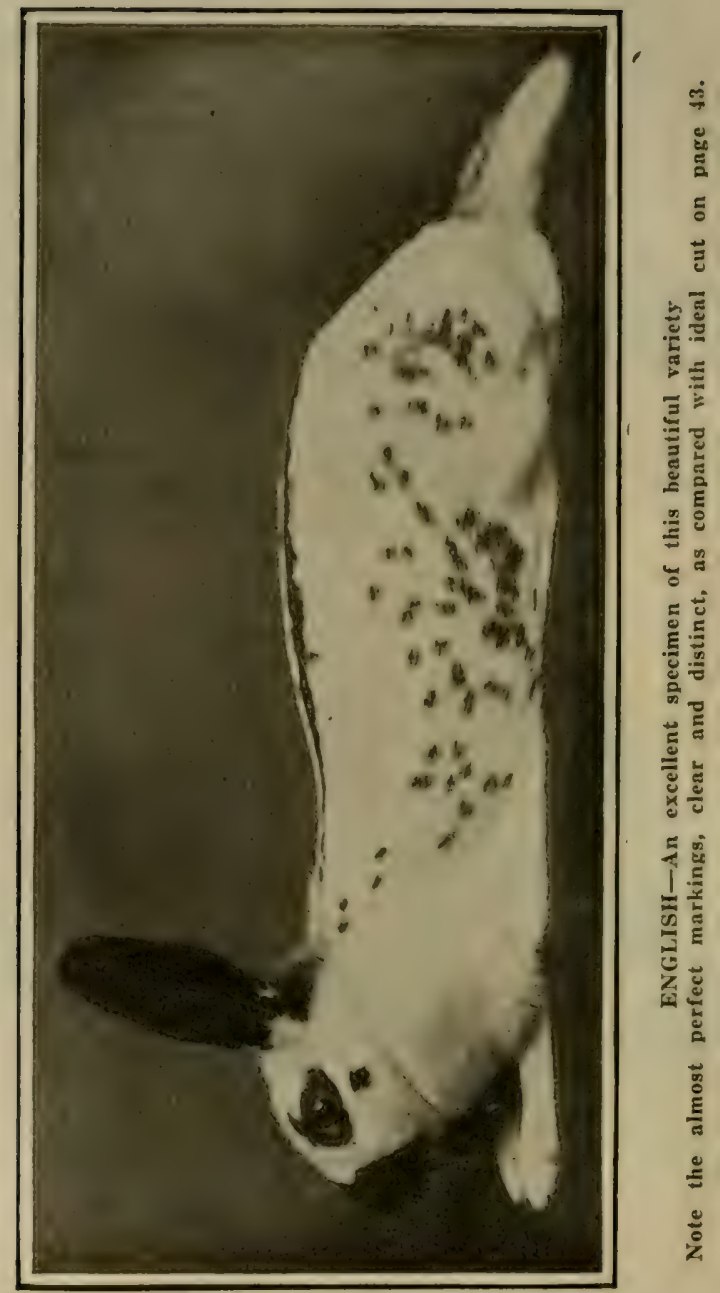




\section{Breeding}

There is but one essential to the successful breeding of Silvers-stock of even markings on both stcs. This implies that males and females are as near like one another as one can possibly have them. If anything, undercolor is perhaps of more vital consideration than surface color, which, as remarked, must have the evidence of even silvering. The coat should be short, and of such feel and consistence like silk.

It is claimed by breeders of this variety, that richness of silvering is intensified by warmth. This, of course, comes from the English method of rearing the variety, and where climate and consequent environment must be considered, also the propriety of winter breeding, always injudicious unless accompanied by artificial heat. The latter is a factor only when one breeds for show classes as scheduled according to age limits at all times of the year. At the age of six months the finished lustre of a Silver is supposed to be complete.

\section{Standard of Points}

Undercolor, a deep rich blue black ....25

Evenness of silvering throughout .....20

Sharp, even bright ticking .........15

Short, full coat ................

Ears, neat, well set on; bold, bright eyes 10

Size-about six pounds ..........5

Condition and shape ..............15

100

\section{Silver Fawn, Silver Brown, and Silver Blue}

are varieties not recognized to any appreciable extent in this country. At shows one sees occasional specimens purporting to represent them, but their breeding is of such uncertain success, as to warrant scarcely any real interest in their support. For utility purposes, they are just as appropriate as the Grey. Standards-except color-same as Silvers. 


\section{Englisin}

'This is a "made" rabhit by English fameiers, and among them has many staunch admirers. It cannot lay claim to superior merit over any other variety beyond the singular markings that characterize it, and correctly bred, these are quite beautiful and odd.

The breeding of English rabbits is always surrounded with considerable uncertainty, and in no variety is the necessity for reliability of strain emphasized as perhaps in this. Lately, also, some slight modifications in their Standard markings have been made that do not by any means simplify breeding.

Persistent inbreeding is the more likely road to success toward characteristic points, and as our English friends invariably do, they follow it with a vengeance.

The peculiar markings which typically identify this variety are known as "herring bone" and "chain"-the former from shoulder along the entire back, and the latter along sides, ending on both shanks. Ears are solid black and the eyes are also surrounded by a solid circle. "Butterfly" nose is considered by many as important a point as that relating to ears and feet.

Head Markings:-

\section{Standard Points for the English Rabbit}

Perfect butterfly smut ...........15

Circle around each eye ...........8 8

Eye spot, clear from eye circle .....6 6

Eye, clear and bold ............. 3

Ears, neat and free from white, not over four inches long ......... 5

Borly Markings:-

Neat saddle, herring-boned in any dis-

tinct color ................. 10

Sides of body to be nicely broken up in small patches, not to catch saddle markings .................

Chain markings, even as possible on each side ................12

Leg Markings:-

One distinct spot on each leg ..Fore leg 6 Hind leg 2

Belly spots, should be six .........6

Color ..................... 5

Size and shape, 6 to 8 pounds ....... 5

Condition, good coat, not baggy ...... 5 


\section{Polish}

This is the "White Rabbit of Easter," and when bred to Standard qualifications, is an exceptionally handsome variety.

It is pure white over all, has pink eyes, and in physical outlines closely resembles the Himalayan (without the dark points). In shape it is neat, and not by and means pudgy, and has little in common with the white rabbits one sees running about yards, kept in filthy small boxes by children, and reared mostly for Easter occasion. Very few of these are Polish. With its solid whiteness that gives continuity to outline, there is apparent all the while something striking in the spry and bold appearance to the animal, and quite typically accentuated in the inquisitive pink eye. When on the alert there is a characteristic grace that removes all compactness out of the body, with the result of real beauty in outlines.

Its fur is of fine quality, short, close to the body, smooth and of silky texture. Ears are short, well set on, thin, and finely covered with fur, the latter point being good evidence of thorough breeding.

Because of their immaculate whiteness-and, by the way, there must be no evidence of brassiness in the coat-Polish must be bred in clean hutches, so constructed as to prevent direct sunlight into them.

There are no rules of special importance for mating other than the male and female should be well matched as to quality of fur, ear finishing and perfect health. Any evidence of brassiness must also be avoided, a caution quite essential when new specimens are purchased.

Standard Points for Polish

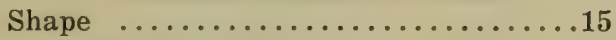

Size-three to four pounds .........10

Quality of fur ................. 25

Purity of color ............... 15

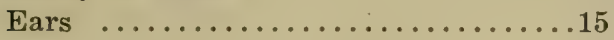

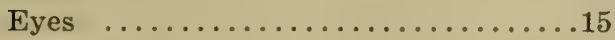

Condition .................. 5 


\section{Havanas}

This is one of the very latest varieties and was first introduecd as an exhibition specimen into England, in 1910. The correct color is dark brown to dark chestnut brown and blood red brown changing with the varying light. From Holland, Havanas have been sold to go to France, Switzerland, Germany, and quite a few have found their way into the United States. In France they appear to have been crossed with the Belgian Hares, the color of these specimens being light tan brown, and the frame and ears are consequently much larger than in the original variety. The pelts are of considerable commercial value as an imitation bearer. Furriers require a rough, longish coat, and the Dutch variety appears to be the one most bred for this purpose. Havanas are strong and hardy and easily reared in outside hutches of ordinary dimensions. The show type that appears to be superior is the smaller, neat, short coated variety. The larger ones often exhibit a dewlap and are somewhat coarse and awkward looking. The eye is deep brown, changing to ruby and quite a feature of the variety whose most pronounced fault after the variation in color, appears to be a preponderance of white hair's in body and ear's. The general appearance of the Havana is somewhat similar to the Imperial, with a decided blue cast to be seen on the belly and thighs. There are wonderful possibilities in the Havana and we look forward to them becoming great favorites in the United States.

\section{Standard of Points for Havana Rabbit}

Color-A rich, bright brown all over, with undercoat of

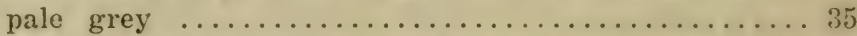

Shape and Size-Exceedingly fine and elegant, somewhat like the Black-and-Tan. Head and neck medium. Weight, when full grown, not to exceed $5 \frac{1}{1 / 2}$ pounds $\ldots \ldots \ldots 20$

Ears-fFour inches long, fine in substance, small, straight and carried upright ........................ 10

Feet-Very slender and straight, with brown toe nails ... 10 Eyes-I -arge, the color of the fur, showing a red light in the pupil, yet having a soft and gentle expression ....... 5

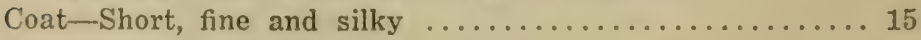

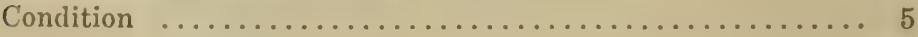




\section{Imperial}

The ideal Imperial may be described as follows: Shape and size, similar to that of a Belgian buck, but shorter in limb and weighing, when full grown, from 6 pounds to 7 pounds. Color, dark blue, of one even shade throughout. Fur, soft and bright, and rather longer than in the short haired varieties. Head, narrow and tapering, eyes being long, bright, and deep blue in color. The ears should be about $4 \frac{1}{2}$ inches long, round at the tips, carried erect, and set rather closely together. The commonest faults are white hairs intermixed with the blue, rusty color, brown eyes and bars of a lighter or darker color on feet.

\section{Standard of Points for Imperial Rabbit}

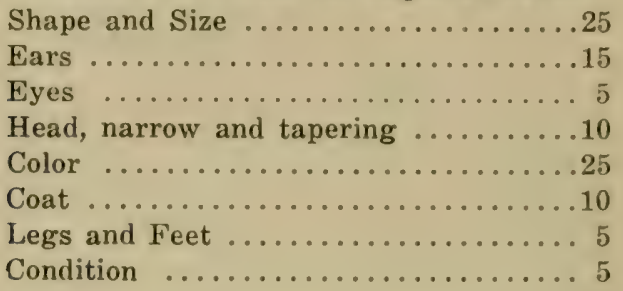

100

\section{Selfs}

It was not my intention to touch on Selfs and yet the book would scarcely be complete without some reference to the endeavors being put forth at present to popularize Self-Blacks and Blues. The production of such varieties presents little difficulty in the matter of color, and all that is required to be done is to reduce size and shape to the Standard governing the Polish or White Self rabbit.

Breeders of these new varieties which give every proof of rapidly becoming popular are obtaining them by different methods. Blacks are being bred by mating dark Silver Greys and the common wild rabbit, caught when young and tamed, and from Polish and Silver Greys. Both Self-Blacks and Blues are common enough in litters of tan and English and this presents an easy method of obtaining stock. Self-English are, however, much too strong in type, and therefore not the best means of securing the desired end. The first method of producing Blacks is the best and for Blues the Self-Blues often bred in a litter of tans is equally useful. 
No Standard of points has been drawn up, as yet. The only guide to breeders is the Standard for Polish. Neatness, shortness of ears and coat, combined with purity of color, are the points to aim for, and the rabbits when produced are to be of the "bantam" variety. There is no doubt about the success of the newest of new varieties, providing the Polish type is adhered to, and it is safe to predict a successful future for Selfs.

\section{American Blue \\ (Formerly Called The Vienna Blue)}

This variety is an introduction from Germany, where it has been extensively bred for meat and fur. The color is a beautiful dark steel blue throughout, with eyes to match. As compared with the Flemish, it is more upright and shapely, and weighs about ten pounds. Dewlap small.

\section{Standard of Points}

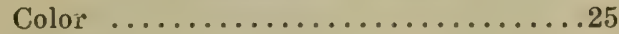

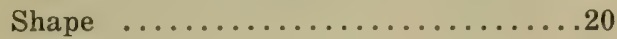

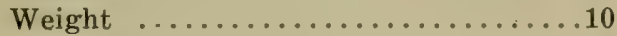

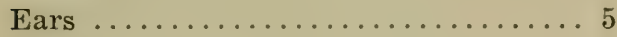

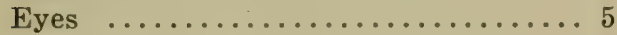

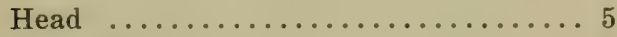

Legs and Feet ...................20

Condition ....................

100

\section{Japanese}

The Japanese rabbit is rather an oddity and is very rare in this country. The color scheme is intended to represent the rising sun, and consists of irregular circles or bands and patches of different colors, running around the body to represent the sun's rays, and the undercolor, varying from cream to brick red, representing the sun. While the markings may be very irregular, they must be clear and distinct and not of a mottled appearance. In shape they are short and thick-set and weigh about eight pounds.

\section{Standard of Points}

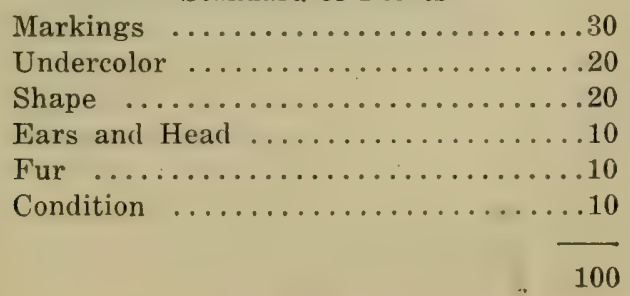




\section{The Flemish Giant}

As the name implies, this is the largest of all varieties of rabbits. By reason of its size the meat for food purposes is not as fine grained as that of its more classic rivals, the Silver and Delgian; but on the whole is quite desirable from the fact that it does not require many months to reach the same equivalent in weight which others attain only at maturity. Its meat is therefore all the more tender and appetizing.

The origin of the Flemish is somewhat obscure, but late in the ' 60 's or early in the ' 70 's, there was developed in Holland and Belgium a cross-bred rabbit that was given the name "Leporine." Later this was introduced into England, and here is what one author says about it: "Since Leporines so-called were introduced into this country they have been bred continuously, but with distinct and different objects-in the one for size, and in the other ostensibly to develop a rabbit of the form, color, and fur of the wild hare. The larger race has been called Patagonian, but is now recognized in a different type as the Flemish Giant."

It is of course, then, a "made" rabbit, which accounts, no doubt, for the difficulty encountered by fanciers to breed reliable markings.

By reason of its immense size, the Flemish can without prejudice be named King of fancy rabbits. Specimens have been produced that were said to weigh 20 pounds, while the average weight of Standard bred stock should be at least from 14 to 16 for females, and 12 to 15 for males.

Whether this can be attained by American methorls under the environment and climatic conditions peculiar to this country, remains to be seen.

If one can not, or does not care, to breed this variety for Fancy, it is of excellent utility use. The mother being large, naturally has more nourishment for her young than a smaller variety; so that by a bit of attention to feeding, her offspring can be made to weigh near 4 pounds at six weeks, and at ? months will reach 6 pounds. One fancier informed me that he has grown them 8 pounds, and some 9 at three and one-half months old. In event, the Flemish should prove decidedly profitable as a urtet proposition. 


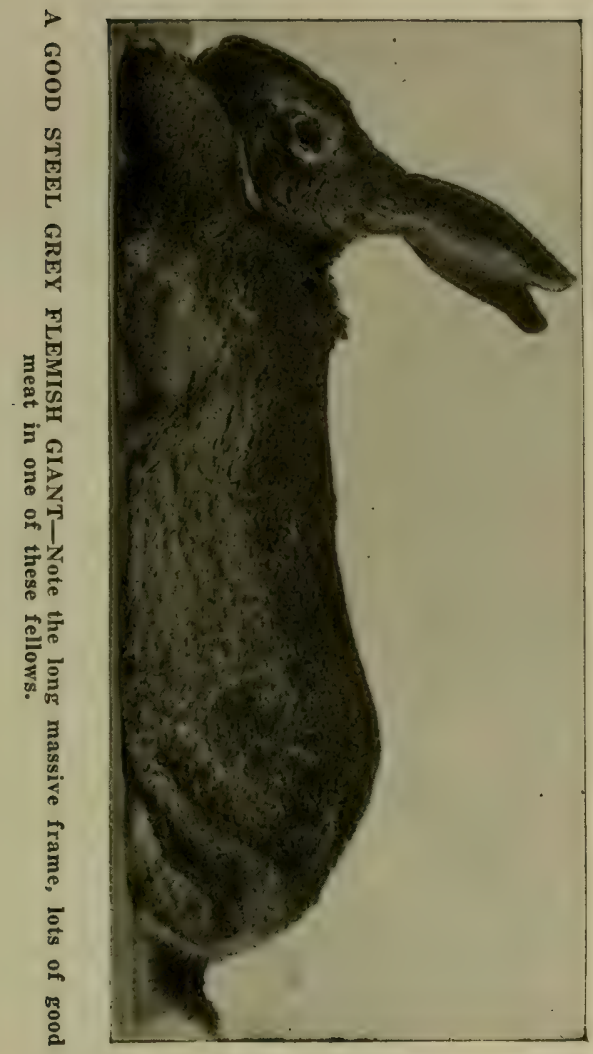





\section{Mating}

In all my remarks with reference to the different varieties, I shall speak of them in the light of being thoroughbred stock. I am not in favor of mongrelism for any purpose, and all the less so in any living thing that is utilized for either food or Fancy use. The methods suggested are therefore done so with a view to qualify for Standard requirements, and the breeder can so apply them whether rearing stock for show or market purpose.

When getting ready to mate, look over the stock with care and see that all intended specimens are sound and of good coat. Consider size and evenness of color with particular criticism.

For utility, no particular rule for mating is essential other, perhaps, than size and health, and it has been experienced that nice, dark bucks mated to "smoky" does will produce the largest stock as to frame and weight. For show purposes, however, matters are considerably different.

Each specimen must be made an individual study with a view to fight against every fault that should not appear in an exhibition entry. One must pair up for length of frame and massiveness, and to this end select specimens as near Standard in points of merit as one has been. Any defect in one of a pair always appears liable to show itself with more emphasis than a desirable point so that it is all the more important to select breeders of perfect body, good ears well set on, nice large eyes, straight and strong limbs, perfect set tail, massive and firm body as near of the steel grey color as possible. Mate dark steel greys, if one has them; but if there is ruddiness in one of the mates, it must not be on the male side. A black or intensely dark steel buck mated to a ruddy doe, usually gives good results; for in breeding Flemish it appears necessary to frequently fall back on black to maintain the essential dark tinge for true steel color effect.

A black buck mated to a light steel grey. doe will reproduce dark steel greys, and a dark steel grey buck mated to a black doe will result in a shade that seldom fails to attract a knowing judge.

\section{Littering}

The period of gestation is 31 days, and if it varies more than a day longer, or two at most, there is something wrong. The doe will begin building her nest, and pull fur to line it with, any time from 10 days to an hour or so before due to kindle, so that it is necessary for her to have material for the purpose such as short hay or straw scattered about the hutch.

Have the nest box so situated, if possible, that one can look into it without moving out of place, and sufficiently roomy for 
the doe to have free movements within so as to obviate danger of trampling the young. And I will say here, that Flemish require larger quarters in general than any other variety, because of their size. Plenty of room means better success with them.

A few days before the doe is due to kindle have before her continually a dish of clean, fresh yater. Many does become feverish at this time, and will not infrequently destroy their young if the desire for water cannot be satisfied beforehand. This would be unfortunate, and occasionally it genders the desire for blood to the extent of making cannibals out of them with every subsequent litter.

After the doe has kindled look over the nest and see if any dead are among them. If so, remove these with as little disturbance as possible, at the same time diverting the mother doe's attention away from the nest with some tempting greens or other delicacy.

The matter of permitting a doe to bring up an entire brood is for the breeder to decide, but best results will eventuate by leaving no more than six at most. Above this number calls for extra attention with food and care.

I know not a few who have succeeded in bringing up litters of 9,10 and 11 , one instance of which turned out every one a prize winner. But as a matter of Fancy, few fanciers permit a doe to rear more than four, fostering the remainder with a doe bred at the same time, or destroying the smaller ones out of a batch.

With Flemish, or other of the giant varieties, it is desirable to attain as rapid and as much growth from the first day on as one can, and the more youg there are in a nest, the more each will hinder the other's development. It is only a matter of several days, also, until there is a tyrant in the lot who preempts more than his individual share.

Flemish in the nest can from the first day be quite well selected for quality as to prospective standard points, like this-steel greys are known by their pink bellies and dark backs, while the blacks are virtually one shade on back and belly alike. What will turn out as light greys will have decided pink bellies, the tinge of which spreads well up the sides.

During the time a doe is suckling her young, an excellent dish to help growth is a sop of bread and sweet milk in connection with the evening mess. This is also an ideal "conditioner" for the young after leaving the nest up to six weeks old.

With regard to feeding generally, each fancier seems to have a method he personally thinks best. Some do quite well, while 
others have less success; but I am safe in saying that more rabbits are lost from injudicious and too frequent overfeeding, than from insufficient and less frequent.

All varieties are fed along similar lines. But just bear in mind continually that the giant varieties require approximately more food.

Standard for Steel Grey Flemish Giants-Size and Weight Bucks 12 pounds or more. Does 14 pounds or more.

Points

Size considered, irrespective of weight $\ldots \ldots \ldots \ldots \ldots \ldots$ Color-Dark steel grey, even or wavy ticking over entire body; head, ears, chest and feet alike. Belly, and under part of tail as near white as possible ............. 20 Body-Large, roomy and flat, with broad fore and hind

quarters. Does to have dewlap, evenly carried ...... 15 Legs and Feet-Strong in bone, large and straight, color of them to match that of body $\ldots \ldots \ldots \ldots \ldots \ldots \ldots \ldots$ Head and Ears-Head large, full and shapely, with large bold eye of dark brown color. Ears moderately thick, carried neatly erect. Head and ears to match body color ..... 10 Condition-full, short coat, flesh firm, healthy ........ 10

\section{Cuts and Disqualifications}

Any grey, steel, sandy, or other shade on the belly or under tail, except a streak of grey in each groin, sandy, brown, or red color mixed through the body fur should be penalized according to quality of competing specimens. Inferior size, crooked legs, barred feet, screw tails, lopped ears, camel backs, and small narrow heads, or heads entirely too "bull-shaped," are disqualifications.

I will also add, that there is no small tendency for Flemish to throw a ruddy brown color shade; and while stock of this tinge usually has the making of large specimens that will do well for utility use, as show exhibits they are absolutely worthless in the eyes of an expert judge.

To breed true and harmonious steel grey, is no easy matter, and the correct Standard shade; or rather, permanent color is rarely apparent in its perfect tone until completing the second molk.

NOTE-The Standard calls for belly "as near white as possible" thereby following along lines laid down by English fanciers, who demand "pure white." However, it is impossible to 
get a white belly, or even nearly white, without more or less sandy color cropping out on neck and legs, hence the American breeder, in order to get the beautiful even body color, generally favors the German Standard which demands an even color throughout. The best American judges favor an even lark steel grey body color, harmoniously blending into a somewhat lighter shade on the belly.

\section{Grey Flemish Giants}

The Grey Flemish Giant is a strain of the Flemish bred more particularly for great size that is not attainable in the Steel Grey variety. The Steel Grey has been bred with certain color requirements in view, and to this end size has been sacrificed to some extent by infusing blood of some of the smaller varieties, such as the Silver Greys, Himalayans, etc. In the Greys, considerable latitude in color is permitted by the Standard, any shade of grey not conflicting with the Steel Greys, (steel grey is a disqualification in this variety), either light grey, sandy or reddish grey, but should be as nearly uniform as possible. Size to be as great as possible, not less than 13 pounds for the bucks and 15 for does-five points cut for each pound underweight. Bodies to be long and massive, broad quarters, strong and powerful legs and feet. Does to have dewlap evenly carried. Standard points as follows:

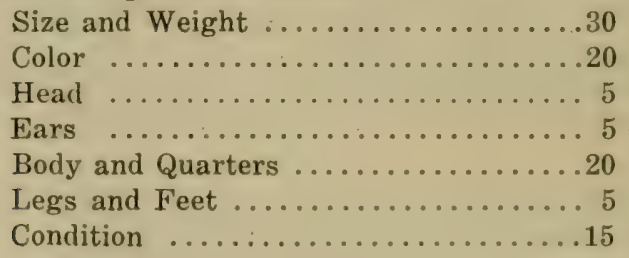

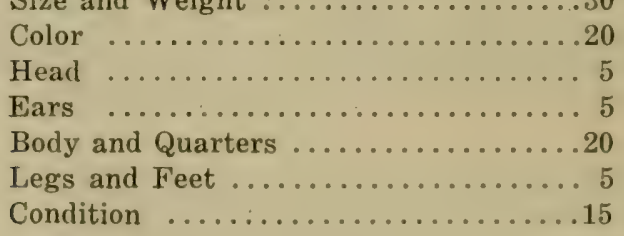




\section{Solid Colored Giants}

The color should be solid throughout, free from any foreign color. Weight and size same as the Steel Grey Flemish. The White Giants should have pink eyes; others, eyes to match body color. Does to have dewlap evenly carried. Standard of points as follows:

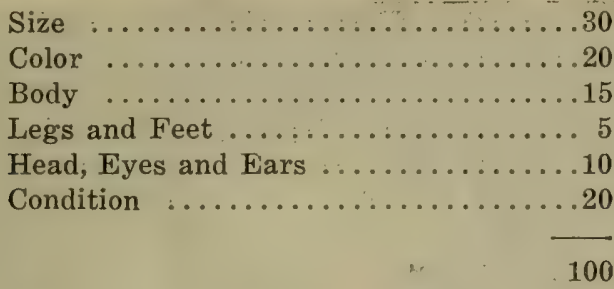

\section{American Spotted Giants}

\section{(Formerly Called the German Checkered Giant)}

This beautiful rabbit was introduced into this country a few years ago from Germany. Its great utility value, being equal to any of the Giant varieties in that respect, and its beautiful markings, are rapidly making for it a place in the front ranks of both fancy and utility breeding. In size and weight it ranks with the Steel Grey Flemish, but possibly somewhat lighter boned. The color of the perfect specimen is identical with that of the English rabbit, except that it does not have the "chain markings" and the patches on the sides of body should be large and but few in number as compared to the English. There should, however, be not less than two of these patches. The "butterfly," eye circles, cheek spots, teat marks, ear and saddle markings, all similar to corresponding English markings, may be of any solid color, but must be uniorm. The body color is pure white. Disqualifications, any two colors in the markings, absence of important markings, side patches and saddle markings in solid patch. Does to have dewlap evenly carried as in all other Giant varieties.

Standard of Points

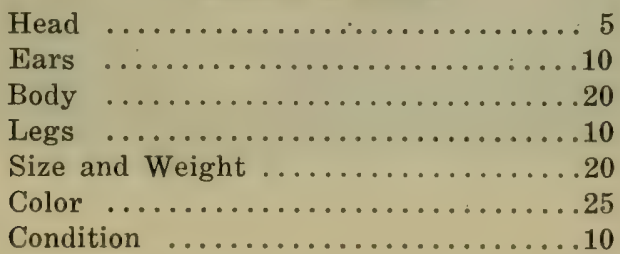




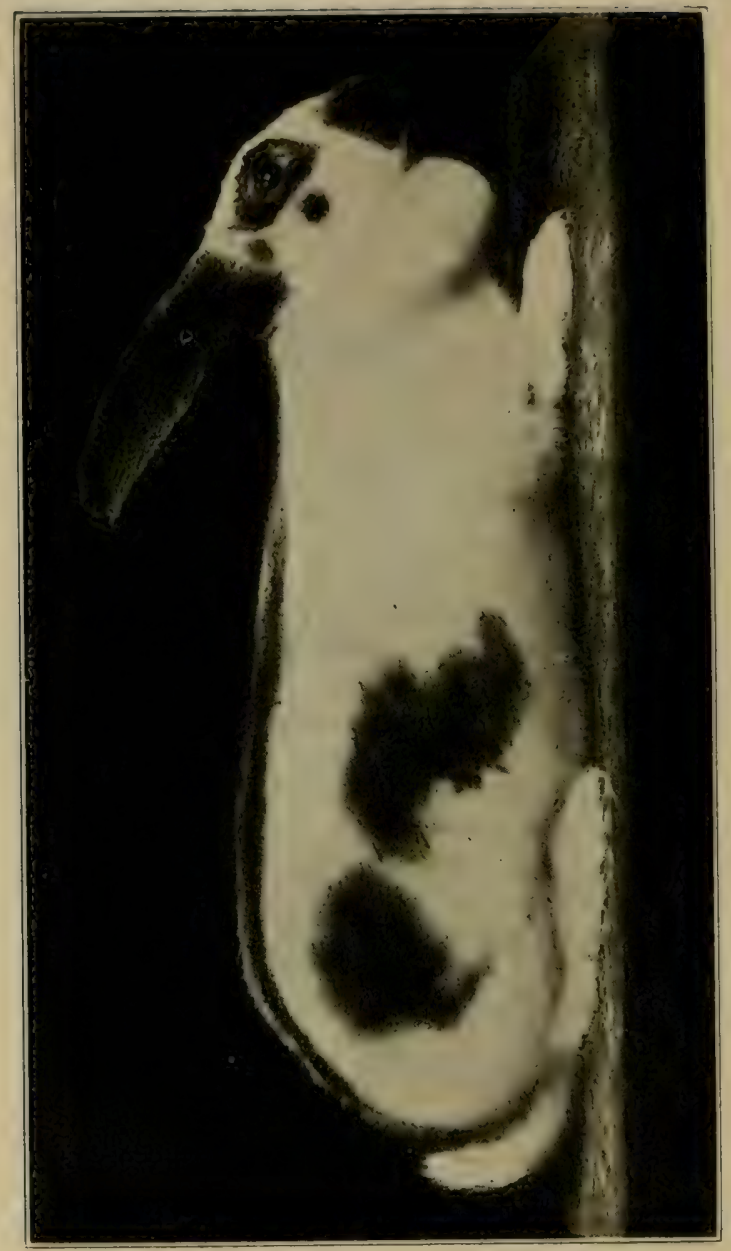

$\stackrel{\vartheta}{E}$

ב⿱艹

2응

둘

웅

$\pm$

:

랑

2

कू

군

ซั

i

를



응

둔

है

둥

$\therefore$

옹

के

हू. 


\section{The Belgian Giants}

The Belgian Giant is the result of crossing the Belgian Hare and the Flemish Giant for a meat type. In color characteristics it should measure up closely to that of its more aristocratic brother, the Belgian Hare, but in shape and size should be large and imposing, with legs rather heavy boned, similar to other varieties of the Giant varieties. Does to have dewlap evenly carried.

\section{The Standard}

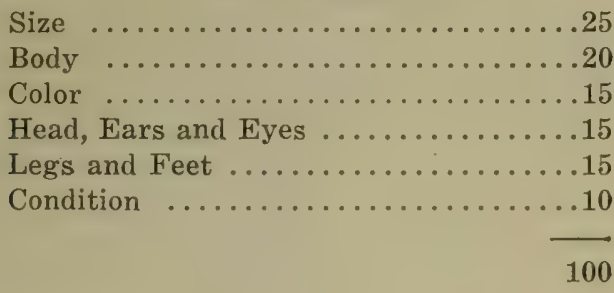

\section{New Zealand Reds}

The New Zealand Red is one of the latest additions to the list of "American made" rabbits and has become one of the most popular. It made its first appearance about 1906, and was claimed by its promoters to be an introduction and importation from New Zealand. Investigation has shown that no such rabbit is indigenous to New Zealand, but that a rabbit of somewhat similar appearance to the first so-called New Zealand Reds that appeared in this country, now inhabit the southern part of New Zealand, having been originally imported to that country from Scotland, and was there known as the Scotch rabbit. Be that as it may, the animal, as it now exists, is, without question, an American made product, bearing but little resemblance to its reputed ancestors.

Because the animal is so evidently a product of the ingenuity and skill of American fanciers, rather than that of some alleged importation of foreign stock of doubtful character, and, believing American breeders should be honored by conferring upon it a good old American name, instead of a foreign one, an attempt was made in 1916 to change the name to American Reds. This move was, however, defeated because of the tremendous popularity the variety had already attained under its original name. The rapidly growing popularity of this variety caused much spirited discussion, and some misunderstandings and bit- 
teriess, but at last all factions got together and are now united in presenting their claims for a variety that is certainly second to none in the rapidity with which it has improved in color and type, as well as gained in popularity.

like the American classes in poultrydom, the New Zealand may be styled as the "happy medium" between the light-weights and the heavy-weights. While not so large as the Giant varieties, it matures more quickly, reaches a "frying size" on less feed than the Giants, and is more meaty than its smaller, though perhaps more aristocratic cousin, the Belgian Hare.

There seems to be a tendency among some breeders to breed for extremely heavy weight-to make Giants of them. This is a serious mistake, and I am inclined to think that judges should penalize overweight just as severely as underweight. The New Zealand is in a class by itself, and to my mind, it would be folly and ruinous to the variety to try to compete with the Giants in size. The New Zealand occupies much the same position on the commercial rabbit plants as the White Leghorn does on the commercial egg farms-that is, at the head of the list. Don't destroy that position by destroying its individual characteristics.

In length of body and breadth of quarters, the New Zealand should be, as the Standard has it, "medium," and with legs "medium heavy bonerl." A good specimen will give the idea of strength and meatiness, but more agile and without the clumsy massiveness of the Giants.

In color, they should be a "reddish buff, carried well down to the skin and evenly over the sides and hindquarters, free from black hairs, not dark or smudgy, or light buff. Belly, reddish cream." Legs and feet same as body, free from white. Ears same as body and without black lacing. Eyes hazel in color. Does to have dewlap evenly carried.

Standard weights: Bucks, 9 pounds; does, 10 pounds.

\section{Standard of Points}

Head ..................... 5

Ears ...........................

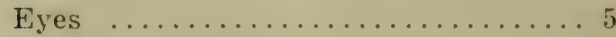

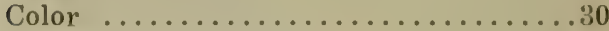

Shape .......................

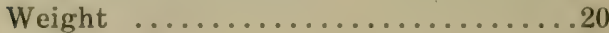

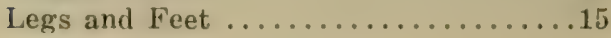

Condition .................... 5 



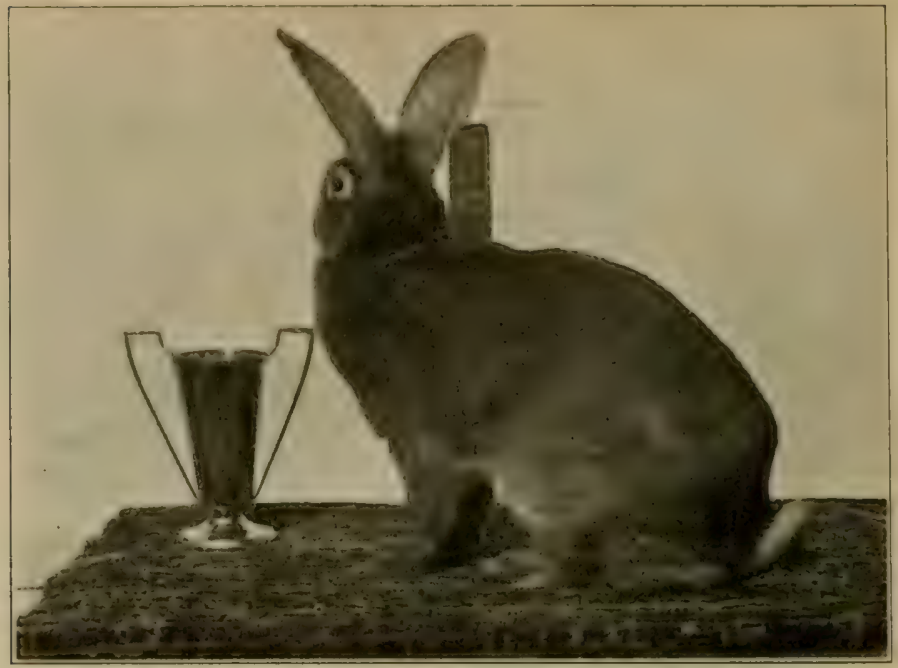

ANOTHER PRIZE-WINNING NEW ZEALAND

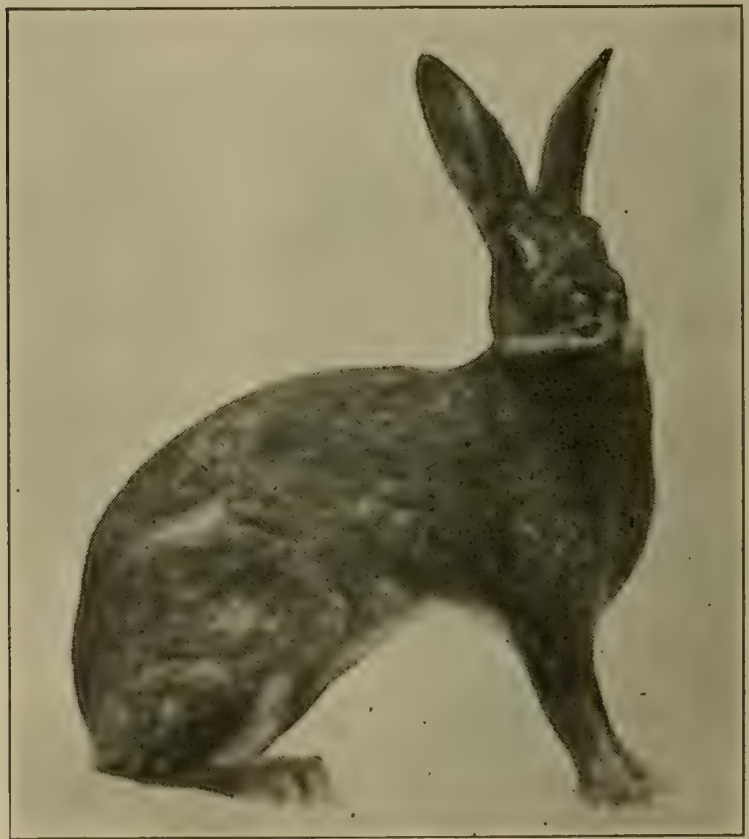

A (iOOD BELGIAN HARE DOE-Full of life and vigor. Note the alert "racy" appearance typical of this variety. 


\title{
The Belgian Hare
}

\author{
By Dr. W. F. Roth
}

\section{Introductory}

As alluded in a former chapter what I shall remark concerning methods of rearing, and the "keeping" of Belgians in general, can be applied to all varieties heretofore mentioned.

There is no essential difference in housing, cleanliness, feeding, and practical attention other than the salient points specified with each variety. The general principles for mating, breeding, the matter of pedigree records, and bringing up along intelligent lines, apply virtually alike in all.

Of all the varieties of domestic rabbits, the Belgian Hare has maintained highest popularity. This is due largely to its many excellent qualities in all respects, and correctly bred, offers to both fancier and utility breeder the widest scope for satisfaction and usefulness. And bred, also, in harmony with Standard characteristics, there is about it a grace and beauty in both shape and color that is not found in any other variety.

\section{Origin}

There is no positive information available as to correct origin of the Belgian Hare. Its name would have one naturally infer that it originated in Belgium, but I am not aware that it was by Belgian breeders ever designated by the subjoined term Hare, unless in later years.

An English writer says: "The Belgian Hare is so called from its resemblance to our English hare, and from its Belgian origin. It has, however, no blood relationship or affinity to lepus timidus (common hare), but is to all intents and purposes, a rabbit." Technically, then, the Belgian is named Hare by courtesy, and is a rabbit in fact, the English wild hare being the pattern that has stood for fanciers of that country as an ideal toward which they have directed their breeding since its introduction from Belgium. With all this idealism, however, the Belgian will never be an exact likeness of its prototype, for without the admixture of blood from the latter there can be no more than a similarity.

Belgian breeders claim, that what is now the upbred Belgian Hare was originated by them from a cross of the wild hare indigenous to that country, and their common rabbit. This asser- 
tion, though, has never been proven within my knowledge, and I doult if it is true. If they have succeeded in mixing the blood of two distinct species of animals, it was going without the bounds of zoological probabilities, and what many have subsequently attempted only with failure. There are, indeed, some features about our present Belgian that lend possibility to the claim, but when one appreciates the continual contention against development of the persistent rabbitry dewlap, there is less room for belief.

Naturalists describe the wild hare of Belgium, by a "fur of dark reddish color, with white belly and weighs from six to nine pounds."

In its original type the Belgian Hare, so named, was introduced into England sometime about 1856 to 1860 . It came with the name Leporine. No immediate progress was made by English fanciers, and it was not until some fifteen years later that attention was directed toward a specific type. In the last twenty years, however, much advancement was accomplished, largely accentuated by the interest aroused throughout this country.

To better appreciate the idealism toward which Belgian fanciers breed with the wild hare as prototype, it will not be inapropos to remark a bit of natural history concerning it here:-

Virtually every country has a wild hare that is indigenous to it, and in no two countries are the species identical. That is, there is no difference in specie habits, but it is either larger or smaller, with such modification of color markings as its environment seems to demand.

America has several species, the most common of which is the "Northern Varying Hare," so named on account of accommodating its color markings, as it were, to the locality it inhabits, in the northern countries changing entirely to white during the winter months. In summer it is brown, varied with black tipped hairs, the prevailing color in the more southern countries.

Then we have the "Prairie Hare" (lepus campestris,) discovered by Lewis, and is never found east of Kansas. This species is most abundant about Salt Lake and in Utah generally. The fur is white in winter with here and there brownish spots, while in summer it is a yellowish grey.

The "Wood Hare" (lepus sylvaticus) is a small variety, and frequently confounded with the common rabbit. It ranges from Hudson's Bay to Florida, and in physical characteristics has much in common with the wild rabbit of England.

"Trowbridge's Hare" (lepus trowbridgii) is the smallest of all American species, and is found only on the Pacific coast. 
The species which is indigenous to England and Scotland, is perhaps the most beautiful and characteristic of all, the world over; and as previously mentioned, it is this that has been made the prototype for attainment with the domestic variety.

In natural history, the hare is described in the following language: "The common hare is known from the rabbit by the redder hue of its fur, the great proportionate length of its blacktipped ears, which are nearly an inch longer than the head; by its very long hind legs, and its large prominent eyes. When full grown it weighs on the average about 8 or 9 pounds, and sometimes even 12 or 13. In total length it rather exceeds two feet, the tail being about three inches long. The color is greyishbrown on the upper portions of the body, mixed with a dash of yellow; the abdomen is white, and the neck and breast yellowishwhite. The tail is black on the upper surface and white underneath." This quotation is rather broad, and no doubt meant to be general for the hare species, while that native to England (the prototype of the Belgian Hare) is somewhat more pronounced, the animal being rather longer and consequently more racy. The English wild hare is typically "built" with long, thin fore legs, rather full chest nicely tapered into an upward trend of the belly that ends in a racy tuck-up at the flank, and the latter fortified by a pair of strong-shanked thighs of powerful propeling muscular action in the well-formed reachy hind legs. Color that of the fox in full "bloom," a rich tinge of old gold, and the back from shoulder to tail tipped with beautiful ticking, "like a wavy field of grass in summer." Ears erect, and "foxy" in attention and color, with pronounced black points. Head rather broad across the skull, short, strong, and a bit thick, with a "pop eye" that stands out bold and alert, quick and nervous as if taking in all surroundings at once.

The wild hare will invariably bring forth its young in a nest (called a form) built on top of the ground, while the rabbit will "make a hole" (called a burrow) in the ground, line it with fur pulled from the mother's borly, and have a litter of 4 to a dozen. The mother hare will rarely have more than four and more frequently but two or three.

Another differing feature of the hare from the rabbit it is claimed, is that the former brings forth its young with the body covered with fine hair, and the eyes open, while the latter are born immature, uncovered by fur, and the eyes closed for ten days. I can not verify this assertion concerning the hare leverets out of personal observation; but from the fact that the hare and rabbit is both of the genus rodentiae, which are all night 
foragers and born with eyes closed, I am at a loss to reconcile this particular characteristic.

Distinctly, all Belgian Hares of consequence bred in this country are of foreign origin, and with but few exceptions, direct descendants of stock imported from England. What specimens came to America from Belgium and Germany are as different from the English type as a Percheron is from the Kentucky racehorse, and there is little about these that appeals to the classic fancier. One sees occasional alvertisements of "Grey," "White," and "Black" Belgians. There are none such, and the name is more a whimsical misnomer for an uncertain cross-bred rabbit or the result of self-colored sports.

\section{Physical Characteristics}

When the expert horseman wishes to purchase a speedy driving animal, he first inquires where, and from what stock it is bred. It must, first of all, have an ancestry of recognized and demonstrated quality. This implies health, speed, and durability. Then he looks the horse over from every point of view-front, sides, behind, close and afar. He does this with the animal in pose and when in action, and notes every contour of head, body, and limbs. He wants a driving "machine" that has all its physical parts harmoniously and scientifically arljusted for easy action that makes time with the least effort. Shape of head, expression conveyed by set of ears and attention in eyes, carriage of tail, shape of body with taper toward flank, strong shank action beneath a well-formed back-all these characteristics make for qualities desired. And so with the thoroughbred Belgian Hare.

In speaking of its physical characteristics we have in mind all that one sees in outline, contour, shape, size, length of limbs, ears, eyes, expression and color markings. It is a picture of type that aims for an ideal, and as before mentioned, since this ideal is largely made up in the physical characteristics of the wild hare, it is necessary in breeding the clomestic to constantly keep this before us.

No one man in the Fancy the world over has done more toward bringing the Belgian Hare to its present physical status than Mr. John Noble of England. His high abilities as a scientific breeder, fine perception of physical points, and all requirements that make for success, are only accentuated by the rare qualities of the man as shown by his gentlemanly courtesy toward every one, that I am willing to concede him all the honor so meritoriously but modestly earned. Mr. Noble has "made" the Belgian what it is more than any one else, and this is what he says about the making: 
"I have made a special effort to develop the shape of the Belgian Hare ever since I decided to make this variety my specialty, and have succeeded in breeding some of the best ever bred. Most fanciers know that we wish to breed to represent the wild hare in general style. You will therefore select your specimen with fore legs as straight and long as possible and the hind feet long and fine also; ears about five inches long, and carried similar to the wild hare; head (rather) long. The neck must fall low from the ears, with a graceful curve along the back, and a gradual rise to the hind quarters, which should be well rounded-not chopped off abruptly.

"This specimen of which I have drawn the outlines is to a very large extent idealistic. A successful breeder is an idealist. You will always have pictured in your mind's eye what you wish to see realized. You will not be satisfied with your realization for as your practical efforts advance, your ideal keeps advancing. Consequently you are always living in a state of hope."

Another breeder of note, Mr. Wilkins, has the following to say of the physical characteristics that to his mind constitute a typical Belgian:

"The body of a Belgian should be long and fine in build; the forepart should not be heavy, but fine and graceful; the back nicely arched and rounded from shoulder to tail; the haunches round, not choppy; fore legs should be long, fine, and well set on; that is to say, they should be so placed as to lift the fore part of the body well from the ground and let plenty of daylight under it. The head of a Belgian should be long and lean, with prominent eyes full luster. The ears should be well set on the head, carried erect when in motion, and laid on the shoulder when in repose. They should not be too short, as shortness of ear causes a rabbity appearance. The correct length is five inches. The neck should be fairly long and slim in proportion to the body. The bones of the hind legs should be long and lean, not thick and chumpy. Tail should be straight and in no ways curled. The whole properties of the make-up of a Belgian should combine to present to the eye, as the wild hare does, a look of gracefulness and activity. A thick, choppy, angular Belgian is an abomination."

This latter picture is even more idealistic than the one drawn by Mr. Noble, and is decidedly more away from the real wild hare type, notably its head and neck. However, the possibilities of these pictures are exceedingly fascinating, and to attain them, a real art.

It will be noted that in the above descriptions no mention is made of color characteristic-a feature that to many fanciers. 
appears of almost greater significance, apparently, than that of shape; so that one might be led to think from this silence that color markings are of inferior importance. As previously remarked, color should have its share of considerate attention, but never made to supersede shape. Nature is fickle with color identity, as shown in the ever-changing variableness of the wild hare according to season and environment.

The wild hare is the race-horse of the native rabbit family, and the Belgian that of the domestic bred. This point should be constantly in the fancier's mind when breeding for quality; so that by all science available in the breeding art he keep away from bulkiness, bigness, and general rabbity outlines, just as the breeder of speed-horses keeps away from the common farm product.

But this is not to convey the inference that raciness of shape means necessarily a small animal. Standard weight is eight pounds, and this is not by any means difficult when one gets length rather than compactness. Leave the big, compact stock to the utility breeder, for this sort should never be specified as fancy, but made a distinct class by itself after the German and Belgian type. It is the trade in stock of this latter "make" that has done breeding for classic Belgians great harm, and it would not be injudicious to create two classes with a view of opening a channel for show recognition to breeders whose ideas for size outweigh those of raciness. This would place the utility rabbit on a basis of equal breeding for its particular qualities with that of the classic type. Possibly, too, the advisability of distinguishing names for clear differentiations of the two types would not be amiss. I shall add here, that associated with an understanding of physical characteristics there is frequently a misinterpretation of type for shape, so will insert what Mr. Ziegler, a leading American fancier and judge, entertains as a proper definition of the former:-

"Type is the aggregate of characteristic qualities. A Belgian Hare true in shape might be a very poor type, and again a specimen perfect in color may be a poor type. It takes good color and good shape to be a good type. A specimen that scores high according to Standard requirements is a good type, and one that would score 100 in shape, size, color and quality would be perfect type (est inventus). Quite often the word "type" is used when only shape is meant. The shape of the Belgian adds to the makeup of Belgian type, but by no means will shape alone determine its type."

I will leave the interpretation of this quotation to each reader individually, and with it the inference that a show speci- 
men of any species of exhibit judged by the score-card system, is subject to the judge's individual interpretations of score-card points; and that it is as rare as snow on Fourth of July for two judges unknown of each other to aggregate an identical average for the same specimen-a fact that demonstrates something "out of joint" with either the judge or the Standard, most likely the latter. So long as the English and American Standard remain as at present, comparison judging will be nearest correct and satisfactory. With regard to type, I am personally not inclined that color takes a leading part, and has little more to do than a mark of identification possibly; nor does it appear to me logical that "a Belgian Hare true in shape might be a very poor type."

\section{Dewlap}

By visitor and novice the question has often been put to me: "What is that lump under the chin?" "Why is it there," and by the fancier and breeder, "How are we to get rid of it, since the Standard qualifies 'no dewlap?" "

The dewlap exists by reason of the Belgian's rabbit origin, and to get rid of it has been an effort of all good breeders from the first; and while its riddance is not yet a complete success, I am glad to note that we are gradually "getting there" more and more.

Technically, the presence of a limited dewlap does not disqualify in the show room under a competent judge, but specimens with pronounced accumulation of a "lump" should be condemned both as breeders and exhibits, since it appears that the tendency to reproduce this objectionable point is quite prone; and all the more so when the least evidence of it is apparent in males. For purposes of Fancy, therefore, no buck should be used as a stock-getter that has not a clean, well outlined neck, and whose progenitors have been likewise so.

Anatomically, the dewlap is neither fat nor gland, but rather a combination of both, with an added affinity to enlarge in harmony with the functions of reproduction. It is virtually an extension of the milk glands in modified form, and is greatly accentuated by frequent gestation. To out-breed it means attention to the selection of proper stock, and to judicious mating with regard to frequency and age. What has been accomplished thus far is largely the result of junior matings, or matings with one side under age maturity, preferably the doe. In other words, there must be a doe, at least, a physiological condition of subnormal development in the reproductive sphere, with consequent stock of finer physical proportions.

That objection to the dewlap should exist, at least to a limited degree, as a factor entering into classic breeding of Belgians, 
does not necessarily follow; but since we aim to reproduce them as near true hare type as possible, its elimination becomes all the more necessary, for the more of it we have the less hare quality wo possess.

Personally, I have never seen a matron doe without any evidence of it at all, however slight, and $I$ have seen many as well as bred of some of the best specimens yet prorluced; but if one can breed up to a standard of no evidence in junior does, and not much in matrons, we can be well satisfied when all other characteristics come within high quality. Success, if at all attainable, lies in a carefully sustained strain.

\section{Color}

Associated with breeding the Belgian, there has continually been more or less diversity of opinion as to what constitutes a correct color for it. In fact, fanciers have taken sides over the issue, and in many instances came near the point of acrimony about it. "The flame is not worth the candle" compared with the value of physical characteristics, wherein lies the true hare picture.

Some advocate the deeper tinted shade styled by them "mahogany red," while others stand by the now popularized tinge specified as "golden tan." As will be seen, there is scarcely a decided opinion on any shade.

Standard requirement calls for "rufous red." Why this indecisive term was made descriptive for color I am unable to say; and it is quite certain that the popular color now in vogue is, technically, not rufous. That the term is confusing is made apparent from various expressions vouch-safed by those trying to define it with specific wording, as "golden tan," "golden chestnut," "chestnut tan," "mahogany red," "chestnut brown," "brownish red," etc. One customer wrote me he desired a doe with "dark red" color and another wanted one "cinnamon brown."

The term rufous is derived from the latin root rubro, meaning red. Dictionaries define it as "a dull red tinged with brown." Tan nowhere enters into any definition of it; though to define the latter perhaps aids in understanding its association with the former.

Tan is defined as "yellowish brown," or "to make brown by exposure to the rays of the sun." This would seem to imply what is to be conveyed by "golden tan."

\section{Breeding for Color}

Bear in mind from the outset, that to obtain color, even approaching correctness, is the most difficult feature associated with breeding high class Hares. One can breed a thousand speci- 


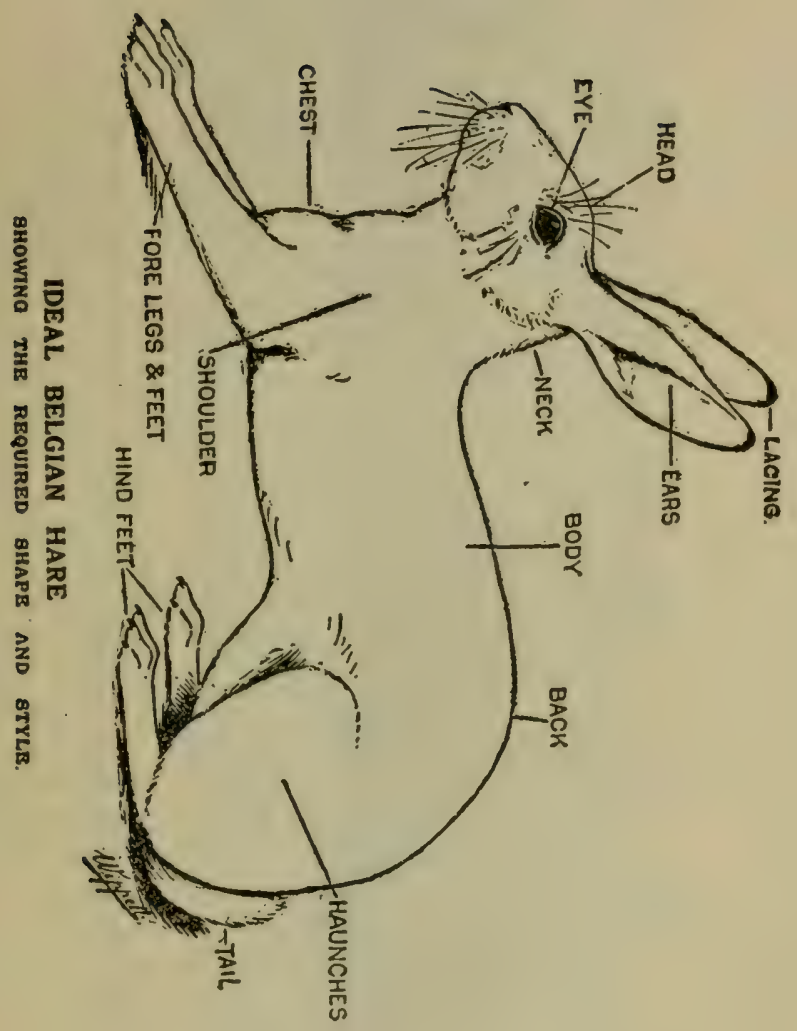



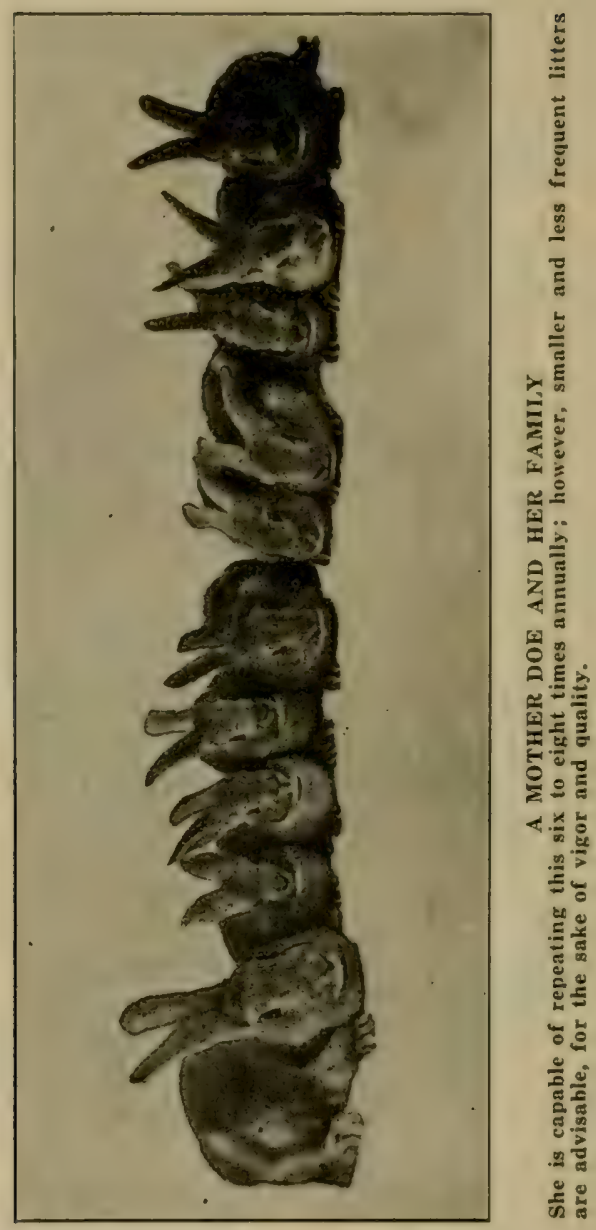
mens, many among them of excellent shape and good looks in general, yet not one in the lot that comes up to finished color points. Breeding for color is the ignis fatus ever present with rearing Standard Belgians-"now you have it and now you don't"-but there certainly is a large pleasure in "trying to catch the thing."

The first factor toward securing substantial color-and it is the substantial kind one wants-lies in the selection of breeding stock that is known to throw reliable depth of true tan. With this trait thoroughly established in a well built strain, many disappointments are already conquered. It will cost a bit more to start out with breeding stock of reliable reputation, but to secure specimens whose blood carry the science of years spent in its production, will place one a long ways on the road that has been hard traveling for the breeder before, and obviate many risks, disappointments, and other troubles that come with inferior stock. I can fortify this assertion with the assurance that in the past eight years not a single specimen marked white on feet or shanks has shown itself among my flock, nor a one without palpable shade of tan on the belly fur.

As remarked in a former paragraph, the popular color tinge at present most prized by many good fanciers, and toward which the Fancy in general has been working since the past ten years, is "golden tan," so named. A good specimen is quite handsome, and to breed for this tinge considerable of a fascination; but I question the lasting qualities on account of its proneness to turn lighter with each successive generation. Unless one maintains constant infusion of blood from darker tans there will eventually be too much white.

A Fancy, I dare say, has somerhat the elements of society -an institution of changing moods - so that the color for Belgians today is by conservative fanciers classed more as a fashion than a point of lasting quality.

Whatever point one breeds for, keep constantly in mind that the power of transmitting it lies strongest in the procreative energy of a properly selected male. This is as true of color as of all other physical characteristics. The female is more a medium through which a species is propagated than by it. Now and again one comes across what I shall term a masculine female, or a feminine male, if such are paired together, the stronger characteristic points will have their imprint from the former; but such matings are undesirable.

To breed for color, therefore, seek the tinge that is desired in a carefully chosen buck. Study and settle in mind just what that tinge shall be, then select a male a least bit darker and 
deeper; for it is better to breed with room for "back-breeding," than to select too light a tinge from the outset. If one decides on "golden tan," mate such a buck with a doe of the "chestnut tan" shade, and in both give particular attention to depth of undercolor. It is this latter that makes for permanency for the future. "If 'chestnut tan' is to be the tinge, have the doe a trifle lighter than the buck."

Once one has carefully built up a hardy, reliable strain from vigorous progenitors, the task to bring just what is desired will not be so difficult. But permit me to assure my reader that haphazard matings with haphazard selected stock spells failure in all the salient points that make for interest in scientific breeding. It matters little whether these points imply color or physical characteristies, if one desires to build, the foundation must be philosophically right. There can be no true interest or enthusiasm possible out of a makeshift source, and if these principles are not included in the makeup of prospective fanciers, they had better breed for market from the start.

Personally, I admire "golden tan" color on a Belgian; but for permanent quality and persistent reliability, "chestnut tan" appeals to me as most desirable, and when seen in a specimen of rich bloom, there is something about it that speaks for dignity, quality and substance of breeding far surpassing the "flashy red" which needs continual nursing.

Speaking of "golden tan" in his book Ambrose says, "one must remember that such is the most difficult color to produce and maintain, and that it can not be bred successfully without a judicious mixture of the deeper colored ones." Then a few lines farther on the same author says of the latter, "some, I know, pin their faith yet on the old chocolate shade, but these, when compared to a correct golden tan, appear absolutely shabby in the eyes of those who admire beauty for beauty's sake alone."

The inconsistency in these quoted lines lies in the fact that "deeper colored ones" are an absolute necessity to the existence of "golden tans," and to breed the Belgian as a color object of "beauty for beauty's sake, alone," is superseding the physical characteristics that make it a distinct species with a fashionable facl. Wilkins, in his excellent description of what he considers ideal Hare characteristics, does not there associate color as one of them, yet in another part of his book says that "color in the Belgians is of first importance-it is the cardinal point." He too, like Ambrose, is a worshiper at the shrine of fashion. Indeed, the craze for "yellow" has become such a fad, that to placate a warning for the future welfare of Belgians is necessary. It has come to a pass that what is a prize winning specimen in the four 
to eight months classes, and lauded as a wonder, will receive scant recognition ten months hence.

When observing a Belgian Hare from a show point view one notes the colors to constitute black, white, and red, the latter being the prevailing body effect. Absolute white should be confined to the under surface of the tail alone, while that of the belly and under jaw should be tinged with rufous sufficient to give an appearance of rich yellow cream, verging into tan if possible. Such a specimen is evidence of reliable color breeding.

Heretofore, there has been no small contention with points of white in the form of bars across the front feet, and streaks along inside of hind legs, often spreading over the top and down outside. There is no longer much trouble in this respect, owing to better fortified blood lines in well established strains. The fault was largely an outcome from admixture of "any old rabbit" by unscrupulous dealers in this country and England during the boom some fifteen years since.

What black is apparent must be distributed from shoulders along the back, gradually widening down the sides and along the haunches, ending on a line across the root of the tail. This evidence of black is known by the term

\section{Ticking}

and consists, according to one authority of "long black hairs protruding through and among the golden tan ground color, and should be crumpled and wavy, and of a jet black." Others signify that ticking is constituted of "red hair tipped with chocolate black." In harmony with the present tinge of desired "red," the latter is nearest correct.

At this writing I have likely as near the correct "golden tan" as is possible to breed, in one of the most delicate colored bucks to be seen. Richness of blood is superb in the light of present desired tinge. He is out of a popular imported champion, and shows all characteristics of the new "fashion." On seeing him hop about the yard, there is scarcely any indication of ticking. He appears "red all over," and fairly blazes with golden shimmer at twilight (the correct time to estimate true tinge); but when placed in sitting posture and the hand is gently stroked over the back, ticking comes out in almost solid wavelets over the surface, and down the shanks complete.

Close examination shows the long hairs delicately tipped black-a deep chestnut black rather than jet-not more than 3.32 of an inch from their points, with the remainder of their length same hue as their shorter partners in thick profusion about.

On the other hand, in an adjoining pen is a grandson of John Noble's great African Chief, the perfection of chestnut tan. 
This specimen has not a white hair on his borly except under side of tail; and while the above "golden" chap is an attraction to be admired, and would probably win over his partner, there is something substantial about this fellow that stands for unchangeableness in color of a character which one can not do without for keeping the golden ones permanent. In this way he is just as rich of bloom as the yellow one, and as a breeder far superior for reliability. Ticking is alike in both superficially observed, neither showing waviness until stroked by hand.

Personally, while I admire a heavily ticked specimen (providing "red" beneath is right), too much black does not appeal. And few such can be found that will breed desirable rufous as associate color.

What is meant by "wavy ticking" is the black-tipped hairs so placed in rather regular splotches as to resemble the effect of ripples on the water from a breeze.

There should be no black hairs on the breast and chest, fore legs and hind legs. A small evidence on the head is admissible.

Aside from the above references to distribution of white and black, the remainder of the animal should be "red," otherwise "golden tan" or "chestnut tan," according to the fancy of the breedei.

As a digression I will insert a bit of relaxation right here: While sitting at my desk writing the above anent color, I was called out in the yard on a small matter of interest to the children. This attended to, my topic came in mind, and I walked over to the hutches with the idea of seeing how my pets came up to Standard about color points I was trying to tell my readers in these lines. The day was more than warm (only 96 in the shade), and I found eight brood does on the floors all in like position flat on the belly, with fore and hind legs stretched out forward and back. They looked distressed of course, but the picture was a real pleasure; for here were eight, and seven of them as like one another in "color trimmings" as so many peas in a pod. Front feet and legs, breast, neck and ears, sides and hind feet and legs, so uniform in chestnut tan as to make one believe all came from one parent. And those babies with several of them? Well, they were some Belgians in prospective, and I was more than ever impressed with the certainty of what I had on previous occasions advocated, that to attain best results in all particulars, one must mate his Hares in the season when Nature intended they should.

Kindly bear in mind, too, that in using my stock as illustrative to these remarks, I am not doing so with any advertising motive. I breed out of pure pleasure and love for the little 
pets, and for best possible quality entirely as a recreative hobby; and to illustrate from it is mere convenience. I have few to sell at any time, very limited room to breed Hares, and such poor health as to absolutely qualify my efforts. But the pleasure derived from their keeping is by all odds the keenest enjoyment I got out of any recreation in the past 40 years. But to return:

Color points as influenced by age are often a perplexing feature to those not sufficiently long familiar with the breeding of Belgians. They often wonder why youngsters show so light in the first eight weeks - a fact apparent in all those bred from light tinged stock. This, however, will all change with normal conditions of growth, and if the strain is a reliable one as to evenness of tan, there need scarcely be any fear of white markings.

Gradually as age advances, color will also, until from six to eight months the permanent junior points are complete. In England, where shows are held the year round, growth with its accompanying color development is often attained at an age of four months by a process of forced feeding.

Permanent senior color, however, invariably follows the molt of second summer, and if the tan is of good strain foundation, intensity, with additional ticking results. To illustrate this point: A year since a young fancier friend sent a junior doe, then ten months old, to be mated to my imported buck. This doe was exceedingly fine in physical characteristics, but quite light "yellow," considerably grey on the haunches, with very little but rather even ticking. On first seeing her I wondered if my darkest tan buck could sufficiently modify the light tan as to produce even moderate intensity; but on seeing her pedigree I knew just what to do. I knew, also, that with the following molt she would greatly improve. This spring (1911) she came back for a second mating, and I was surprised at the improved tinge, added ticking, and almost total disappearance of grey-one of the handsome brood specimens it was ever my pleasure to see. The mating proved beautifully successful, and I am proud to own one of her sons as a permanent fixture to my rabbitry.

As already stated, procreative energy is strongest in the male. In the sire are supposed to lie hidden the qualities we wish to see brought out as physical characteristics in his offspring. These, in the Belgian, include color as well as contour of body points, so that whatever permanency to them is to be established must be sought for preferably in the sire line. At the same time I would not have you lose sight of what possibilities can obtain through the female as a medium for transmitting specie characteristics; for since Belgians are essentially a "made" creature, 
both lines become important. The female, however, should be studied from her sire side rather than that of her dam.

Many fanciers mate by selecting the male for color and the female for shape and size; others reverse this selection. It is an issue that each fancier can apply as a matter of experiment toward an objective point; but unless both sexes are chosen with due regard for all characteristics, a much larger degree of obvious disappointments will have to be constantly combated, with the risk of failure in the end.

Red, designated as rufous, is therefore what constitutes color for all those parts on the Belgian not specified by white and black - the latter entirely as ticking. This as already described, varies from bright to dark, and is qualified by its tinge as golden and chestnut, with tan as the basic element. The deeper down into the fur this latter extends, the more valuable the specimen in point of Fancy, and if extending to the skin altogether is evidence of extra quality.

There is continually some trouble to secure correct color on the ears of a Belgian; that is, so these appendages harmonize on their superior surface with that of the ground color on the body. Often, also, the ears are too bare of fine hairs, almost naked, indeed, and then either too light or too brownish. They should be very finely covered with exceeding short, red hairs, a nice continuation out of the head covering as far up toward the blacktipped point as possible.

Another failing that seems to be the result of fashion breeding, is whitish-tipped toes-not bars-but a soft cushion of pale hairs where the nails set in. This is not a very evident failing, but by oversight in mating is liable to become objectionably pronounced. Now and then one sees a specimen, usually a bright red chap, with white hairs mingled throughout its body coat. Concerning this they make a loud noise over in the Old Country, and Ambrose says it is a "very serious defect which should at all costs be avoided." They are willing to admit the "defect" as a result of in-breeding, yet advocate the latter with a tenacity bordering on the pugnacious. Best of all, use no specimens whose coats are distinctly marred by alien hairs of white; but at the same time do not throw aside otherwise good ones when such hairs are "far and between," for we must remember that alien white hairs are quite frequently the effect of injury to hair follicles from a scratch with the claw, a bump, or bite during a scrap.

Furthermore, our friends "across the pond" are decidedly finicky about the effect of sunlight as a bleacher to the red. That persistent exposure to sun rays will tan is well understood, but that Belgians ought to be reared devoid of this invigorating in- 
fluence on this account, is begging an issue; and that moderate exposure will be a detriment is also open to question. As an ex. periment I placed one of the bright red chaps in an open, un covered yard, with no protection other than several boxes against rain. The sun shines in this yard up to $2 \mathrm{P}$. M., yet this fellow shows no bleaching after a four month's test, with the temperature above 94 for a week at a time. However, as a matter of comfort I have my hutches roofed over for protection against both heat and rain, since wet is a whole lot more undesirable than heat or cold.

A serious mistake often made that eventually proves detrimental to color effect, is mating specimens before sufficiently matured, or before adult bloom is fully attained so as one may know what to expect. It is a physiological certainty, that while the reproductive sphere can be responsive to its functions at a comparatively early age, its fruit thus early produced can not attain that permanency in physiological characteristics which come from stamina out of a mature body. To come within all physical expectations, then, it is well to permit the reproductive organs as much time for organic functional perfection as the rest of the body; and remember, that once the reproductive sphere is drawn on for functional duty, virtually all life of the being concentrates in that direction, and at the expense of every fiber in it.

\section{Breeding For Shape Mating}

A careful study of the topic that relates to physical characteristics, along with the immediate preceding one about color points, will give practically all essentials that enter into breeding for both shape and color. Analyze the former intelligently, and apply the latter in connection so near as it can possibly be adapted. Use judgment and common sense with what science of breeding one has available. Adjust inferior points in one with superior ones in the other, and remember continually that from the sire emanate the blood line qualities for which we aim.

I have no doubt about not a few fanciers taking issue with my views concerning my contention for superiority in the sire. I have not the least objection, and entirely appreciate that the nearest approach to absolute fact is derived from deductions out of our differences. Yet I must write as I believe, out of actual experience and considerable research; and is it not a fact that in Hares, as in all other stock breeding efforts, the sire has first place whenever there is inquiry after new blood lines?

But Ambrose says, "Success is, to my mind, much more readily secured through the does than through the sires. It is the mothers which perpetuate the main characteristics, and yet every 
one appears to crave so much for sires." The universal law of propagation does not justify the idea advanced in this quotation, nor can it be substantiated unless by instances that are exceptions to general rules. Which is not saying, however, that any sort of mongrel female will reproduce quality stock from a high class sire. Such an inference is not thought of in these remarks, for I am speaking of stock that is supposed thoroughbred on both sides.

There is no question that our present fashionable Belgian Hares are largely the result of breeding from young animals. Such a method conduces to fineness in physical features, and has been a leading factor, no doubt, toward getting the prominence of an objectionable dewlap greatly decreased. I doubt not, though, but that all so far accomplished has been done at considerable expense of constitutional stamina; and whether we are justified to make the sacrifice merely for the sake of a less useful yet more beautiful animal, I leave for each one's individual analysis.

A few years since I wrote one of our leading fanciers for his opinion about mating. This is his reply: "In mating for results I select the doe for shape and the buck for color. To eliminate defects I mate a doe strong in sections of shape to a buck strong in color. I do this with two pairs suited to each other, then select a buck of the one to mate with a doe of the other, and find my efforts have been rewarded." Evidently his ideas run parallel with those of Ambrose.

Another fancier of equal prestige, and who has made it considerable of a specialty to breed for shape, lays all success to the merits of a prominent sire strain imported nearly twenty years since; and I will qualify this by quoting what Wilkins believes is a sire's part in the mating; "The buck plays such an important part in the characteristics of the young in all points, and particularly in color, style, shape, fineness of bone, and head properties, that it is absolutely necessary he must be good in these points." It is from differences like these quoted that we must acquire our experience; for after all opinions are weighed, there is but one sensible course - use the best available specimens "on both sides of the family."

My personal experience has been entirely from well chosen sire lines, and I am quite satisfied with it. I am convinced it is the correct course. Under the topic "Physical Characteristics" will be seen described what is demanded as correct shape. Study that carefully, and frame the picture in a prominent section of the mind, then compare with the stock intended for mating and 
pair up as close to all points of quality as possible, always with the side of preponderance on that of the male.

It is often important to be as well informed with regard to defects, as with points of perfection. If anything, the former give more trouble than the latter. To one specially significant (I am not naming it a defect) I will call attention here-that of "choppy behind." This is an abrupt decline of the spinal bones from a line across the hips to the root of the tail, giving the animal, in many instances, almost an angular appearance. The nearer an unbroken arch is shown by the spinal curve from directly behind the shoulders to the root of the tail, the better will all other outlines harmonize. I doubt if this failing is much a result of strain, as it is from small quarters and consequent lack of jumping exercises.

Also avoid thick heads, lopped ears, and legs that stand distinctly in or out.

I have often been asked as to the propriety of breeding from stock that carries the tail sidewise. When specimens of high quality are otherwise available I would not use such; but if a specimen of excellent points in all other respects, with just this one failing, I should not hesitate to use it-providing the anatomy of the tail is perfect. Physical defects are always apparent at birth, so that by careful examination of youngsters, all unpromising ones can be destroyed. What will turn out as a "twisted tail" can be clearly seen before the youngster is three days old. It is anatomical malformation due to only partially developed vertebrae, or the ligaments that hold them together. But if the miniature tail shows straight at birth, and subsequently "floats" to one or the other side, it will be a condition of habit or overgrowth, rather than a defect. I don't like a "floating tail," but when there is no physical defect, an otherwise good specimen should not be condemned on this account alone.

I have noticed that rapid growth, all the more when intensified by humid warm weather, is a contributing factor toward this failing. Likewise, inactivity enforced by small quarters.

Above all, do not mate specimens not in their full vigor. Shape will be influenced by a diseased body.

\section{Study for the Standard of the Belgian Hare}

REMARKS-A Standard for judging Belgians should constitute sufficient verbiage to make every passage clear and free from misleading descriptives.

The true virgin hare, to whatever country it may be "indigenous" has never been domesticated, nor has it been hybridized 
(so far as definitely known) by admixture of blood from any species of either wild or domestic rabbit. The attempt was made but failed, notwithstanding obvious claims.

In other words, the hare-lepus timidus-has maintained its zoological identity quite as individual as the elephant, lion, or the tiger.

The animal we breed under the name Belgian Hare is not at all of the species lepus-it is purely a species of rabbit bred to a high degree of perfection. Belgian (Belgium) breeders, I believe, claim priority to this species; but in that country nothing near approaching the type bred in England is produced, and English fanciers can justly claim title to its present perfection. The Belgian Hare as reared in America (I mean the typical Belgian) is entirely the product of breeding stock imported from England, and it is the English species of it, so to say, that we must of necessity propagate, unless we hybridize away from the hare type and create an obvious one along rabbit lines.

We may be able to, by reason of climate environment, and other possible influences, produce possibly somewhat of an American ideal though I see no advantage nor likely consummation in the attempt, nor would I advise it.

SIZE-The classic breeder clearly understands what size has to do with breeding the typical Belgian Hare. The uninformed has not, and unless size is made a part of type and intelligently standardized, it becomes objectionable in that it destroys the hare characteristic. Hare type stands for raciness, and this can not obtain when bulk is leading requirement; and there are not a few, I am sorry to say, who think this sacrifice should be made, and to whom I would suggest that if a large rabbit is desired for utility purposes make one by hybridizing the Belgian and Flemish, or Flemish and Silver.

I believe it would be considerable advantage to type if the present weight of eight pounds were reduced a trifle, and a more specific classification made. The following weights, I think, would admit of all practical latitude for Standard results of breeding for racy type:

Does above 10 months old $\ldots \ldots \ldots \ldots \ldots \ldots$ to $71 / 2 \mathrm{lbs}$.

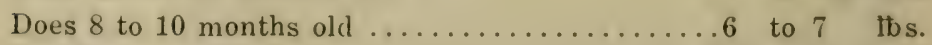
Bucks above 10 months old .............. Bucks 8 to 10 months old ...............

All specimens under 10 months old to be considered as youngsters, and for judging are classed by months limit of age and rated by comparatives. 
WHITE-There has been much discussion among foremost fanciers as to how much white-understood as white-bellied and grey haunches-should be tolerated to pass Standard criticism.

It is a fact that there evists an innate propensity in all animals of vari-colored fur coats to change from dark to lighter shade incident to season or age. The reason is a physiological one, and should be considered when judging an animal of domestic breeding if this characteristic is apparent. To allow certain degrees of white and grey (with consideration of the above phenomena) appropriately placed without jeopardizing the standard body color, would appear admissable. In other words, a specimen answering to every characteristic of type and color features should not be thrown out unless the white on belly and under jaw and grey on haunches exceeds a qualified per cent. into the other color (rufous).

DEWLAP - This appendage is characteristic of the rabbit species, and NOT of the hare. Its presence is evidence of "breeding back" to an original rabbit strain. The nearer free (and absolutely, if possible) a Belgian Hare strain is kept of it by scientific breeding, the closer a pure hare type will it attain. But since the present Belgian is withal NOT a hare per se, its presence to a degree is justifiable, and should not debar a specimen from qualifying in its class.

[NOTE-The dewlap is not a deformity, nor a disqualifying characteristic, unless so abnormally large as to make it such, and clearly indicate the specimen to be entirely foreign to the Belgian Hare type. It so happens that many otherwise good specimens show this appendage in various degrees of development; but which was not apparent prior to maternity, or a certain age, which have reproduced others entirely free from it. These factors should be considered when judging; but a male specimen with more than a mere evidence of dewlap, is to say the least, undesirable as a stock-getter, and should be disqualified if it is akin to that in a doe. The dewlap should not be confused with a not infrequent udder-like enlargement of the breast incident to maternity and which will disappear after the nursing period (unless the doe is again soon bred).]

COLOR-Much discussion and sometimes very caustic, was had as to what constitutes rufous red. According to some authorities, it is a term that admits of a varied interpretation, and the dictionaries define it as identifying a compound color.

The term rufous is from the latin rubro, meaning red. Spelled $r-u-f-u-s$, is the technical Latin form and is translated $r-u-f-$ $0-u-s$, meaning a shade of red; but nowhere is any reason essayed 
why it should identify as brownish-red or a "red tinged toward brown," as dictionaries define the tern.

Broeders, according to their fancy, contend for "Golden chestnut" as the correct shade; some say "golden tan" as still more ideal, and others again say "chestnut tan"- so on pro and con, with no one exactly satisfied. Because of this contention, therefore, I make the term as clear as we at present understand it. Brownish-red is all that can be analyzed out of the term rufous. Of gold there is a light and dark shade according to per cent. of alloy present; but virgin gold is a characteristic tinge, shade or color, as you please, of specific identity. There is no tinge just like it. Of tan and chestnut there are degrees of shade; but it is that shade defined as brownish-red with which we have apparently to do and it is the degrees of intensity, therefore, of this latter tinge from light to dark that must constitute one's judgment of what we understand as rufous. To formulate an ideal color effect in harmony with the conception of the term one will reason thus-take virgin gold as the standard for red, and the dark shade of a ripe chestnut for brown; tone down the density of the latter with the mellow tinge of the former, and you have rufous as it should show on the Belgian Hare.

TYPE-This term has also caused much discussion, all I trow, due to either misconception or misunderstanding, or possibly both. A small knowledge of Natural History, Biology and a bit of Comparative Anatomy, will harmonize definitives nicely so we can apply the word shape as being more commonly clear.

In its compactness type virtually IS shape, though many will haggle otherwise; but what I wish to convey by both (if you please) is-the physical characteristics of the animal one observes as a whole, or perhaps more desirably, an ideal whole. Literally it means "a stamp or mark"; that is, an impress, contour, outline, or physical conformity to a prescribed pattern-if the latter term is allowed. Color is a nominal characteristic; but is not essentially a part of type. The type that should "stamp" the Belgian Hare as ideal must portray raciness-slender, reachy body, thin, firm and lengthy limbs; narrow, racy-looking head; bright, bold, attentive eyes; ears long, thin, almost transparent, and continually posed for attention-the animal altogether portraying a qui vive entirely free from sluggishness, slouch and pudginess. 


\section{Official Belgian Hare Standard}

Adopted by The National Pet Stock Association of America (Same as the English Standard)

Points

COLOR-Rich rufous red (not dark smudy color) carried well down sides and hind-quarters and as little white under-jaws as possible .................... 20

SHAPE-Body long, thin, well tucked up at flank and well rigged up, back slightly arched, loins well rounded, not choppy; head rather lengthy, muscular chest, tail straight, not screwed; and altogether of racy appearance ...... 20

TICKING-Rather wavy appearance and plentiful ...... 10

EARS-About five inches long, thin and well laced on tips, and as far down the outside edge as possible. Good color inside and outside, and well set on ............. 10

EYES-Hazel color, large, round, bright and bold ....... 10

LEGS AND FEET-Fore feet and legs long, straight, slender, well-colored, and free from white bars; hindfeet well colored ............................... 10

WITHOUT DEWLAP . . . . . . . . . . . . . . 10

SIZE-Seven to Eight pounds $\ldots \ldots \ldots \ldots \ldots \ldots \ldots \ldots$

CONDITION-Perfectly healthy, not fat, but flesh firm like a. race-horse, and a good quality of fur ......... 5

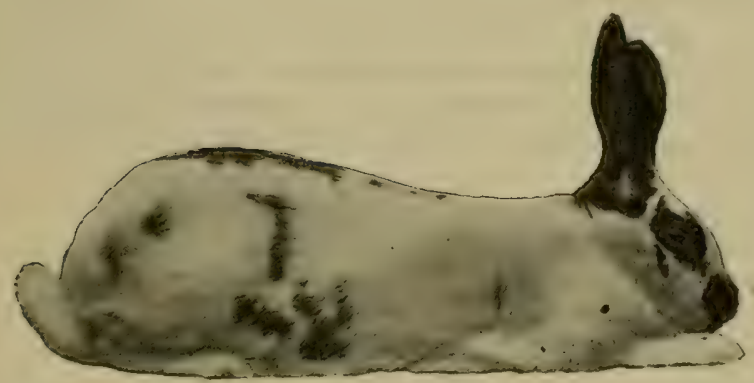

American Spotted Rabbit. Side Markings too small and Indistinct. Saddle too broken. Cheek spots

Smaller and Round 


\section{Table of Weights}

Below will be found a table of approximate weights of the "meat" varieties, attainable by proper feeding and care. While the weights here given are in some cases slightly in excess of actual Standard requirements, the breeder should strive to attain them, or even exceed them, and be satisfied with nothing less.

3 Mo. 4 Mo. 5 Mo. 6 Mo. Maturity

Steel Grey Flemish

American Spots

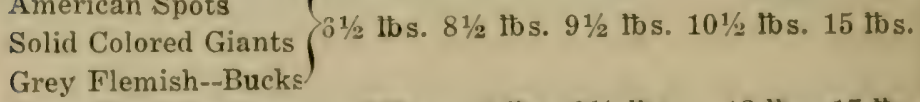

Grey Flemish--Does

New Zealands

Belgian Giants

$7 \mathrm{lbs} .9 \mathrm{tbs} .10 \frac{1 / 2}{2 b s} .9 \mathrm{lbs} .17 \mathrm{lbs}$. $41 \frac{1}{2}$ tbs. $5 \mathrm{lbs}$. $6 \mathrm{lbs}$. $7 \mathrm{lbs} .11 \mathrm{lbs}$. $5 \frac{1}{2}$ tbs. $\quad 7 \mathrm{lbs} . \quad 8 \mathrm{lbs} . \quad 9 \mathrm{lbs} .13 \mathrm{lbs}$.

While the Belgian Hare is still classed as a meat, or utility rabbit, and at one time easily held a position as leader among the table or meat varieties, it has of late years been compelled to yield a place in the front ranks for the Giant varieties and the New Zealands. In the Belgian Hare, many of the qualities necessary in a utility rabbit have been sacrificed for the sake of fancy alone. To strive for a big carcass and tender meat in a Belgian Hare would be to forever bar it from winning in the show room. The hard racy appearance of the Belgian Hare can only be attained by somewhat scant feeding and plenty of hard exercise. For this reason no weights are given in above table for the Belgian. Most of the winning specimens in the show room weigh much less than that specified in the Standard. On the other hand, we have never seen or heard of a competent judge penalizing a Giant for overweight. The bigger, the better chance of winning-everything else considered-providing the weight is not obtained by an overly fat condition. 


\title{
Breeding, Building Up a Strain and Inbreeding
}

\author{
By Dr. Roth
}

Associated with the breeding of every species of live stock there is continually present this persistent bugbear that relates to in breeding - the theories for and against it. Inherent within one's self, no one seems to like it, yet in the regular order of breeding for specific points there appears no other way.

We all are repugnant of the idea associated with mixing blood of relations, and when it comes to pairing father with daughter, brother with sister, or son with mother, we just naturally think it is dreadful.

Regarding such matings in the human family, both Bible and Law has set a ban against it, yet it could not have been otherwise than from such relationship that every species of living thing emanated, if we are to believe the story of Creation, the Flood, of doddering old Lot, and other instances of sacred and profane history. But the subject is one that can be made a volume by itself so that I shall limit myself conservatively.

One primary factor is, to what extent will psychological influence bear on sex combination. With regard to the human species, science has evolved the knowledge of relationship between mind and matter, and it is believed the former can materially influence the latter, hence the social and legal ban against the mingling of related blood.

In creatures of the animal kingdom psychology is supposed to have no part, and therefore inbreeding can not influence tissue formation. Mr. Noble says, "In the lower animals there is no mental strain to take into consideration," nor can there be any knowledge among them that the remotest blood-relationship exists. I have in a number of instances observed, in dogs, we"ll say, that a certain endowment of memory is apparent. After considerable association, sudden separation for some period (quite long, one would think), and subsequent coming together again, joyful recognition was manifest; but the matter of bloodrelationship never seemed the least check to familiarity. Often, also, have I noted the gradual growth of a littex of kittens, baby 
pigs, a pair of pigeons, half a dozen puppies, a young lamb, and a "nest" of Belgians, with a view to studying the length and permanency of filial relationship and parental affection; but in cvery instance, so soon as the parent voluntarily "weaned" its young, there was apparent no further consideration for it than that of tolerated companionship, and often not that. In the light of these facts, Mr. Noble practically asks, "I am still waiting to know why I should not put together any pair of rabbits, that from outward appearance, are perfectly suitable in every respect, both physically and for producing exhibition points."

Another breeder says, "I never consider blood-relationship at all, and do not hesitate to pair father with daughter, or brother with sister."

In no country, perhaps, is inbreeding made a practice in the rearing of live stock as is applied to every species of it in England. It seems an obsession, and a sensible one, mayhap, over there. Rabbits, and Belgians in particular, have been so long inbred that Ambrose remarks concerning it, "We sometimes think we are using quite another strain, when in reality we find, on inquiry, that the stock is not far removed from those which we ourselves are depending upon for success."

I do not wish to set myself down authoritatively as individually advocating either cross-breeding, line-breeding, or in-breeding-rather as remarking of each impartially; but I am not averse to an acknowledgment, until better informed, that a careful study, associated with personal experiments, of the more recent points and developments relative to the breeding of live stock, has modified my views largely in harmony with those of Dr. Schroeder, Superintendent of the U. S. Bureau of Animal Industry, who says, "I am strongly inclined to believe that the evils attributed to inbreeding have been greatly over-rated."

It is interesting to note what the U. S. Department of Agriculture is doing through its several subsidiary divisions by way of experimenting along all principal lines that relate to mating of the different species of domestic animals and fowls. Special attention is given the Mendel theory, as laid down by the monk of this name, whose work consisted entirely, it appears, in experimenting with plants. Government experts believed that the law discovered by hybridizing vegetables, and flowers, would hold out with similar effect when applied to breeding live stock; and while not carried far in this direction as yet, indications point to successful results.

Briefly, the Mendel theory is that of "inheritance of ancestral traits," or plainly that of inbreeding. It embodies the principle of dominancy and recession in succeeding generations, and 
implies, also, that each subsequent third generation in a lineal descent is characterized by predominant physical points of merit to determine in the ratio of three to one. That is, in a third generation there appear three "dominants" to one "recessive," and it is by mating continually out of the former that eventual perfection in thorough breeding is attained.

I have neither time or space to remark at length on the numerous scientific points involved in line- and inbreeding, but it appears the only logical course for the attainment of specific characteristics.

There are three forms of breeding as classified by the terms cross-breeding, line-breeding, and in-breeding. There are defined as follows:

Cross-Breeding is the mating of two thoroughbred breeds of diverse species, as the Hackney and Trotting horse, Alderney and Holstein cow, Bulldog and Hound, Belgian and Flemish, or Dutch and Silver, etc. Subsequent matings of such offspring can be line- or in-bred.

Line-Breeding is mating individual specimens of a breed when interruption in relationship exists by remoteness.

In-Breeding is the mating of closely related ones of the same species.

Line-breeding is illustrated by the subjoined pedigree diagram representing straight line descent for both sire and dam. For convenience I will name two pair by Sheriden mated to Bessie, and Roger to Queenie:

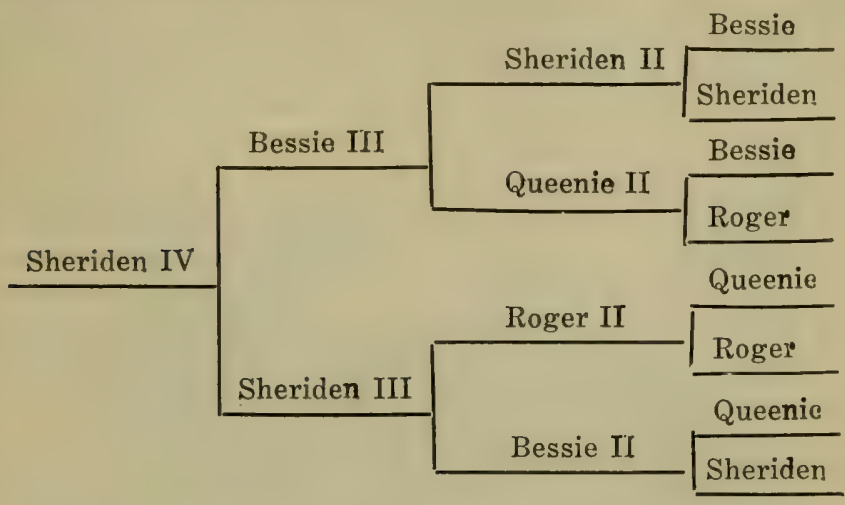

In-breeding needs no illustration, since it implies the mating of direct relations, as, father to daughter; son to mother; brother to sister; father to daughter by brother and sister; mother to son by daughter and brother, etc. 
With regard to this latter form of breeding the U. S. Bureau of Animal Husbandry has bred brother and sister mated in sequence order down to the 10th generation. Cavies being the example, and regarding which Dr. Schroeder writes me, "We have found nothing to indicate that the intensest form of inbreeding, carried on for nine or ten generations, is injurious. That for the preservations and perpetuation of especially fine points, and for the establishment of new breeds through the selection of naturally occurring mutations we are practically forced to resort to in-breeding."

It was apparent that the 9 th generation in this instance was represented by as good health, vigor and Standard points of merit, as the parent stock of the 1st; and, if anything, all points were finely accentuated. The experiment also appeared to show a predominance of the "iominant" elements over the "recessive" in every $3 \mathrm{rd}$ sequence.

Here is an example of absolute straight line descent without a vestige of foreign blood from the second mating on, yet no deterioration in a single element.

One factor stands out pre-eminently above all others in its relation to breeding, no matter along what line the latter is practiced-that of health, and the possibilities from heredity. One should never mate specimens containing physical'defects, nor when affected with disease whose transmission is known to influence the offspring. I am not alluding to physical faults, nor to diseases that are curable by proper treatment. These will not transmit defects; but in the event of in-breeding, essentially close in-breeding, physical defects will likely be greatly accentuated, and constitutional disease all the more.

To start breeding do not begin haphazard. Become acquainted beforehand with the salient principles involved.

The indiscriminate mixing of blood lines without any knowledge of results, is like trying to steer a ship without a rudder. Don't pin faith on the mere assertion that like reproduces like, for unless one knows how Nature does this, she may shoot very wide of the mark. She has immutable laws by which she works, and reproduces defects just as likely as points of merit. She dabbles intimately with the phenomena of heredity.

Study carefully the chapter that relates to physical characteristics, and apply its qualifications to both sire and dam, with their preponderance in favor of the former. This means all that is embodied in shape and color. But when purchasing never ask for a perfect specimen; for there is none. All domestic varieties of rabbits are what they are by virtue of being "made" so, hence 
imperfections continuously crop out. So when buying from a reliable fancier who is a real breeder, say to what you aspire rather than just what you want; for it is not always that what appears the most ideal specimens from a show Standard which will reproduce their kind in exact duplicate. The matter of genealogy must never be forgotten, nor that of dominancy for the prevailing traits. Buy from a breeder who understands the science associated with the art of propagating a species, then build up one's own strain.

Building up a strain implies a start with specimens selected to represent certain qualities and then enlarging these by a process of development and elimination. That is, points of merit are to improve, and those of demerit bred out.

I am presuming one is starting out as a novice with the idea of occupying a position in the Fancy. In such event, as said, buy from a reliable fancier breeder whose strain has the reputation of careful building up for a number of years. See that the stock is free from constitutional disease. Select specimens that represent, at the present desire "golden tan," or yellow rufous, and those of the "chestnut tan" or real rufous. To maintain the former persistently requires the latter. Neither in itself, will breed true continuously without variation. The "golden tan" is liable to shade into lighter, while the "chestnut tan" has a tendency toward brown, with an excess of ticking; but by a careful adjustment of blood lines in the two, one can always expect desirable show specimens.

The matter of mating related specimens I leave for study by the fancier after a careful perusal of the views brought out in the foregoing remarks.

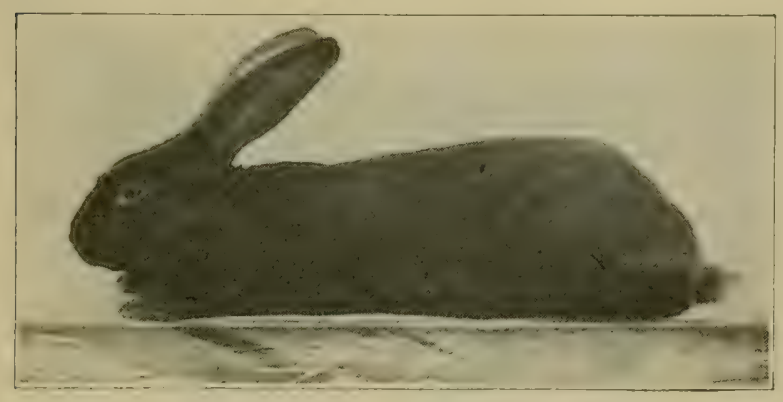

Black Giant. Good Color and Type 


\section{Pedigree}

\section{By Dr. Roth}

This is also a bugbear that is not a specially creditable one in the rabbit fancy. That it is discreditable is no fault of the topic, and that contemptible fraud is practiced by falsifying the lineage of a specimen does not prove that a record of blood lines represented by a given strain is not the right thing to maintain.

I hold that, notwithstanding all the howl sent up by those who antagonize pedigree, it is the only course for the maintenance of a true knowledge of one's stock. I have not yet observed one make a consistent argument against pedigree, and those who are noisiest in antagonism are the most earnest to know what they buy as represented in a reliable record of lineage. That a faker can fake is quite true; but not more so than that an honest breeder is honest. As a rule, a specimen carries inherently the qualities it possesses, and these are always palpable to the informed observer who knows what they ought to be.

By all means keep a record of every animal bred along thorough lines. Without a record of its lineage, what can be known regarding its possibilities for the future. Deductions are impossible without a recorded formula that learls to results. However, any discussion of this topic is superfluous for the reason that it is a universal rule among stock breeders of all varieties of thoroughbred domestic animals, is the sole guide to success, and if not maintained one had as well do a market business from the outset.

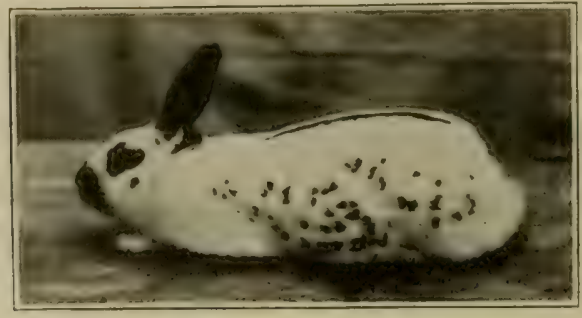

A Very food English. The Chain Markings Should Fixtend Nearer to Base of Ear, and Body Markings are a Little Too Profuse 


\section{Feeding}

\section{By Dr. Roth}

To be successful with rabbits depends perhaps more on practical and common sense feeding than any other feature connected with their "bringing up."

And on the other hand, I am safe in saying that more losses of stock are directly attributable to carelessness or possibly overzealousness of it, than all other adversities. Indeed, the rabbit is by nature, so singularly free from disease( and ver$\min )$ in any form, that whatever ailments are encountered in various ways are nearly all traceable to some error in supplying food.

Nearly every fancier and breeder of some import furnishes a circular or brochure in response to an application or sale of stock, and it is of considerable interest to read over the obvious instructions vouchsafed in it, particularly with regard to feeding. There are few directions in which all agree, and the variance is so great that a beginner must become seriously confused, with the chances of making mistakes very much in his favor. Then, too, what one reads in the several magazines, which devote space to rabbit topics is also of such wide range of opinion that one at first sight must almost conclude that no fixed rule for feeding exists, and that each manages tolerably near according to his own notions. And, is such a conclusion far wrong, I trow?

One breeder speaks of green things with utter fear-almost dismay and uses only the littlest of little of it; another is more liberal, but conservative in quantity, while a third gives as much as the rabbits wish to eat, and all three get along without trouble, apparently. Some advise certain foods in the form of mash, anyway from soft to dry, others feed no mash at all. Then growing youngsters come in for special dieting up to a certain age, and again they come in just the same as the old ones. Thus opinions shift along, and the rabbits that don't die from over-attention may die for want of it, and the rest grow up.

But, seriously, feeding should be managed along intelligent lines just as everything else-not overdone, nor underdone. Common sense comes nearer being pleasing to the rabbits than too 
much concern or not enough. No matter what the creature may be that one takes up for either fincy or utility purposes-from the larger animals to the smaller pets-to be successful with their "bringing up" the first essential is some knowledge of their instincts and physical characteristics. In the case of the rabbit, we know how it lives in the wild state, and that its clomestication was a gradual advancement from that into its present, which should imply, that its food now cannot be greatly modified from what it finds when compelled to hunt for it-summer and winter. To know what this is should not be at all diflicult; for a rabbit exists about exactly as a sheep would were the latter to seek food as an undomesticated animal. This holds good in the domestic state as well. Feed the rabibts as one feeds sheep, and there can't be much room for error.

One instinctive characteristic of the rabbits and which to me personally has been a guiding factor in the successful rearing of it, is that it prefers to feed at night. Unless annoyed, the rabbit in its wild state is quiet dluring the day, and the Belgian very much so if undisturbed, and sees no one. I make it a rule to have mine as little disturbed in daytime as possible, and in connection with this thought I will give my method of feeding and the feed I use.

My rabbits are never restless until approach of evening "meal time" which is invariably at sunset. Then they are fed sufficient that I know the stomach is full in the morning, and the days of long nights, I give but one mess in 24 hours. They are glad to see me in the morning, but not frantic for food, and all they get is a swish of clover hay, or every third day something green. With regard to the latter I am very particular that no medicinal plants are fed. By instinct, a rabbit does not eat them in the wild, but a domestic rabbit by being sometimes long deprived of greens, occasionally forgets himself. Dandelion is injurious and plantain should be fed only sparingly. Turnips and carrots are a good relish now and then; but hay-clover, alfalfa, or timothy is most I feed, both green and cured. Mash feed of any sort I don't use, nor milk at all. Pure water is the only liquid-twice a week in winter, and every day in summer. Once a week I mix a teaspoon tincture of iron in half a bucket of water-a tonic in a way, and keeps them slick. So far I had no sickness among my stock.

(NOTE. Have received several requests for more definite information on use of tincture of iron. Dr. Roth evidently referred to the ordinary ten or twelve quart pail. I usually prescribe ten drops to a quart, which would be a teaspoonful to six marts-about the same as evirently meant by above. C. R. D.) 
My regular feed for the substantial evening mess consists of bran, $1 \frac{1 / 2}{2}$ parts; ground oats, 1 part; whole oats, 1 part; whole wheat, 1/2 part; cracked corn, 1/2 part, and hominy 1/4 part, thoroughly mixed. Young and old are fed alike, except as to quantity per animal. Of course, I expect many to differ with my method, and I shall not object. I have my reasons for feeding this way; my pets are happy, and healthy, and sleek as eels; and as said, were well since I have them. I might add that twice a week I mix a tablespoonful fine salt to four quarts of feed as an elementary essential. Some breeders keep a lump of rock-salt in the run-a serious mistake I think-for salt is a poison in an over indulgence, and causes bowel trouble. I do no exhibiting at shows, but such as do, usually devote some extra attention to feeding in the hope of developing extra sheen in the "coat," and a brisker appearance in general. In England, this is done to quite some degree, and not a few enterprising parties advertise "just the thing to make you win." It is the same in this country and as a precaution wish to say that all "condition" feeds and powders are injudicious extras prepared from business motives, and buyers should know that the various cereals and vegetables which constitute the food of grain eating animals contain all the nutrient nature intended they should have. Feeds containing condiments or medicinal ingredients should always be used with discretion, and all mixtures of this sort that ever came under my notice were merely a combination of the grains usually fed individually in a way, with either cottonseed meal, gluten in disguised form, or sugar obviously prepared, added, with all of which the well informed breeder is likely acquainted beforehand. These mixtures cost more than regular feed, but are they worth more? One important consequence should be persistently remembered with regard to the use of prepared feeds - they usually contain stimulating material in some form-an unnatural effect upon flesh tissue - the re-action from which is always detrimental far in excess to the apparent benefit. The only safe line of correct feeding lies along the course laid out by the physiological laws in nature.

A few paragraphs ahead I spoke of feeding no milk in any form to my stock. I don't like it, and found no occasion to do so. Many, however, do, and I do not wish to advise specially against the use of it as a food. I receive numerous inquiries along all lines of interest in breeding rabbits, and among them are many asking the advisability or propriety of using it for young and old stock. The great danger of feeding milk lies in chemical changes. That it is a good feed for young stock is true, but remember, young rabbits in the wild state don't have it after the 
mother forsakes them. Milk as a diet for young animals was not intended for them longer than the parent supplies it. If one does feed it after weaning the brood, great care is requirerl that it is perfectly "fresh," and only so much given as will be consumed at once. Let none sour in the dish, for sour milk is acid, and causes what in rabbits is known as "slobbers"-a very annoying trouble. Remember, too, it is an animal fluid, and not identical to water as a liquid. Ptomaine poisoning is possible from it. If mixed with dry feed of any sort, be sure that the dry feed contains nothing that will cause chemical changes in the milk. With these precautions in mind, it can safely be used as a feed. I have on several occasions noticed "directions" for feeding cabbage. Some eschew it as a poison for rabbits, while others feed it freely. It is not a poison, and rabbits are fond of it, especially as a green food in winter; but, like all things, don't overfeed, and be sure it was not treated with a paris-green solution against worms in its early growth; nor previously frozen.

Potatoes I never feed, nor do rabbits care for them. Boiled and crumpled in with dry feed, they should not be objectionable; but I consider them too rich in starch unless fed very sparingly. Sweet-potatoes are not as rich in starch as "white," and are somewhat allied to carrots. I feed them sparingly when I have no carrots or turnips. Indeed, all greens should be fed with caution against excess. In summer time when clover is plenty, I feed it daily in conjunction with cured hay-mornings-but it must be fresh cut. Wilted grass, for obvious reasons, is objectionable. Because greens are so plenty during the summer season there is grave danger in overfeerling bunny with it, and I have observed that paralysis is one of the results by losing several valuable young on an occasion when I was called away professionally for three or four consecutive days, while the children enjoyed themselves "tending bunny while you was 'way, papa."

Cleanliness is just as essential for the maintenance of healthy stock as regularity and quality of feeding.

To render one's stock a pleasure and profit one must have no smaller measure of enthusiasm, which implies, that what is worth doing at all is worth doing well, as some moralist has it. No man can be a true fancier or successful breeler and make a name for himself unless he diffuses enthusiasm throughout his hobby. Every creature reared for man's pleasure and benefit must be made comfortable if its most perfect physical characteristics are to be expected. 


\title{
Hutches
}

\author{
By Dr. Roth
}

This means a chest, box, case, or bin, in which rabbits are kept. The little creatures are not at all particular as to dimensions, style, or expense laid out to keep them; but with rabbits, as with the care of all other animals, if one desires to get on well with them it is essential that they are kept with regard to comfort and cleanliness. It does not matter, either, whether reared for fancy or utility purposes, comfort and cleanliness count as much for one as the other, because both are absolutely essential to bring up a beautiful animal as well as a useful one.

The character of the hutches depends on the number of rabbits one intends to rear, and say any number upwards of twenty, the most ideal method is to have them side by side, so built with wire netting that they can see each other. The matter of size is optional, and should be arranged in harmony with the number to be kept in one compartment. Some breeders build their hutches one tier above the other, no doubt as a matter of economy, for space. This method is objectionable for sanitary reasons, notwithstanding every effort to have the floor above unleakable tight.

As said, with reference to feeding, so in this-keep as close to nature as one can possibly manage, and this implies, that a bare space on the ground is nearest right. Here again I will give my method of housing my pets-not essentially as an authoritybut as information for the beginner. I keep a tier of four roomy hutches specially built for four breeding does. These I had made out of two piano boxes sawed in halves and set ends on, with each an outside run, making the room occupied by one doe $2 \frac{1}{2} \times 3$ inside, and $3 \times 4 \frac{1}{2}$ outside, and 2 feet high along the lowest roofline. The nest boxes are fastener on the outside along the back (entire length) a foot wide, and one and one-half high, with a sloping roof cover on hinges. Thus arranged, one can examine the nest without disturbing the doe, besides being convenient for cleaning:

As a precaution against rats I built the floor one foot from the ground, and space partition and pen surrounding of one-inch mesh wire netting. The wood bottom floor is kept covered with 
straw inside, and outside with sand and fine straw. Of eourse, my bereding hutehes are quite romy to be oceupied by a single doe to each empartment, and smaller spaces by one foot every way would answer nearly as well; but if you have the room to spare, make bunny happ! with space for needful exercise, especially for the babies up to weaning time.

It is a rule with me to breed at least two does a few days apart, so the young can be penned together after removal from the mother.

Iy large runs for the growing youngsters are so far, four in number, $2 \frac{1}{2}$ feet wide, and 18 long, with a "hiding" box at the far end. These have ground floors covered with 2 inch mesh wire netting-no, they don't dig through this-they try it once, that's all. Besides these, I keep ten extra hutches-two for individual

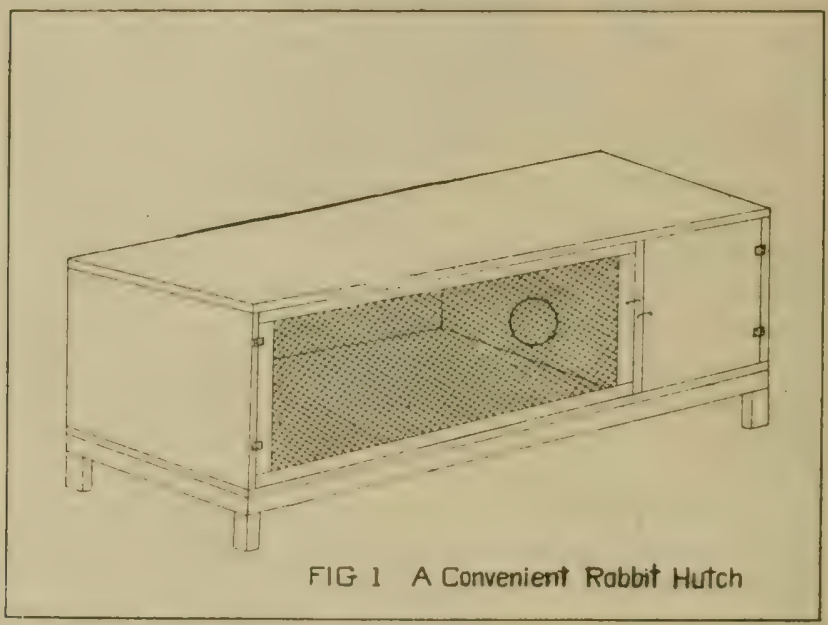

bucks, four for emergency, and four smaller ones for hospital purposes. I also have a prison for unruly tyrants. All these occupy a ground space of $24 \times 30$ feet, which is entirely covered with a roof of tar-paper fastened on skeleton frame-work as a protection from the elements and hot sun in summer, of course, strict attention is given to thorough disinfection aside from the regular cleaning. For this I use the commercial (crude) carbolic acid, which is sprinkled along the sides and corners, inside and out. Droppings are cleaned out every alternate day in summer and once a week in cold and freezing weather. In short, the hutches must be kept clean, dry and disinfected, so I can go out any time, take up a bunny and handle it without soiling my hands or clothes. 
Now, this is my way of doing things, and as previously noted, no sickness has as yet given me trouble of any sort.

In England, the breeding of rabbits is recognized as a fancy, upwards of half a century, and in the past twenty years has received more scientific attention than in any other country, and while individual breeders do not perhaps conduct rabbitries on so large a scale as some in America, there are more devoted to it. In breeding the Belgian Hare special attention is given to the racy type so characteristic of the English wild hare, and to this end the hutches of this variety are built high, rather than wide and long. This is a commendable idea, and goes far toward obviating crouchiness, with the accompanying tendency to develop the objectionable dewlap. Various contrivances, also, are resorted to with a view to the development of ideal points such

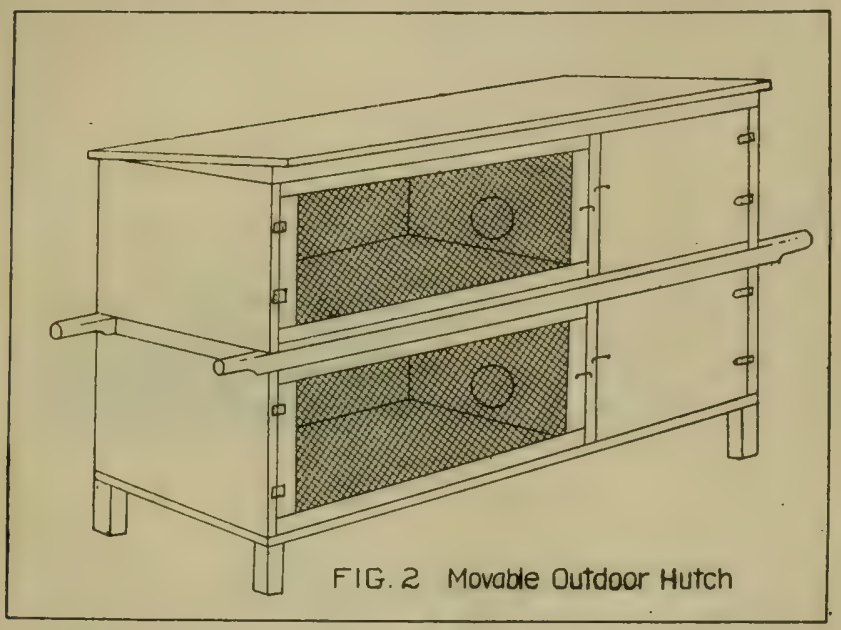

as placing a board cross-wise in the run a foot or so high for jumping exercise, which is supposed to give length of limb, span from shoulder to sacrum (across hips), well set ears, and tuck-up of flank. Feed boxes are built to compel a stretch of the neck in order to reach the food, another factor toward creating length. Such adjuncts are of course, only novelties toward an end; but are indeed essential for obviating objectionable tendencies and training out desirable ones. Then, too, many fanciful ideas can be carried out in constructing hutches which go far to give the breeding an appearance of taste in commendable harmony with the spirit implied by the term Fancy.

Breeding on a large scale necessarily requires space commensurate with the number one's quarter is to contain, and in all 
events must be so that the timid ones in a batch have room to cvale the tyrants always found among it. Absolute freedom for exereise is an essential in utility breeding as well as fancy.

To breed on a small scale and with limited space indivirlual specimens should, if at all possible, never be given less room than 4 feet long, $1 \frac{1 / 2}{2}$ wide and 2 to 3 high. This is, for such who desire only a few specimens for occasional table use, and while rearing them thus they will do well when sensibly attended-in open or closed quarters-they do best of all with as much room as one can spare.

A convenient indoor hutch (Fig. 1) is one 6 by 2 feet, with a movable partition dividing off a third of the space at one end for a nest and sleeping chamber. The partition has a smooth hole to permit passage of the animals from one part to the other.

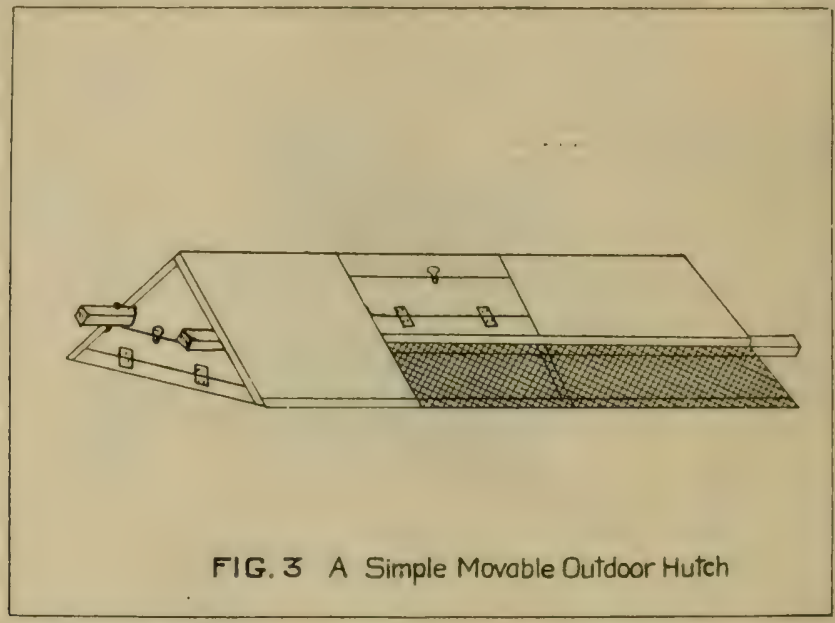

The front of the hutch has two doors, one of wire netting, the other of wood. The wooden door leads to the sleeping chamber and should close tightly. It is best to use metal hinges for the doors. The partition may slide in a groove between the doors or may be put in and taken out through one of the door openings.

Outdoor hutches should have sloping roofs and overhanging eaves to protect them from rain. The screen door should have a sliding cover of wood or be fitted with a removable cloth cover. Small holes bored near the top of the hutch will afford all necessary ventilation.

Movable hutches (Fig. 2) have some advantages. They may be carried outdoor in fine weather and taken back under shelter 
at night during storms. Long, narrow cleats projecting at both ends of the hutch are all that are needed to convert the ordinary hutch into a movable one. Two forms of outdoor hutch sometimes used are shown in Figures 3 and 4. That in figure 3 has no floor except a wire screen, permitting the rabbits to eat grass.

In conclusion of this topic on hutches allow me to emphasize again the positive necessity of cleanliness and disinfection, whether the room occupied be large or small; for once sickness gets among a herd its eradication is often a serious trouble. An excellent disinfection, as well as a point of cleanliness, is to whitewash all board-work with a lime solution strongly impregnated with crude carbolic acid and if a handful of salt is added

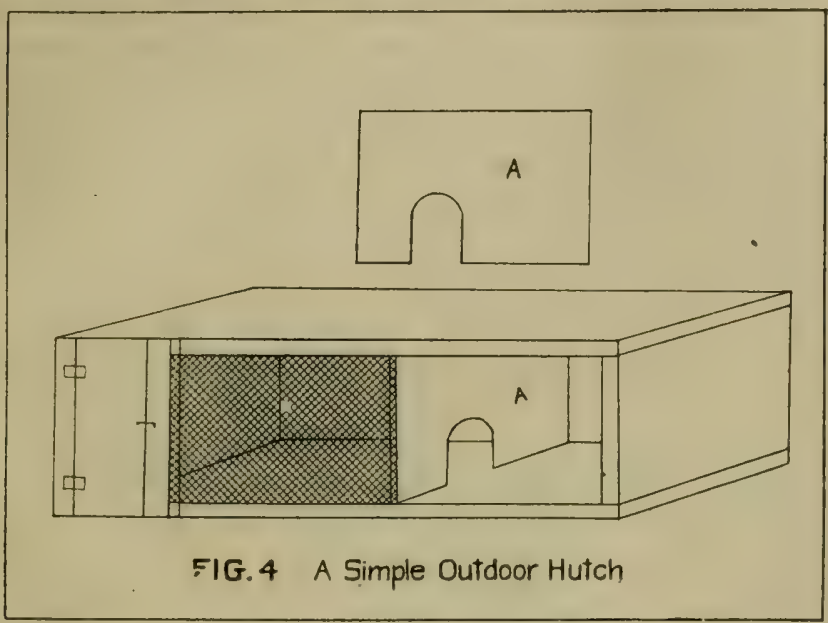

to the lime while slacking hot, its "sticking" and lasting quality is greatly enhanced. By following along the lines here explained, the housing of rabbits will be a matter of comfort and success, with every possible source of disease eliminated. 


\section{An Ideal Rabbitry}

\section{By C. R. Deardorff}

There are many styles of rabbit houses, good, bad and indifferent. Some have been built with the sole idea of keeping "bunny" warm; some with the idea of getting the largest possible number in the smallest possible space without any regard to ventilation; some to the other extreme of a large and expensive house with few hutches; and some with no definite idea at all. These are all radically wrong. The rabbit does not need, nor does it succeed in a warm building. All it needs is protection from drafts, storms, excessive heat and strong sunlight. Given these, together with correct sanitation and feeding methods, and we need not give a thought to any cold less severe than 20 degrees below zero. It is true that warmth is necessary to obtain great earage in the Lops, and great size in the Giants, but if warmth is obtained at the expense of ventilation and pure air - then earage and size is obtained at the expense of vitality.

It has been demonstrated and proven that the "open front" style is the only really successful method of housing. In this style, the rear end and both sides are boarded up tight, and the front mostly or entirely open, being covered only with close mesh wire netting to keep out rats, mice, birds, etc. Burlap or muslin covered frames are provided to close the openings in stormy or extremely cold weather. These curtains, by reducing the rapid circulation of the air, tend to retain the warmth generated by the animals' bodies, and at the same time permit the escape of impure air through the pores of the fabric.

Many are building long houses with tiers of hutches running lengthwise of the building, at the rear, and a long aisle running entire length of building in front of hutches. This is much better than a closed house, but has some serious objections. In the first place, it is expensive. Did you ever stop to figure that a long house takes much more material than a square one of the same capacity?

Another objection is that the long house is subject to bad drafts, unless partitions are built every 12 or 14 feet.

To overcome these objections, and at the same time retain all the advantages of the "open front" house, I have devised and offer in this chapter, plans and specifications of my Ideal Rabbitry. 


\section{Bill of Materiai}

2 pieces, 2 in. by 6 in. by $14 \mathrm{ft}$. for end sills.

2 pieces, $2 \mathrm{in}$. by $6 \mathrm{in}$. by $16 \mathrm{ft}$. for side sills.

13 pieces, $2 \mathrm{in}$. by $4 \mathrm{in}$. by $14 \mathrm{ft}$. for studding.

4 pieces, $2 \mathrm{in}$. by $4 \mathrm{in}$. by $16 \mathrm{ft}$. for plates.

7 pieces, $2 \mathrm{in}$. by 4 in. by $16 \mathrm{ft}$. for rafters.

3 pieces, 2 in. by $4 \mathrm{in}$. by $14 \mathrm{ft}$. for uprights.

315 sq. ft. roof sheathing.

$450 \mathrm{sq}$. $\mathrm{ft}$. drop sidir g, $14 \mathrm{ft}$. and $16 \mathrm{ft}$. lengths.

3 rolls roofing:

14 feet, 42 inch poultry netting, 1 inch mesh, for front.

20 lineal feet $1 \frac{1 / 4}{1} \mathrm{in}$. by $4 \mathrm{in}$. for door frame.

1 set:-lock, latch and hinges.

\section{For hutches:-}

420 sq. ft. flooring, $12 \mathrm{ft}$. lengths.

350 lineal feet $1 x^{\prime} 2$, for door frames.

115 lineal feet $1 / 2$ 1..ch mesh wire, 18 inches wide, for doors.

12 pieces $1 \mathrm{in}$. by $4 \mathrm{in}$. by $12 \mathrm{ft}$. face strips to hang doors on.

3 pieces $1 \mathrm{in}$. by $4 \mathrm{in}$. by $10 \mathrm{ft}$. for bottom of partitions under hay racks.

4 pieces $1 \mathrm{in}$. by $8 \mathrm{in}$. by $14 \mathrm{ft}$. uprights in front of hay racks.

9 pieces $2 \mathrm{in}$. by $4 \mathrm{in}$. by $10 \mathrm{ft}$. hutch floor joists.

97 feet, two foot poultry netting, one inch mesh, for hay racks and long partition in middle group of hutches.

24 pair 3 inch $\mathrm{T}$ hinges.

Sills may be laid on cement blocks, better yet built on solid concrete foundation. Floor may be of dirt, cinders or concrete. In either case build it up 4 to 6 inches inside of foundation to make it dry. No provision on above bill for foundation on floor. If wood floor is desired, add for floor joists and flooring, but such floors not advised on account of affording harbor for rats. Use $16 \mathrm{D}$ wire spikes to nail studding, plates, etc., $7 \mathrm{D}$ wire nails for siding, sheathing, hutch floors, facing strips, etc.-door hinges, latch and lock to suit your fancy.

Cornice, frieze, corner boards, outside casing, etc., have not been provided for, as they are not absolutely necessary, but are very desirable if it can be afforded, to make an attractive outside appearance.

\section{Floor Plans of Ideal Rabbitry}

Dimensions, 14 feet by 16 feet; Shed roof; Rear wall, 6 feet high, front wall $7 \frac{1}{2}$ feet high; Each hutch, $2 \frac{1}{2}$ feet by $5 \frac{1}{2}$ feet floor space, and 22 inches high; Three tiers of hutches-total number, 24. One front corner for feed bins, the other for baled or loose hay; If loose hay, put in an upright to keep hay in 
place. Cover top hutches, and space above, toward front ends, may be used to store extra feed and water dishes, ete. Make a conditioning, or work table, with drop legs, under either, or both, screened openings-each about 16 inches wide by 30 inches long.

Studding is to be set to suit dimensions of hutches, note location as shown on Fig. 1. In cutting studding, observe that the pieces as billed are $14 \mathrm{ft}$. long-and that one piece cut will make one rear and one front studding. Double corner studding, also on each side of door.

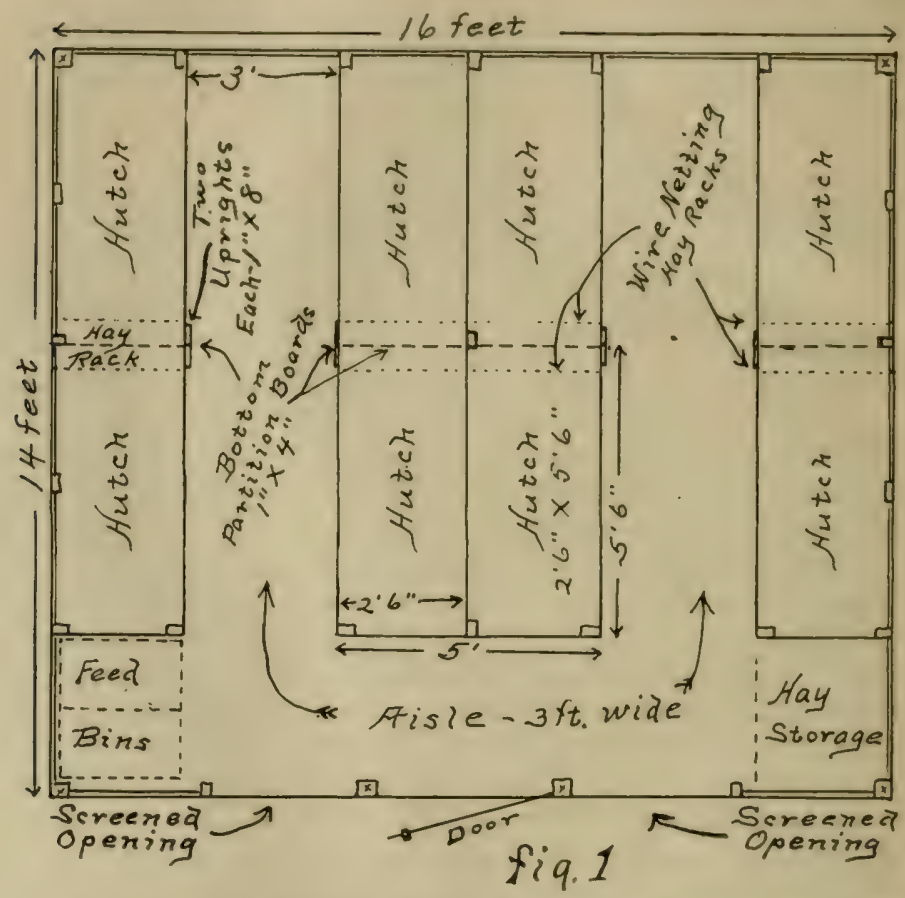

Plates are to be lairl double on front and rear walls-none needed on sides.

Rafters spaced 32 in. center to center.

Uprights are to be cut as follows: Four of them to reach from floor to top of top hutch, and placed one at each front outside corner of hutches to support hutches. The other two are to be cut to reach from floor to bottom edge of middle rafter to help support roof and hutches of middle group.

In building the hutches, hutch floor joist should be $2 \frac{1}{2}$ feet long for side tiers, and 5 feet long for middle group of hutches. 
Spike to studding and uprights, excepting middle joist can be spiked only on studding end on outside tiers, and to middle upright in middle group. The outside end of these middle joists are to be supported by face strips and one by eight uprights as shown in Fig. 2.

Run floor lengthwise and nail to joist with groove edge toward front. Plane front board to a square edge and let it project over and come flush with front top edge of face strip.

To get the proper slope to floor for drainage, rip a strip from the top edge on each end of the 5 foot joist, $1 \frac{1 / 4}{4}$ inches wide at the end to a point at the middle. The $2 \frac{1 / 2}{2}$ foot joist may be ripped the same way, or simply lower the outer end $1 \frac{1 / 4}{4}$ inches.

Removable nest boxes should be provided. A good one is a box $18 \mathrm{in}$. long, $12 \mathrm{in}$. wide and $12 \mathrm{in}$. high, with a removable cover. The top of this box provides a good place for the mother

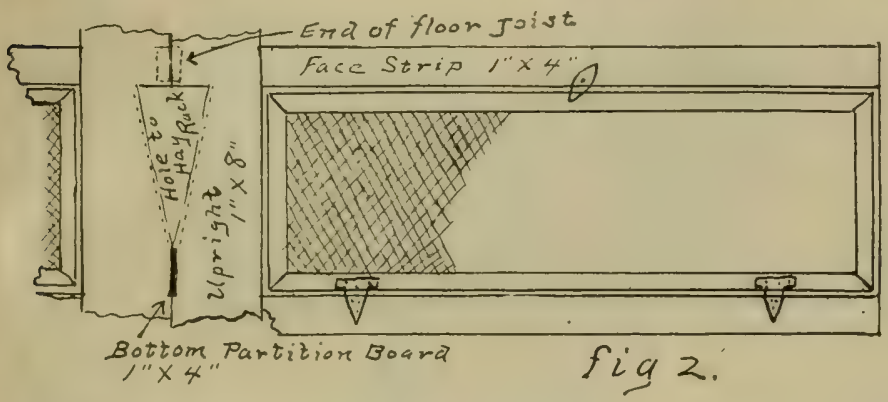

doe to retreat from too persistent youngsters. A hole, cut from top edge, 8 in. deep and 6 in. widle, furnishes means of ingress and egress.

The above drawing shows construction of front of hutches, hutch door, and feed rack partition. Note also location of end of floor joist. This does not show in the completed work, the face strip being nailed into end of joist, and then the two 1 by 8 uprights nailed on, edge to edge as shown. Before nailing on the uprights, cut the pieces as billed, into 7 foot lengths, then hold up and mark at the bottom of each face strip; cut in 4 inches and rip off triangular piece as shown, and then place the two boards with cut edges together as shown, to form openings to hay racks. These uprights, together with the face strip, sustain weight of outer end of middle floor joist, the other end being nailed to studding.

Partitions of hutches are made by using a piece $1 \mathrm{in}$. by $4 \mathrm{in}$. at bottom and stapling one inch mesh poultry netting to top 
edge on each side, ('xtending to top) of hutch and attaching about five inches back from the vertical. thus forming a $\mathrm{V}$ shaped hay rack about ten inches wide at the top, and running to a point at the top of the four inch bottom strip. This rack can be used from either or both silles, and is easily filled through the V shaped opening in the upright boards, without opening any doors or other contrivance- a great saver of time.

Attach the wire netting to door frames on the inside, so rabbits will not gnaw corrers of frames.

\section{Front Elevation of Ideal Rabbitry}

The entire front is sided up $2 \frac{1}{2}$ feet from the bottom, and extends three feet from each corner the balance of the way up. The door should be not less than $2 \mathrm{ft}$. $8 \mathrm{in}$. wide, and upper part covered with wire netting as shown. The two wire covered openings should be exactly the same size, so muslin covered frames are interchangeable.

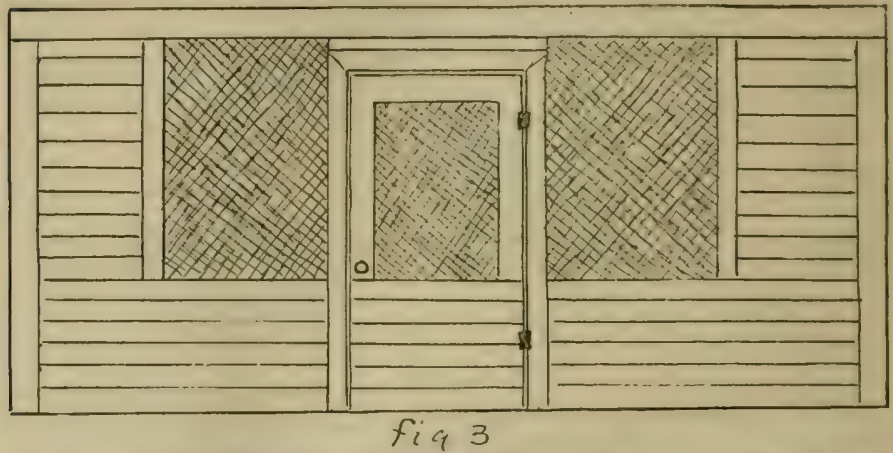

A "hood," two feet wide and twelve feet long, may be extended from top of front, projecting over the loor and openings. This will keep out rain and snow under ordinary conditions, without having to put up the muslin covered frames, and is very desirable in sections where sudden or severe storms prevail.

Advantages claimed for the Ideal, over the long type house are: First, Economy: The long type house, to contain the same amount of hutch room requires 720 lineal feet dimension stuff; the Ideal, but 490; The long type, 101 feet foundation; the Ideal, 60 feet. The long type, $682 \mathrm{sq}$. $\mathrm{ft}$. side wall; the Ideal, 405. The long type, 299 sq. ft. roof; the Ideal, 255. The long type, 247 feet floor; the Irleal, 224. The long type requires on an average about 45 per cent. more material than the Ileal, an item worth considering:

Second, Convenience: In the long type, one would have to walk 90 fect to inspect the entire rabbitry and return to the 
door; in the Ideal, only 40 feet. In the long type, it is 45 feet from the door to the farthest point in buildings; in the Ideal, but 15 feet. In the long type, one can clean three hutches, or fill three hay racks without moving from his tracks; in the Ideal, he can attend to twice that number-each side of aisle.

Third, Adaptability: The long type house is too narrow to be practical for hardly any other purpose. Supposing one gives up rabbit raising at some time in the future, or wishes to sell, and prospective purchaser is not interested in rabbits, then the building is not much of an asset. A building less than twelve feet wide is not suitable even for a hen house.

The Ideal is of dimensions that it can be easily and economically converted to use for many different purposes-poultry house, tool house, storage room, wagon and buggy shed, garage, cow barn, sheep shed, etc., etc., according to individual needs of owne:

Fourth, Superiority in Light and Ventilation: In the long type house with the entire front open, plenty of ventilation is obtained, but is rather drafty. On stormy days, there is an excess of openings that must be closed with muslin curtained frames. In hot weather, there is an excess of light and heat, and awnings must be provided to shade the hutches. On the other hand, if the front is partly closed then drafts are prevented, but part of the hutches are protected from the sun's hot rays, and part are not; while the ventilation is unequally distributed.

In the Ideal, there is no hutch that does not receive direct light at some time during the day; none but what are entirely shaded part of the day, and at least partly shaded all of the time. The ventilation is perfect, reaching every corner of the building without possibility of a draft. In stormy and extremely cold weather, there are only three small curtained frames to place, as compared with four times that in the other type house.

The bill of material, instructions, and cuts shown herewith will enable anyone with ordinary mechanical ability to construct his own rabbitry without hiring expensive labor. If one wishes to increase the size of his rabbitry, he can easily add one or more units at any time. Simply remove the feed rack or bins at either corner, cut an opening through, and build on another unit at that end. In this case, the siding on that end should not be removed, as it is needed to prevent drafts-simply cut an opening large enough for a door. Each unit added should be just like the original, excepting of course, the expense of one side wall will be saved, and the front door on added units may be dispensed with, using a wire covered opening instead. 


\section{Yards}

\section{By C. R. Deardorff}

Natural conclitions, as nearly as it is possible to provide them, will go far toward assuring good health and vigor in rabbits, just as with poultry and other stock. If one has room to arrange outdoor runs or yards for his rabbits, he will be amply repaid, not only in the increased health and vigor of his stock, but he will find the problem of care reduced to a minimum.

For breeding does, outdoor hutches may be built, as outlined in the preceding chapter, which may be greatly improved by attaching a movable yard to be used therewith. A good plan is to build a pen, or cage, about 3 feet wide and three feet high, and six to ten feet long. Use 1 by 4 stuff to make the frame, cover top and bottom with two inch poultry mesh, both sides and one end with one inch mesh. At the open end place the nest box, making some convenient arrangement for feeding, watering, etc. The nest box should be raised from the ground a few inches, and made damp-proof and draught-proof, and should be easily detached from yard to facilitate handling and moving. This outfit can be moved from place to place on a grassy plot, and thus avoid contaminating the ground, as well as providing bunny with fresh grass to nibble at every day. A splendid hutch to use with such a yard can be arranged by taking a good water-tight barrel, knocking out the side bung and covering hole on inside with wire screen. Place this barrel on supports hollowed out to fit the side of barrel, with bung-hole side down, to provide for drainage.

Another good plan, but one involving more expense, is to build a series of narrow yards, say 3 or 4 feet wide, and as long as space and means will permit. Previous to building your yards, level the ground nicely, cover the space to be used with two inch poultry mesh and on top of the mesh spread an inch or two of good soil. Seed this down with a good grass suitable to the locality, or "sod" it over with cut sod. When well sodded you are ready for your yards, which should be built of one inch netting and covered with two inch netting to keep out cats. Build individual hutches, each two feet wide, two feet high and three feet long, with a nest box in one end from 12 to 18 inches wide (according to the size of your rabbits) and 12 inches high. The 
top board of this nest box should be removable to permit examination and cleaning of the nest. This top board also provides a retreat for the mother when the youngsters persist in annoying her after leaving the nest. With such a system, it is necessary to provide yards in excess of the number of breeding does, so no one yard need be used continuously, else the sod would be destroyed. The hutches should be located at the end of the yards and moved along from yard to yard as the grass becomes exhausted. If one has a good sod, one hutch to every three yards would probably be sufficient in most cases.

The expense can be considerably reduced by dispensing with the sodding, but in that case the bottom wire should be placed at least six inches beneath the surface, and the soil to the depth of about five inches renewed at least twice a year to prevent contamination of the soil with disease germs. In this case it will not be necessary to build individual hutches, but instead build one long continuous hutch two feet high and two wide and divide into compartments as long as the width of the yards. The roof should be divided into sections and hung on hinges to provide access to each compartment.

Several yards should be provided for the youngsters after they are weaned so that those of nearly an even age only need be yarded together. These yards should be enclosed with one inch mesh sunk into the ground an inch or two, and should be covered with two inch mesh to keep out cats, or if one has rather large yards, he can save expense and serve the same purpose by attaching horizontal pieces about a foot long and extending out from top of post. Let the netting of the fence turn outward at the top of post and extend to the ends of these cross-pieces. This will form an angle over which a cat cannot crawl, and will form a very effective protection. It will not be necessary to cover the bottom of these yards with netting as rabbits do not dig until approaching maturity.

Separate the males from the females as soon as the sex can be determined. If any of the males are to be castrated, they may be left with the females or turned with the males-it does not make much difference, although if breeding on a somewhat large scale, it would be advisable to provide a separate yard for castrated bucks.

To maintain peace among the rabbits in the yard system it must be remembered that strange rabbits must not be turned with another bunch after they have reached a "scrapping" age. If found necessary to unite several lots, it may sometimes be accomplished without much trouble by putting the whole lot together in a new location, but never by putting a lot with an- 
other lot in a location already occupied for some time by any of the bunch. The older residents will resent the coming of the others. liy putting the whole lot in a strange location, they will usually be so occupied with their curiosity of their strange surroundings that they may forget their animosity toward each other. This scheme will, however, sellom work with breelers that have become accustomed to separate hutches.

Bucks will often get along amicably together long after reaching maturity if yarded at some distance from the does, and not used for breeding.

The necessary number of hutches should be scattered aroun.i the yards to provide shelter from the weather, and should be damp-proof and draught-proof. They may be of most any style pleasing to the breeder, but should be of small size and numerous, rather than one big hutch, so the more timid ones may secure seclusion from those that are inclined to be pugnacious. The writer has found it to be a most satisfactory practice to set up a few fodder shocks around in the yards of the half-grown and more mature animals. This provides not only an ideal shelter and place of refuge, but abundant rough feed, which accompanied by a little extra feed to vary the diet, will carry a bunch of rabbits through the winter in fine shape.

We will close this chapter by giving a little stunt the writer has tried out in a limited way, to prevent rabbits from digging and also to prevent fighting to a certain extent-or at least prevent serious damage from fighting. The system can only be used on animals not intended for the show room, as the operation disqualifies them. It has been found to work very satisfactorily in most cases, and is simply this: Clip the end off each toe-nail just so it brings a tiny drop of blood.

Will just add that snuffles and its kindred diseases are strangers in a rabbitry conducted intelligently and systematically on an out-door system. 


\section{Preparation for Show Room}

\section{By Dr. Roth}

The inherent desire within the breast of man is to produce something just a little better than his brother, to show it just a little better than his brother, and to win just a few more blue ribbons in keen competition in the show room.

When one desires to exhibit at shows with the hope of winning prizes, some special attention to stock beforehand is necessary and if several consecutive exhibitions are scheduled one must not forget that such journeys with their incident "wear and tear" will be a severe tax on the constitutional stamina of finely bred specimens. Many an excellent rabbit has been destroyed by overshowing, or insufficient attention connected with the journey. And we have no short distances of shipment, either, nor do the express companies run special cars for exhibits of this sort. Reading over the excellent show reports by our English fancier friends, I was often amused at the concern that occupies them with regard to distances, which at most is rarely beyond 200 miles, and seldom above 50 . Here we are obliged to consider time rather than distance, and very seldom, except with small local shows, that less than 600 miles are involved.

Make careful selection of the specimens intended for exhibition, and say 4 or 5 days before date of shipping, place each separately in a coop as near the size to be occupied at the show as one can arrange, and something within about 10 degress as warm as one would think the show room to be. This consideration is quite necessary, and all the more so when stock has been openair reared. The fact that rabbits are fur animals, and thus quite densely clothed, seldom finds thought in the heads of show committees, who more often place such exhibits in steam heated rooms than a proper environment.

Coops containing exhibits must be kept scrupulously clean so as to obviate all danger of soiling the fur, which should every morning be liberally sprinkled with talcum powder, nicely tousled through as to get near the skin, and then combed and brushed until the powder is all worked out. First two days use a wire brush, and subsequently a medium soft bristle. Use no water or cosmetics of any kind unless there is some disease of the skin that needs attention. Under the chin and belly stroke 
the fur with a small round stick shaped like a baton or drumstick. This will bring out contour to the head and body, and acquaint the specimens with the pose expected by the judge. This attention must be applied only to bucks of the Flemish variety, and not to does. The latter must be stroked entirely by hand, and the dewlap gently manipulated, so as to assume correct position and shape-evenly placed beneath the chin.

There is a popular notion that raw egg fed to a fur animal will produce "sleek coat," and that gunpowder fed to a horse will increase his action. Now while many of these "notions" appear amusing, and often quite worthless, there are others, withal, that have more practical sense than humor; for in the above there exists no small physiological virtue. Egg, we know, is rich in albumen, and gunpowder in the necessary reconstructive elements-carbon, potash, nitrate, phosphorus, and sulphur, which enter into tissue construction of which nerve and muscle is made up.

Raw egg can be given in the form of flip, which is made by beating one in a cup of sweet milk, add a teaspoonful of sugar, and two tablespoons of Sherry wine or brandy. If the animal will not drink this out of a dish, it can be given by spoon, or pipette.

Whole wheat added to oats is also excellent a few days before showing. It is rich in gluten, and this latter puts "bloom" on the fur.

After return from the show, an egg-flip is again a good "pick-me-up" for the effects of wear.

Have the shipping coops sufficiently roomy so as not to crowd, floor well littered with saw dust or chaff, and ventilation for comfort.

In the Belgian Hare the animal should be long and thin, both in borly and limbs. The ears should be long and carried well backward. There should be practically no ticking at the selection age, say three or four months. The hind feet should be level in color, the same being carried well up the hock. One mistake is often made in selecting specimens that show choppiness, but my advice is to get rid of these at all costs. You have here a small gauge to select promising youngsters by. After having made your selection they should be placed in large, roomy hutches, fed on stimulating diet and should have every care and attention paid them. Don't understand this to apply to all varieties of rabbits, for it is my intention to apply the above only to the Belgian Hare. What would be necessary in the selection of the Belgian Hare would be fatal to a Flemish Giant. Condition, however, must not be misunderstood. It does not represent fat or bulky 
station. It appeals to me as a means whereby specimens exhibited may be shown in a state representing a high standard of excellence, consistent with the points of the variety.

In all varieties shape must be given first consideration and it is absolutely necessary that youngsters be given as much exercise as possible. It is well to construct a running hutch with a jumping board across the middle, compelling them to race around the hutch and in jumping over the hurdle they will harden the flesh and decrease the size of the stomach. The exercise, too, is also important to increase the length of limb. Many English breeders in preparing choice youngsters for exposition, or when the specimens are under a great strain, advocate the use of egg flip. Give each rabbit a teacupful for the evening meal. While for the morning meal, give a little green stuff and the best oats and wheat mixed, two-thirds oats, one-third wheat, while a little clover hay should be added to the morning or midday meal.

One of the great secrets of success is in proper grooming. With the short coated varieties a thorough rub with the bare hands, following it up with a dry chamois skin, is all that is necessary. There is nothing better than a low table to use for grooming. Cover it with a piece of carpet or clean sack, nailing it down so that the specimen may have something to grip on to with his feet. You will find this a comparatively easy way to groom them. When the specimens are moulting they should be groomed at least once a day and their housing should be carefully looked after for they are very susceptible to cold at this time. Place the specimen on the table and vigorously rub the coat in the direction in which it lies and persevere until all the loose coat is removed, finishing off with briskly rubbing the specimen all over with a dry chamois skin. Belgian Hares need a little attention to the fore legs when moulting its young coat. It should be held firmly by the ears and the other hand should be used to pull the legs one at a time, allowing the hand to slip so that all the loose fur may be removed. Under no consideration resort to plucking for this is altogether outside the province of grooming and can at once be detected by any competent judge and the specimen would be disqualified. Specimens thus handled have the advantage of not only being well groomed but at the same time, well trained and this is absolutely necessary for success in the show room. There is nothing more trying to a judge than to have a wild, restless, untrained specimen to handle, and in many instances specimens have gone down that if properly handled before the show, would have been easy winners. 


\section{The Rabbit Hospital and Medicine Chest}

\section{By C. R. Deardorff}

Every well regulated rabbitry should have its hospital ward and medicine chest. For your hospital ward, a few hutches may be partitioned off from the others in your regular rabbitry, or, better yet, built in a corner of some convenient building at some distance from your rabbitry. These hutches should be well ventilated, without being drafty, and should be kept scrupulously neat and clean. These hospital hutches, as well as the entire inside of your rabbitry, should be painted with a good disinfecting white water-mixed paint, or prepared whitewash. For this purpose nothing is better than the following: Slack $25 \mathrm{Ibs}$. good lime, while still in a doughy state, mix with one pint crude carbolic acid, then with sufficient water to make a good whitewash. Apply two coats, allowing the first to dry before applying the next. Apply a new coat each spring and fall. The floors of all hutches should be painted with two or three coats of a good waterproof black roof paint. It is best to paint the floors when first laid and before applying whitewash to the walls. In building the floors, use matched flooring, painting each tongue and groove with white lead or roof paint as it is being laid. Glazed feed and water dishes are best as they have no pores or cracks to harbor disease germs. Clean them daily, and disinfect by scalding two or three times per week-daily in case of infectious disease.

Now as to your medicine chest. The drugs and medicines you should have available at all times are mostly those that are indispensable to, and usually kept in the family medicine chest. There is no particular reason for keeping a separate collection for your rabbitry-it is sufficient to see that the articles are kept on hand and available to use when needed. The following list will be found to cover the needs of the average breeder, and will also be in demand for use about the home, and for home treatment of minor human ills.

Absorbent cotton, carbolated vaseline, castor oil, Epsom or Rochelle salts, common baking soda, tincture of aconite, sulphate of magnesia, tincture of nux vomica, spirits of turpentine, spirits of camphor, sweet oil, sulphur, carbolic acid, sweet spirits of nitre, permanganate of potash, pulverizerl arrowroot, boracic 
acid, peroxide of hydrogen, and perhaps a few others as occasion demands.

The more common uses for which the above drugs may be needed, also the dosage, are as follows:

Carbolated vaseline for annointing wounds and sores, and in connection with other drugs as a basis for salves and ointments.

Castor oil, one of the best laxatives and corrective for stomach disorders. Dose, one tablespoonful.

Epsom or Rochelle salts, two other splendid laxatives, and will correct liver troubles. Dose, half a teaspoonful dissolved in a little water.

Common baking soda will relieve a sour stomach and correct evil effects of soured or spoiled foods. Dose, one third of a level teaspoonful dissolved in a little water. To treat a number of specimens collectively, dissolve a heaping teaspoonful to a quart of water and keep before them several days.

Tincture of aconite is splendid for relief of colds, catarrh and in allaying fever. Will prevent and cure snuffles in its first stages. Dose, three to five drops in a teaspoonful of water.

Sulphate of magnesia, ten drops to a pint of drinking water, will relieve costiveness.

Tincture of nux vomica, ten drops to a quart of drinking water, is recommended as a stimulant for the digestive organs, and is said to stimulate the genital organs and induce backward does to breed.

Spirits of turpentine, one part to five parts sweet oil will relieve bronchial affection, such as rattling in the throat. Dose, ten drops daily to an afflicted specimen. As a worm medicine, mix equal quantities of turpentine and sweet oil and give thirty drops. Follow in a couple hours with a tablespoonful castor oil. Avoid giving turpentine to a pregnant doe.

Sweet oil, as above, and with sulphur as below. Also as a mild laxative. Dose, two tablespoonfuls.

Sulphur, mix with sweet oil and apply with a swab for ear canker, mange, etc.

Spirits of camphor is a good remedy for slight cases of diarrhea-add a few drops to the drinking water. Also good for bruises and sores where the skin is unbroken.

Carbolic acid as a deodorizer and disinfectant. For deodorizing and disinfecting feed and water dishes, when boiling water is not conveniently at hand, use a two per cent, solution to rinse dishes after thoroughly washing with water and soap. To cleanse castrating knife, and to wash hands before and after treating a wound or open sore, use same strength. To spray floor and walls of hutches, use a four or five per cent. solution. 
Sweret spirits of nitre for kidney trouble. Dose, six drops in a teaspoonful of water.

l'ermanganate of potash as an antiseptic to cleanse the system of disease germs and to prevent the spread of colds, bronchitis and similar troubles. Dose, about as much as will lay on a dime to a gallon of drinking water-enough to color the water to a deep purple.

Pulverized arrowroot. Dose, one teaspoonful to a cup of milk, given daily until relieved, is a good remedy for diarrhea. In severe cases, or in dysentery, give twice a day a teaspoonful of warm water to which has been added three drops oil of peppermint and one drop of ether.

Boracic acid as a cleansing and healing agent for open sores and sore eyes. Sprinkle sores with the dry powder. For sore eyes, dissolve a tablespoonful in a pint of boiling water, and when cold bathe the eyes thoroughly.

Peroxide of hydrogen, as a cleansing agent to remove and prevent infection of sores and wounds with disease germs. Contrary to popular belief, it has no particular healing value to a fresh wound that has not become infected.

There are a number of meritorious preparations on the market designed to keep bunny in good health, but if the breeder will exercise good judgment in the matter of feed and sanitation, he can, with the aid of the drugs mentioned, successfully combat nearly every ill that may visit his rabbitry. As to tonics, the following well known articles will usually suffice without resorting to "condition powders" of unknown composition and uncertain value. Don't use any of them to excess and don't try to use the whole list at one time. Remember I am recommending them as occasional tonics and not as a regular diet.

They are-the bark from an apple tree branch-Throw the branch to bunny, it will strip the bark as it wants it; A few used tea leaves mixed with the regular mash occasionally; A few drops of sweet spirits of nitre in the drinking water; A pinch of sulphur in the feed occasionally-careful, not too much; A few drops tincture aconite in the drinking water-about ten drops to the gallon.

Sometimes a tonic is advisable to help prevent the spread of colds, snuffles, etc. The following is recommended:

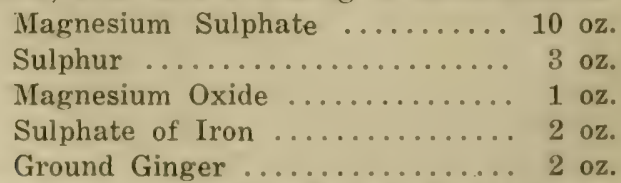

Mix and feed in mash at rate of one tablespoonful to ten rabbits. 
Sometimes rabbits become emaciated, weak and unproductive without showing signs of actual illness. It may be worms; if so, treat accordingly, but if not and no other apparent cause, it is probably what is known as asthenia, or "going light," just a gradual wasting away. For this, give the following tonic: 30 grains each of powdered fennel, anise, coriander seed, cinchona, one dram each of powdered gentian and ginger, and 15 grains of powdered sulphate of iron. Mix thoroughly and give four grains in food twice daily.

The dosage given above in each case is for mature rabbits. For younger animals, give correspondingly smaller doses, as for instance-half above doses to four months old specimens, quarter doses at six to eight weeks of age.

\section{INDIGESTION}

I have been requested to add a paragraph on indigestion. This trouble is caused from overfeeding, or unbalanced ration, such as too much dry feed or concentrated feeds. The affected animal will mope in a corner of the hutch and refuse feed. It appears to be in great pain and will sometimes, when forced to move, drag its hind parts as in first stages of paralysis. The bowels appear distended and hard.

Treatment: Give a tablespoonful castor oil; if not relieved in two or three hours, repeat. Reduce the grain and dry feed ration and feed more greens or succulent feeds such as carrots and mangels.

(NOTE-The writer receives a great many requests for advice as to home treatment, questions of housing, care, etc. Most enquirers fail to give sufficient data to enable me to form an intelligent diagnosis of their troubles. That I may be able to give better service to enquirers, and to avoid unnecessary correspondence, I have prepared an "Information Blank," a copy of which will be mailed on request. This blank, carefully filled out and returned will give me a much better idea of the nature of your trouble, than a long rambling letter. Address me at North Judson, Ind.-iC. R. D.) 


\section{Ailments of Rabbits}

By Dr. Roth
Rabbits of all kinds are remarkably free from disease if they are properly cared for. With many years of breeding to my credit, I find that prevention is the best possible cure. There is too much coddling of rabbits and they are as a consequence, not hardy enough. If you have vigor and pay for the proper attention to feeding, housing and sanitation, you will have little or no disease. Under no conlition breed from stock that is suffering from snuffles, scurvy and vent disease. If you wish to build up a stud that will be permanent and a pleasure to you, it is absolutely necessary that you breed from specimens that are perfectly sound and healthy.

\section{SNUFFLES}

We are preaching the gospel of fresh air and it is one of the very best preventions of many diseases. Above all, get busy and correct the first symptom of disease. As a general thing in the early stages it is easy to cure but after well seated it is almost impossible to affect a satisfactory cure. The most prevalent disease is the snuffles. Common sense methods in selection and housing has very materially recluced this disease and yet they are susceptible at all times to colds. When the first appearance of a cold or sneezing appears the specimens should be taken in hand at once. One of the very best remedies to administer is ten drops of tincture of aconite in the homeopathic form in a drink of water or milk. Rabbits suffering from snuffles should be kept in a warm, well ventilated hutch, well bedded with hay and thoroughly disinfected. Easy digested foods should be given them. Boracic powder and iodoform powder in epual parts blown up the nostrils has been used with excellent results.

(NOTE. The question has arisen as to whether ten drops of aconite as prescribed above is not too much, or whether Dr. Roth meant ten drops to one dose. I think he meant it as one lose, but am inclined to think it rather strong. I usually prescribe three to five drops in a teaspoonful of water, given twice or three times daily according to age and severity. However, it should be remembered that tincture of aconite is not made as strong as it was several years ago, and ten drops could probably be safely given in severe cases. As the tincture was formerly made, the dosage prescribed for humans was one to five dropsnow it is given as five to fifteen (lrops. C. R. D.) 


\section{SLOBBERS}

Indigestion is the cause and should be treated as follows: Take one tablespoonful each, chlorate of potash and powdered ginger, adding one pint of water; let stand for a few hours, shake thoroughly and give teaspoonful doses twice a day.

\section{PARALYSIS}

There is no cure for this. You will find the animal dragging its hind quarters around the hutch as though the hip bones were broken. Kill at once and put it out of its misery.

\section{SKIN ERUPTIONS}

Treat these with an ointment made of equal parts of petroleum jelly and flour of sulphur, rubbing it well into the scurf. If you are troubled with sore hocks resulting from dirty hutches, apply the same remedy.

\section{DIARRHEA}

Youngsters are particularly troubled with this disease after they have just been weaned. Sudden weather changes such as excessive heat or excessive cold will cause it and in some instances is the result of fright. An abundance of green food, if too wet or stale, will often cause it. When the symptoms are first noticed, all green food should be removed and they should be fed on old clover hay and dry grains. Mix one teaspoonful of pulverized arrowroot in a teacupful of milk and give the specimen daily until the diarrhea is checked. Pine sawdust acts as a disinfectant and is a splendid floor covering and absorbent during this period.

\section{EAR CANKER}

This is a very troublesome disease and extremely painful to the animal. If proper attention was paid to cleanliness there would be little trouble along this line. The symptoms are a thick yellow discharge from the inside of one or both ears; the eye on the side that is affected appears to be very weak, with a slight discharge; the rabbit loses condition and does not relish its food. The discharge from the ear arises from ulceration in the deep recess, and is difficult to cure. Clear out the discharge by a little pressure and a sponge or soft rag soaked in warm water, but take care that none of the water falls into the ear. When dry, drop into the ear finely powdered and dry boracic acid, or equal parts of subnitrate of bismuth and finely-powdered iodoform. The head should be held on one side, and either of the powders dusted into the ears twice a day, introducing the powder as far as possible. The animal should be fed upon the best food; and extra care in this respect will be required for if the rabbit becomes weak its chances of recovery will be very slight.

Another excellent remedy is an application of a mixture of sweet oil and sulphur, equal parts. One to three applications will 
usually cure. Apply with a bit of cotton or soft cloth attached to a small stick.

\section{INSECT' PES'TS}

Fileas are a constant source of worry to rabbits, especially to Lops. Any good insect powler well worked into the skin will rid the specimens of these pests. After thoroughly dusting and rubbing it well into the coat, it is well to use a small tooth comb to remove them. A splendid insect powder is made of equal parts of Persian insect powder and tobacco powder well worked together.

\section{RUNNING A'T THE EYES}

This is a common disease but is easily cured by placing a little zine ointment on the eye-ball, closing the lid over it and working it in well. If you have a stubborn case, dissolve a tablespoonful of boracic powder in a pint of boiling water and when cold bathe the eyes thoroughly. If any running sores develop iodofor'm ointment will give immediate relief.

\section{CONSTIPA'TION}

This can readily be overcome by feeding an abundance of green stuff and cutting out the corn and hay, feeding only a meal mash, to which a little boiled linseed has been added. If no response to this treatment, give half a teaspoonful dose of syrup of buckthorn daily until again normal.

\section{SKIN TROUBLES}

There are a number of forms of skin troubles resulting in bald patches. This should not be neglected for many valuable specimens have been ruined in this way. Cantharides ointment will kill the parasite and assist the fur to grow.

\section{ABORTION}

The prevention of abortion is difficult. Disinfect the hutches thoroughly and do not feed flowers of sulphur during the breeding seasons.

\section{VEN'T' GLEET'}

The cause of the disease has not as yet been thoroughly worked out. I am convinced that it is similar to gonorrhea in the human family. Isolate the specimen, disinfect the hutch from which it was removed. Give 30 grains Epsom Salts and twice a day inject a four per cent, solution of cocaine and immediately after a solution of nitrate of silver, four grains to the ounce. The fifth day commence a small copabia capsule daily and inject acetate of lead, 1 drachm to the pint. Feed rather low and dust any sore places outside with iodoform. Under no consideration, breed an animal showing the slightest symptoms of this disease. 


\section{Castration}

\section{By C. R. Deardorff}

All males not intended or fit for breeding purposes should be castrated. The operation is very simple and should be in general practice by both the commercial breeder and the fancier. None but strictly high grade males should be used or sold for breeding purposes, and the temptation to sell males of inferior quality to the uniniated at high prices can be so effectively met in no other way as by following the practice of castrating all such at an early age.

Castrated males do not fight and may be safely yarded together in open yards in considerable numbers and varying ages. They grow faster, make bigger carcass, and produce meat of a much superior quality to that of the ordinary male. When it is desired to finish them off for market, they take on fat easily and quickly and on much less feed than animals not unsexed.

To get best results, male rabbits should be operated on as soon as the organs begin to become prominent-usually at from two to three months of age in the heavier breeds, and a few weeks older in the small breeds. However, old males that have passed the age of usefulness as breeders, may be safely and profitably operated on, and end their careers as a meat product of very superior quality.

The operation is best performed by two persons. The assistant should get down on his knees, and, grasping a front leg and a hind leg in each hand, hold the animal between his knees with its back toward his body. The operator should then (if right-handed) grasp a testicle between the thumb and forefinger of the left hand, pressing firmly between the organ and the body. With the right hand make a vertical cut in the skin as it is stretched tightly over the organ, just sufficient that the pressure of the left thumb and forefinger will cause it to pop out. Now grasp the testicle with the left hand and pull about two inches away from the body, then sever close to the body by using a scraping motion of the knife. By scraping the cord until it parts it will not bleed as with a direct cut. Repeat the operation on the other testicle. Before commencing operations it is well to cleanse the castrating knife with a two per cent. solution of carbolic acid. The wounds will heal rapidly and need no stitching or applications, except that in fly time, it is well to annoint the wounds with pine tar to keep flies and insects from annoying the animal. 


\section{Tanning the Skins}

By C. R. Deardorf

Beautiful fur garments, rugs, mats, lap robes, etc., may be made from rabbit pelts, if taken during cold weather when the fur is in its prime. Perhaps the most economical and satisfactory way for the busy man is to send the pelts to a near-by tannery to have them tanned ard made up, but there is satisfaction and pleasure to many people in doing things themselves. To such, this chapter is addressed.

There are several preparations on the market which may be purchased, and if directions are carefully followed, will produce very satisfactory results. In all of these preparations, as well as the process described below, there is one essential to goorl results that must be remembered, and that is-the degree of softness and pliability in the texture of the finished article is largely dependent on the amount of elbow grease expended in the way of pulling, working and rubbing.

To those who wish to follow the whole process of home tanning from start to finish, the following is recommended as reliable and as giving excellent results:

Trim the pelts and soak until soft, then remove the fleshy substances and soak in warm water for an hour. Now take borax, saltpeter and glauber salts, of each one-half ounce, and moisten with soft water sufficient to allow it to be spread on flesh side of skins. Put it on with a brush, thickest where the skin is thickest, double the skin together flesh side in, and keep in a cool place 24 hours, but not allowing it to freeze.

Then, wash the skins clean and take sal-soda one ounce, borax one-half ounce, refined white soap two ounces, melt slowly together, being careful not to allow the mixture to boil, and apply to the flesh side as at first. Roll up again and keep in a warm place 24 hours.

Next, wash the skins clean as before, and apply two ounces of saleratus dissolved in hot (not scalding) rain water, sufficient to well saturate them. Dissolve in another solution, four ounces alum and eight ounces salt in hot rain water, and when cool enough to allow handling without scalding, put the pelts in and leave for twelve hours; then wring out and hang up twelve hours to dry. Repeat soaking and drying two to four times according to desired softness of skin when finished.

Finish by pulling, working and rukbing, and finally rubbing with a piece of pumice-stone. 


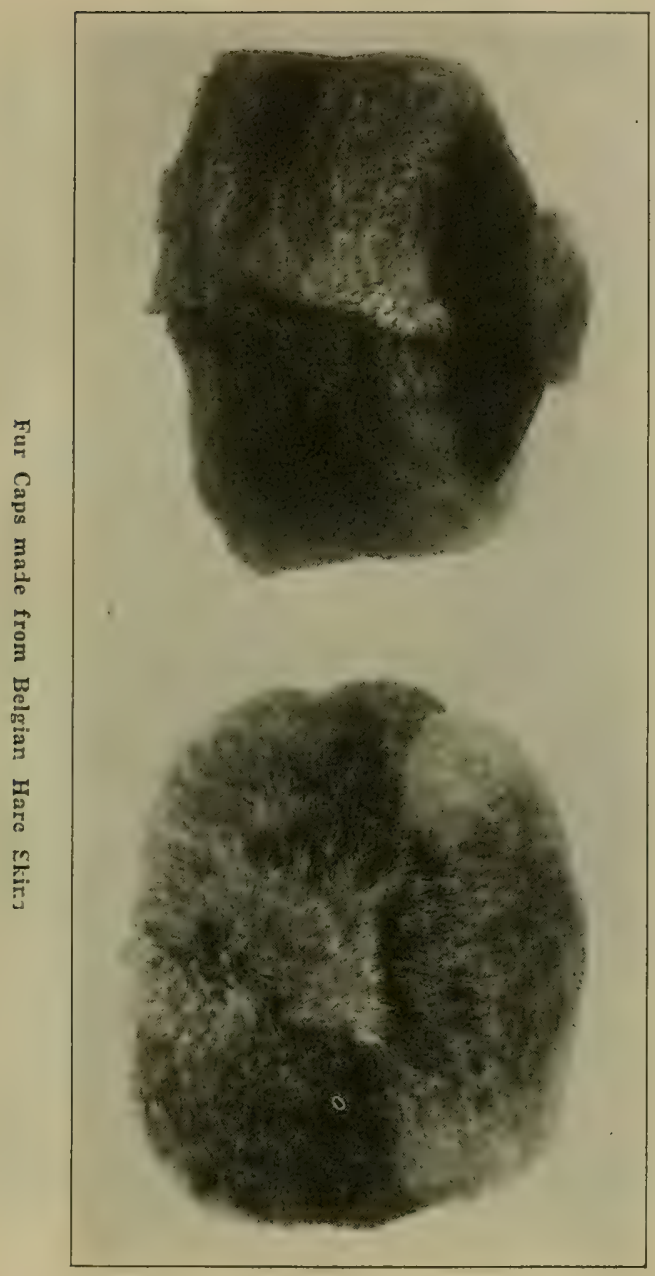




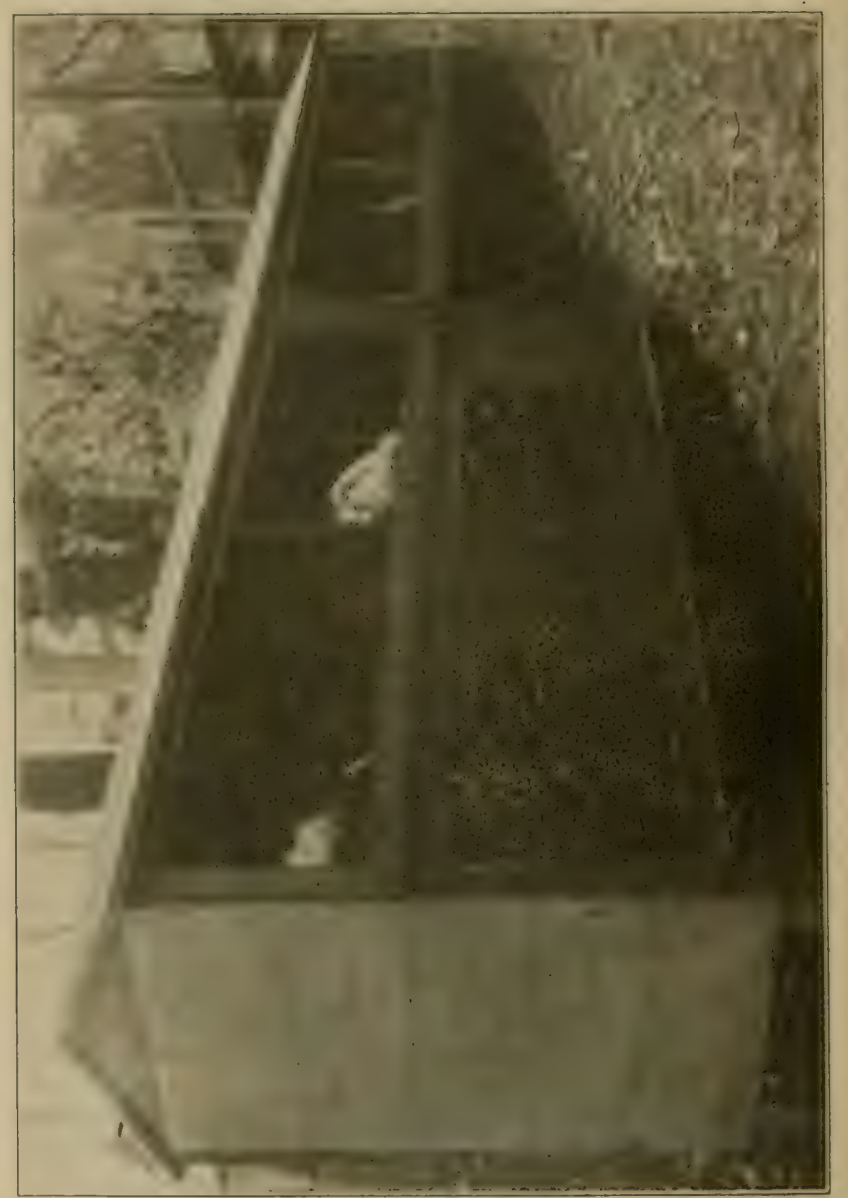

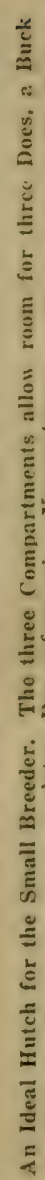




\section{Nurse Does}

\section{By C. R. Deardor $f$}

To get the best quality in fancy stock, it is not advisable to allow a mother doe to attempt to raise more than five or six youngsters, and sometimes it may be advisable to restrict the size of the litter to not more than three or four. Small litters are especially clesirable in the case of the Giant varieties, where size of the mature specimen is of supreme importance. Many does will produce eight to ten, and sometimes more, young at each kindling. If nurse does are not available, the only thing to do is to reluce the size of litter by killing the poorest. It goes hard with most breeders, an! especially beginners, to do this, but it pays in the increased value of the remaining youngsters and in the chances of raising them to maturity.

In order that the breeder may avoid destroying any of the young from his most valuable does, and at the same time control the size of their litters, it is advisable to keep on hand a number of nurse does. These may be the less valuable of his regular stock, or he may keep a variety especially adapted to this purpose. By many, the Dutch is considered as the best to use as nurse does. They are hardy, very attentive mothers, and give a good flow of milk. They are small eaters and therefore more economically kept than the larger varieties.

When a breeding doe has accepted service, breed also, on the same day, one of your nurse does. In case the breeding doe is known to produce large litters, it may be advisable to breed two nurse does for her. It is a good idea to breed two regular breeding does and three nurse does on the same day if practical. An inferior male may be used for service to the nurse does, or any one of your stud bucks that will not be used excessively by such service. However, don't abuse Dutch does by breeding them to Giant bucks.

When the does have kindled, remove and destroy the young of the nurse doe, and substitute a part of the litter you wish to preserve. Substitution in this way may usually be made at any time up until the time the young first leave the nest, but it is obviously advisable to divide the litter within the first two or three days. I prefer doing so on the second day after kindling.

Attempts to substitute youngsters after they have left the nest are seldom successful. The doe is apt to resent and kill the strangers, but it seems she can only discover the deception when they are outside of the nest, and after they have escaped detection in the nest for a few days, they acquire the nest odor, and are safe. 


\section{Pedigree and Registration}

\section{By C. R. Deardorff}

The manner of making a perligree is very nicely illustrated in the chapter on "Line-13reeding," and discussed there and under the subject of "Pedigrees," by Dr. Roth, elsewhere in this book, hence it is unnecessary for me to go into details on that subject. Will urge, however, that no breeder, of either commercial or fancy stock, should neglect to keep an accurate pedigree record, if not because of demand of the "fancy," then for his own guidance in the matter of intelligent breeding.

Registration is a method devised to keep an accurate record of all high class breeding stock, available for inspection at all times by any one interested, and to act as a check to misrepresentation of stock cffered for sale or for stud service. Such systems have been worked out, and are in almost universal use, for all domestic animals of high breeding--horses, cattle, hogs, sheep, dogs, cats, rabbits, etc.

Excepting in detail of operation, all systems are practically the same and with the same end in view-to protect both the breeder and the buyer. In brief, the general plan is this: An accurate record is kept at a central or home office, of all registered animals-their pedigrees and ownership. Each animal is given a designated number of a consecutive series, and is eartagged or marked accordingly. It is an easy matter for the prospective purchaser to go to the records and verify any little tale of "winnings" or "breeding records," with which the versatile breeder may have been entertaining him.

While it is practically impossible to devise a system that will be an absolute guarantee against trickery, yet it can be readily seen that with even a very laxly conclucted system, considerable protection is offered, and that it would be impossible or at least improbable, that a trickster could escape detection for any great length of time.

At present there are three systems of rabbit registrationI will not undertake to say which is the best, but will say that in this case, I would suggest "the bigger the dose, the better the merlicine." In other words, use all three of them. They are:

The National Breeders and Fanciers Association, Secretary, C. S. (Gibson, 1045 W. Warren Ave., Detroit, Mich. This asso- 
ciation registers rabbits that are consiciered worthy, only by examination of specimens by official registrars. Apply to secretary for name of nearest registrar.

The United Kennel Club registers rabbits as well as dogs, cats, cavies, etc. This Club register's on "blood lines" alonethat is on pedigrees and previous registrations. No personal inspection. For blanks and particulars, write to United Kennel Club, 3410 Beach Ave., Chicago, Ill.

For registration in The Internatior al Hutch and Loft Association, write to the secretary, L. E. Woods, 116 S. Salina St., Syracuse, N. Y. This association registers rabbits in two classes. For ordinary registration, pedigrees must be submitted and the animal pass personal inspection of an official registrar, as 75 per cent. perfect. For "Advanced Registration," the specimen must first be registered as above, and also include a record of show winnings to substantiate its claim to such registration. Apply to secretary for name of nearest registrar.

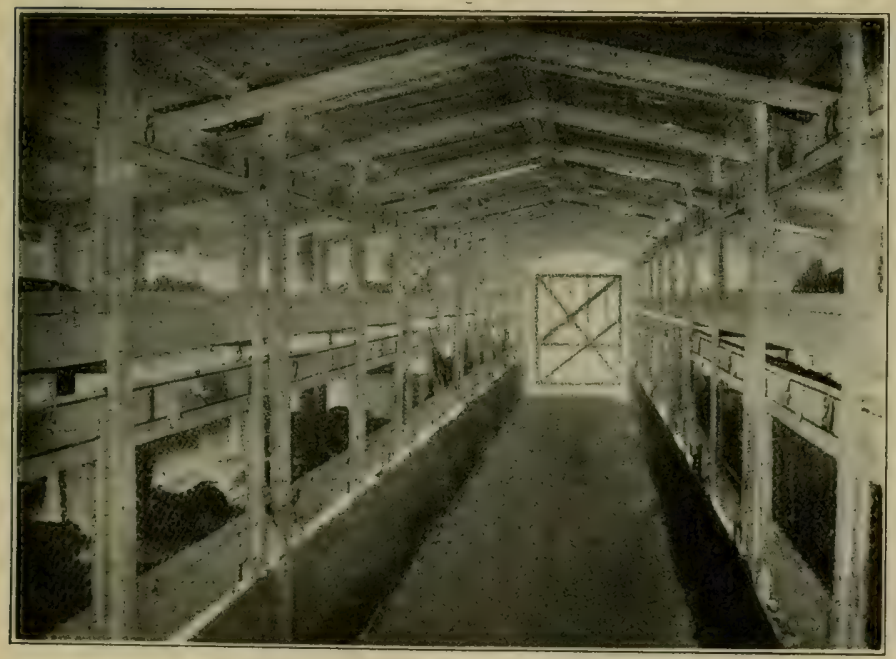

Inside view of a type of Hutch in use by many Successful Breeders 


\section{Condensed Information and Rules for the Rabbitry}

$1-$ Be as quiet in the rabbitry as possible.

2-Exclude all strange dogs.

:-Avoid entering the rabbitry about mid-day, because at that time the inmates are generally asleep, and prefer quiet.

4- be as regular as possible in the time of feeding.

5- Be equally so as to the days for thorough cleaning.

(i-When any offensive smell is perceived in any hutch, find out the cause, and apply a remedy.

7-Never allow the first symptoms of any complaint or disease to be neglected, for all ailments are more easily cured when treated at once.

8--Separate any diseased rabbit from the others as soon as discovered.

9-Frequently "look over" your stock yourself.

10-Examine the noses, eyes and roots of ears also the internal ear, to detect any appearance of scurf, mange, ear gum, or cancer.

11-Let the air of the rabbitry be renewed as frequently as possible, to insure health of inmates.

12-Keep the temperature of the rabbitry as genial and equitable as possible.

1:--Keep the feeding dish for suckling does constantly replenished as the animals require more nourishment during that time.

14-In proportion to the number of rabbits the doe has been suckling, so regulate the time for her pairing again.

15-If the litters are too frequent the stock will be weak. Quality and quantity are both important, but one must be subservient to the other:

16-Avoid handling young rabbits, especially when in the nests.

17-Fxclude mice from the hutches or rabbitry if possible, for one mouse may cause the does to neglect their young ones. 
18-Never leave the rabbits to the care of inexperienced attendants. One day's ignorance as to their wants may permanently injure the stock.

19-If the rabbits are to be improved in condition, use but little green food.

$20-$ Never give green food wet.

21 - So-called "cheap" foor is more expensive than the apparently dearer, which is more nutritious. The most wholesome saves both the pocket and the rabbits, as six months' trial will prove.

- 22-Use as few artificial means as possible in the rearing and management of your rabits.

2:3-Protect them from a damp and foggy atmosphere as much as possible, as such is more injurious than a dry cold one.

24-Make a study of your rabbits, as to their habits and requirements, and experience, which will enable you to become a successful fancier, will be speedily gained. Never forget that rabbits are not the offensive creatures some persons would have you believe. In a well-arranged rabbitry, where the health and comfort of the rabbits are studied there is little or no disagreeable smell.

25-If your buck is a good one do not allow him to serve more than three does per week. One service is sufficient and will prorluce as many or more young than two or three services.

26-Does may be kept together in one compartment until they are bred, but each buck must have a separate hutch after they are three months of age, or they will injure each other by fighting.

27-Bucks become virile at about four months of age, but do not reach perfection in form or coloration until about eight months old, and should not be userl for breeding purposes until matured.

28-If a doe commences building her nest and pulling hair two weeks after being bred, it is almost a sure indication that she is not with young, and that she clesires to mate. Breed her and thus save two weeks time in obtaining a litter.

29-Always take the doe to the buck's hutch when breeding, as she is less liable to fight if not in season, being in a strange place. Do not leave them together more than a few minutes, as this will decide the question either way. If the doe is unwilling to breed take her back to her hutch and try her next day, or until she will breed. 
:0)-Feed hay in suitable racks to prevent soiling and wasting. They may be marle in any convenient manner to suit the fancy of the breeder. One inch mesh poultry netting tacked to one end of hutch, about three inches from floor at bottom, and inclining inwards toward the top, makes a very economical and convenient rack.

a1-Place watcr dishes for breeding does high enough to prevent the youngsters from getting into them. They need no water until noarly weaning age if mother doe is properly fed and cared for. Always arrange water dishes in such a manner that they cannot be overturned and contents spilled. Feed greens the same way, high up so youngsters cannot reach them. They will pick up what the doe drops on the floor, which will usually be ample for them.

32 -Never pick a rabbit up by its ears. When you see some one else do so, ask him how he would like the same treatment. To lift a rabbit, grasp the loose skin just behind the ears with one hand, and let the rump rest on the other. To carry it, allow it to rest on the forearm, or on the borly under your forearm, while controlling it by the grasp on the skin as before.

33-Keep hutches clean and disinfect occasionally. Cleanse feed and water dishes two or three times per week with boiling water-oftener if necessary. If you feed wet mashes or milk, cleanse after each feeding. Absolute cleanliness is essential to success with rabbits.

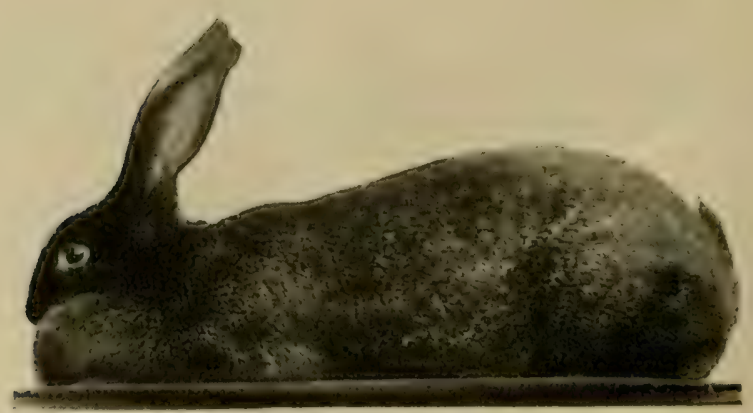

A Good Type of Black Giant 


\section{Preparation for the Table}

\section{By C. R. Deardorff}

Rabbit meat has been pronounced by physicians as one of the most nourishing meats and is especially suitable for convalescents and people with weak stomachs. It can be prepared in a great many dainty and appetizing ways, but it will be the purpose of this chapter to give only a few of the more easily prepared and thoroughly reliable recipes, together with brief directions for slaughtering and dressing the rabbit.

While domesticated rabbit, at most any age or size, makes a very superior article of diet, if properly prepared, it is at its perfection at about two months of age. However, it is more profitable to kill at four to six months of age. At the latter age it has reached a size that represents a maximum of gain on a given amount of feed, and has sacrificed but very little in quality.

To kill, take the animal by the hind legs in the left hand, letting the head hang downward, strike a quick and rather hard blow on back of the neck with the edge of the hand or with a small stick. Cut the throat at once and hang head downward by means of loops of cord (previously prepared) attached to the hind feet. Cut a small opening in the abdomen between the hind legs and fill the carcass with cold water two or three times. Remove the pelt by first running the knife around the first joint of the hind legs, then slitting the skin from one joint to the other across near the tail. Free the skin from the legs, turning it inside out and drawing slowly down toward the head, leaving the fat attached to the carcass, and being careful to avoid tearing the thin flesh over the abdomen. Now cut the pelvis bone, working carefully so as not to cut the walls of the intestinal tract at this place and open down to the neck. Remove the entrails, cut off the feet and wash the carcass, thoroughly drying it with a clean cloth. The heart and liver are to be saved, also the head, after removing the eye-balls, if you wish it. Allow the carcass to stand in cold salt water an hour or so.

When usirg more than one rabbit for any particular dish, animals of about the same age should be used so they will cook up evenly. If one has a cool place to hang them, the quality of the meat is much improved by killing a day or two in advance.

In the winter, a considerable number may be killed and dressed 
at one time and hung up to freeze, thus very greatly improving the quality of the meat.

\section{FRIED RABBIT}

Lse a young rabbit, six to eight weeks old, in no case over three months old, for best results. Cut in pieces and roll each piece in a mixture of flour, pepper and salt, and fry in butter and lard, as you would chicken, to a nice brown. Time, 80 to 50 minutes according to age and size.

\section{FRIED RABBIT AND ONIONS}

This is a good one. Cut the carcass into joints, soak in salt water all night. Take two pounds of onjons to each rabbit; peel and slice. Fry the sliced onions in good lard until they are nicely brownerl. Next, fry the joints of rabbit until they are nicely browned. Now put onions and rabbit together in a saucepan and stew very slowly. Season to taste when stewed.

\section{STEWEU RABBIT}

Cut into joints, put in kettle with some small pieces of fresh pork. Add hot water and salt, cook until done and dry. Then fry for a short time and lift into a dish. Now make a nice brown gravy, by putting a tablespoonful of flour in the kettle and adding hot water. When done, pour over the rabbit.

\section{RABBI' PIE}

Joint the carcass and soak two hour's in salt water. Put into sauce pan and stew until done and remove bones. Line sides of your baking pan with biscuit dough, put in the stewed rabbit, with a few slices of bacon-also a few cubes of beef, if liked. l'ut on the top crust, not forgetting to make a small hole in top for the steam to escape. Bake in a moderately hot oven about 30 minutes.

\section{RABBIT AND DUMPLINGS}

Joint the rabbit and soak two hours in salt water. Take one large onion sliced. Pepper and salt to taste. Mix six or more suet dumplings. Put all in saucepan with some good stock, and stew slowly two hours.

\section{POTIED RABBIT}

Cut the meat off the bones into suitable sized pieces, place in inclividual jars with diced bacon and mushrooms. Boil the bones with what meat remains on them and the head, also a suitable amount of carrots, celery and onions, also a little thyme. Crush; salt and season to taste. Thicken slightly, strain to remove small pieces of bone and cover the meat in the jars with this, put on the licls and bake slowly until tender; serve in the jars.

Where individual baking jars are not available, the following method can be used: 


\section{Another Method}

Pack the pieces of rabbit in a stone jar, filling in the spaces between with bacon and veal-a pound each-cut to dice, into which the liver of the rabbit has been mixed, cut fine; add mace, clores, black pepper and salt to taste. Place thin slices of bacon on top. Cover with a lid of plain paste made of flour and water. Set the jar in a pan of water and bake in a slow oven. Keep from burning by placing a greased paper over the paste. Put no water on the meat. When done set away to cool, then pound the pieces of rabbit, bacon and veal to a paste, taking out the bones, and $\mathrm{mix}$ in the gravy from the bottom, if any. Add more seasoning if necessary. Press solid into cups or small jars, cover the top with melted butter, and set away in a cool place.

\section{RABBIT SALAD}

Use a rabbit that has been boiled until tender, cut into small pieces, and use three parts rabbit to one part celery, which has also been cut. For a dressing, use the yolks of four eggs, five tablespoonfuls vinegar, a little salt and pepper and one dessert spoonful of prepared mustard. Cook the dressing until it has appearance of custard, and mix thoroughly with the rabbit and celery when all are cold. Mix a cupful sweet cream with it when ready to serve.

\section{PRESSED RABBIT}

When rabbits get old they are very nice pressed, and are fine for a cold lunch. Boil until the meat begins to fall from the bones, grind or cut the meat fine and season with salt and pepper. Pour the broth over it and put all together into a vessel and cover with a plate and weight on top and let stand until cold, when it can be sliced and served. A little bacon added when the meat is boiling and ground up with the rabbit meat makes a desirable improvement.

\section{BROILED RABBIT}

Use a young rabbit, boil in salted water five minutes, dry and broil as quickly as possible. Dish on hot platter and season with salt, pepper and butter.

\section{ROAST RABBIT WITH ONIONS}

Place a layer of onions in the bottom of pan, then a layer of meat neatly cut, add another layer of onions, and alternate with meat until the pan is filled. Scatter a few small pieces of bacon or fresh pork through the rabbit meat. A double roaster is best, as it keeps in the steam more thoroughly. No water is needed, as moisture is furnished by the onions and meat.

\section{ROASTED RABBIT}

Soak rabbit in salt water thirty minutes, without cutting up. Grind or chop fine a slice of fat salt pork or bacon, and mix with 
snfliejent bread crumbs to fill the cavity. Season with minced onims and chopped parsley, salt and pepper to taste. Stufr the rarcass with this mixture, cover with thin slices of bacon, pour a (up of water in the pan and bake one hour, basting frequently. Thicken the drippings with browned flour, season with salt and pepper. Serve on hot platter with slices of bacon, slices of lernon and lettuce.

\section{BAKED RABBIT}

bone or not as desired. Lay alternate layers of rabbit and thin slices of bacon, season with thyme, sage and thin slices of onions. Partly fill the dish with water, bake in a slow oven for one and one-half hours. Use a deep covered baking pan, or casserole.

\section{FIRELESS COOKER METHOD}

This is delicious. Joint the rabbit. Cut the largest pieces to make the pieces as nearly uniform in size as practicable. Brown well in hot butter or bacon fryings. Place in fireless cooker vessel with just enough water to cover. Add finely chopped onion and parsley, and two or three slices bacon cut into small pieces. Salt and pepper to taste. Boil gently for thirty minutes, then place in fireless cooker for six hours.

\section{JELLIED RABBIT}

Boil until the meat will fall from the bones, and leave in the water over night. In the morning, chop fine, season with butter, pepper and salt, and press in a mold until firm.

Or-Boil tender, cut in small pieces, and season with salt and pepper. Adld a half box gelatine soaked in cold water to the liquor (not less tha.s a quart) in which the rabbit was boiled; strain through thin muslin, and when it begins to thicken, add the meat; put in molds and place on ice to harden.

\section{JELLIED RABBIT AND PIGS FEET}

This is a good one, especially fine for cold lunches. Use rabbit and pigs feet, about equal parts by weight; soak the pigs feet over night in cold water, clean and remove the toes. Soak the rabbit for the same length of time in salt water. Put both in a kettle with enough water to cover, add an onion finely minced. Boil until meat readily separates from the bones. Season with salt and pepper when nearly done. When done, lift from kettle, leaving the liquor to keep hot, and pick the meat into small pieces. Put in crock and pour over the hot liquor, which should be pretty well boiled down, but still sufficient to cover the meat in the crock. If an additional flavor and relish is desired, add to the hot liquor before pouring over the meat, pure vinegar, or spiced vinegar, in proportion of one-half cup to six pounds of meat. The whole mass should be thoroughly mixed in the crock and then set away to cool. Slice and serve cold. 







$$
\begin{aligned}
& \text { LIBRARY OF CONGRESS }
\end{aligned}
$$

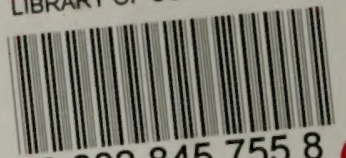

$$
\begin{aligned}
& 00028457558
\end{aligned}
$$

